\title{
$i_{2}-1143$
}

LA-5619-MS, Rev.

Informal Report

UC-39

Reporting Date: November 1974

Inued: December 1974

\section{Calculations of \\ Laser-Induced Spall in Aluminum Targets}

by

A. R. Larson

This report supersedes LA-5619-MS issued May 1974.

of the University of California

lOS ALAMOS, NEW MEXICO 17544

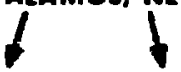


In the interest of prompt distribution, this LAMS report was not edited by the Technical Information stoff.

Printed in the United States of Americc. Arailable trom National Technical Inlormatios Service

U.S Deparmen: of Commerce

5255 Fort Rozad Rroad

Springfie!d, YA $2215 !$

Price: Panted Copi \$4.00 Mictolicine $\$ 2.25$

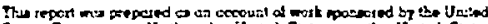

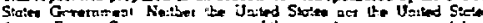

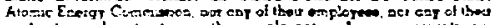

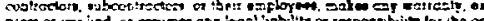

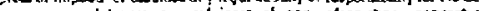

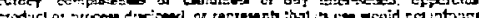

primiteiy onitod ropil 
CONTERTS

I. InTROdUCTION .............................. 1

II. MEthiods of calculation ........................ 1

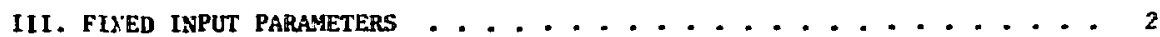

IV. LASER-TaRGET INTERACTION AND TARGET RESPONSE .............. 6

v. Parameter varlatlots ........................... 16

VI. CONPARISON HITH EXPERIMENT . . . . . . . . . . . . . . . . . 22

VII. EFFectS of AIr ON SPall Calculations . . . . . . . . . . . . . . 22

VIII .CONCLUSLONS AND RECONRENDATLONS . . . . . . . . . . . . . . . . . 24

A. Conclusions .................... 24

B. Recommendations ...................... 25

APPENDIX A - ABSORPTION OF LASER LIGHT . . . . . . . . . . . . . . . . 25

APPENDIX B - IMPLICIT FINITE-DIFFERENCE METHOD FOR SOLVIXG YONENTUM

EQUATIONS . . . . . . . . . . . . . . . . . . . 27

APPENDIX $C$ - VALUES OF INDEPENDENT VARIABLES USED IN THE PaRAYETER STUDY OF ALUMINUM AND CORRESPONDIKG RESULTS OF THE CALCULATIONS ................... 29

APPENDIX D - LASER PULSE SPACING . . . . . . . . . . . . . . . . 32

APPENDIX E - DERIVATION OF LASER F:TER LEVEL FOR BREAKDOWN OF

CLEAN AIR ........................ 33

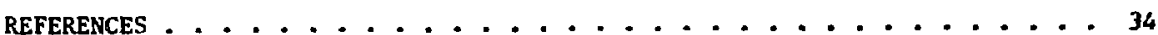

\begin{tabular}{|c|}
\hline 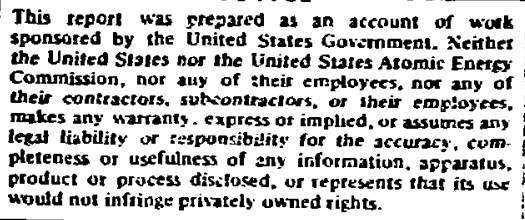 \\
\hline
\end{tabular}


CaLt2LAJ

$\$$

A. K. Barmo:

\title{
ASTRET
}

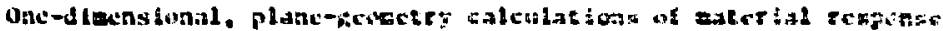

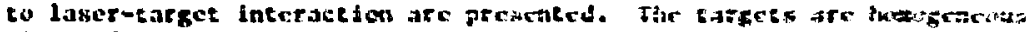

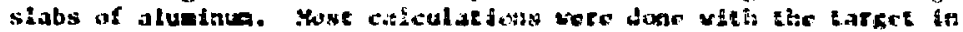

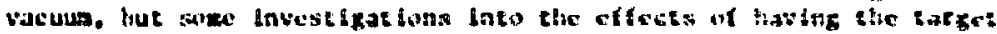

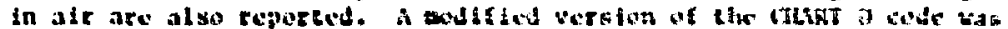

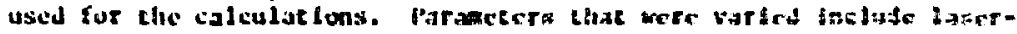

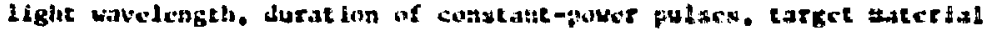

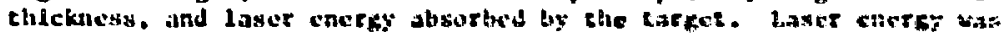

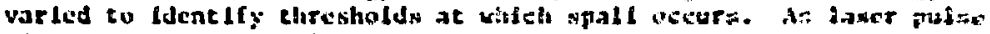

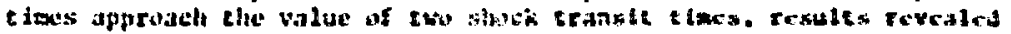

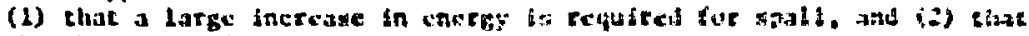

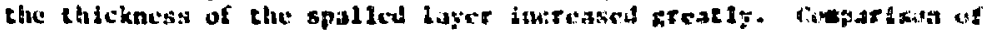

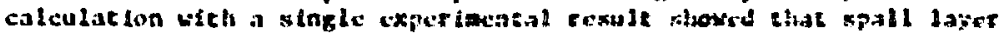
thickness as calculated agreer with thit acasutad.
\end{abstract}

\section{INTRODUCTION}

Lasers provide a aeans of depositlng enets: on a target in a controlled space-tine reictence. yecause the tine fivolved can be shorter than gasdynamic response times, lasers proyide an effuctivo gechan 1 sm for generat ing shock waves. These shuck waves can then be used to sause spall dange. spallation of a target by a laser has becn reported experimentally by at least two authors. Anderhoin' repurted spaling 0.5 an lead with a 7-J, 12-ns ruby laser, and fox and Barr 2 have spalled 1 to of 6061-T6 aluminum with a 1- to 2-ns, 75-J pulse from a id:glass laser.

This report presents the resules of an analyt $1-$ cal investigation to deteraine the usefulness of short-pulse ( $\leq$ 1.0-us) lasers in generating shock wives of sufficient magnltude to cause spallation in metal targets. The study had two objectives: (1) to find appropriate methods of performing the calculations and (2) to use these acthods in studying the effects of several independent variables.

This work was performed for the army Missile Command, AYSMI-RR, Redstone Arsenal, Huntsuille, AL, wnder Contract MIPR-A-31682-23-7114.

\section{Mentots at calcitatrios}

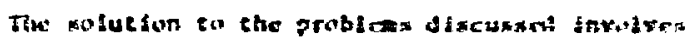

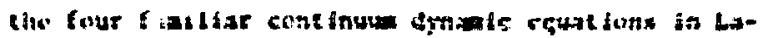

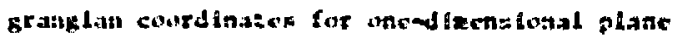
beonctry. $2 . c$.

\section{Contervalion of Yata}

$$
\frac{4}{x}-\ldots \frac{4 y}{2 x}
$$

Conxervation of thernewe

$$
\frac{3 x}{d t}=-\frac{1}{x} \frac{x+y)}{x x}
$$

conservaston of tiner rx

$$
\frac{\partial z}{\partial t}=-(p+\phi) \frac{\lambda}{\lambda t} \frac{1}{\partial}-\frac{1}{\partial t}+s
$$

and the Equation of state,

where

$$
\begin{aligned}
& \text { - density } \\
& u \text { - velocity } \\
& 0_{x}=\text { stress in } x \text {-direction } \\
& Q=\text { artificial viscosity } \\
& p=\text { pressure } \\
& c=\text { specific internal energy }
\end{aligned}
$$


F energy flux fros radiat low and electronic conduction

$S$ - encrgy source tore (laser light, in this case).

A computer code is required to solve the numerical analogs of these equatlens. The code nust have bullt-in equation-of-state capablity to define the fonizat lon levels necessary to conpute the laserlight absorption cosfficlents. The well-documented and accurate code. Ciwar $D$, written by Thospson and Lauson $^{3,4}$ of Sandia Laboratorles, Mbuquerque, $\mathrm{x}$, provides the right tool. Fasilarity with the document describing the code is assumed.

To summarize, CHART $D$ solves the fintedifference analogs of the Lagranglan equations of totion with energy terms in rectangular, cylindrical or spherical coordinates. Thermal and electron conduction, spall, and refoin calculations are included. Equations of state that describe all the different states of cutertals can be calculated by the code or taken fram a data tape. Consistent with the assumption of local therbodynamic equilibr $1 \cdot 4$. energy is eransported by a flux-1inited diffusion approximation. Elastic-plastic deformation Is included.

The CHART D code had to be nodifled for calculating probleas Involving laser intaraction; this rodifled version is referted co as ChaRT $L$.

One of the additions to ChaRT $L$ is a mechanisn for laser-light absorption. The mechanism used is that of free-free absorption taken from Spitzer. 5 A more complete discussion of the method is given in appendix a.

The CHART D code uses explicit finite difference to solve the mosentum equation. To produce a stable solution. the time step aust be controlled by the courant condition, i.e.,

$$
\delta t=\text { mintmun value of } \frac{\delta x_{1}}{c_{1}}
$$

where $\delta x_{1}$ is the thickness of zone 1 and $c_{1}$ is the sound speed in zone 1 . To establish the energy required for spall under sone conditions, the laser power levels were such that certain reglons of the material had small values of $\delta x_{1}$ and kach nubers much less thin 1. This situation cassed the courant condition to give such sall tine steps that the required colquter time becane large enough to linit the nuaber of polnts chat could be established in a paraneter atudy. An iaplicit Inite-difference method of solving the mosentus equetion ${ }^{6}$ was formlated in a maner that could be used by CHART $L$ and was added to the code. In iaplicit solution has the advantage that the the step is no longer 1 foited by the Courant condition. This type of solution is described in Appendix is.

\section{ILL. FIXED INPUT PARAYETERS}

Input paraneters that resained fixed throughout the calculations are discussed in the following paragraphs.

The only carget material is alwinum. Plane geonetry is used. L.e., one-dimensional rectangular coordinates with the $x$-direction normal to infinfte planes. The carget antertal is a hosogeneous slab of aluminu in vacuun. Exceptions to this general rule are problens run to investigate the effects of air, discussed in Section VII.

The problew setup requires dividing the target into a finite number of zones. Because the CHART D code is baset on the Lagranglan formulisw, the mass of each of these zones remains constant throughout the problem. When the laser is initlally turned on, the energy penetrates a very thin layer. The thlckness of this layer can be estimated from the skin-depth fomula for aicrowaves, $\Delta x_{p}=c / w_{p}$. where $c$ is the speed of 1 ight and $\omega_{p}$ is the plasa frequency. Assuring fully tonized alwinum at normal density, $\Delta x_{p}=0.6 \times 10^{-6} \mathrm{c}$. The zone nearest the laser was chosen to be this thickness to wock up light absorption for the shorter pulses and for the early phase of probleas.involving long pulses. This approach is consistent with the "jump-all" wode used in the absorption routine (see Append $(x$ A). A zoning nass rat 10 of 1.1 vas used to Increase the zone size unt 11 zones becane large enough for constant-mass zoning.

The option of using the subrout ines in CHART $L$ to calculate equation-of-state and opacity data (as opposed to ustag data stored on agnetic tape) vas exerciseal in these calculations. Up to 24 variables, called the $Z B$ array, 3,4 can be entered for grieratIng equation-of-state data. Although the data for aluainu are the sase as those stored in the CHART L code, sowe inportant paraeters that have neaning without reference to specific equations are repeated 
heie for ease of reference, along with definitions of the vartables. All variables in charT $L$ are in cgs units, except temperature which is expressed in electron volts (1 eV $-1.60203 \times 10^{-12} \mathrm{erg}$ ). Sone variables of the $2 B$ array are:

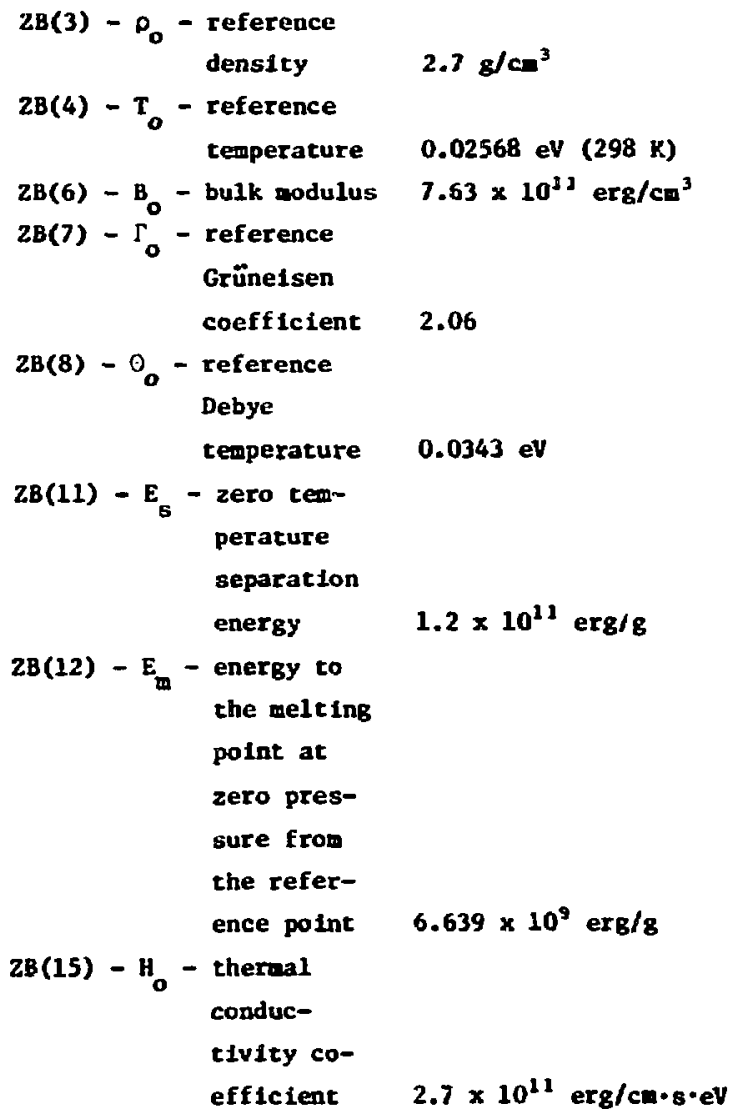

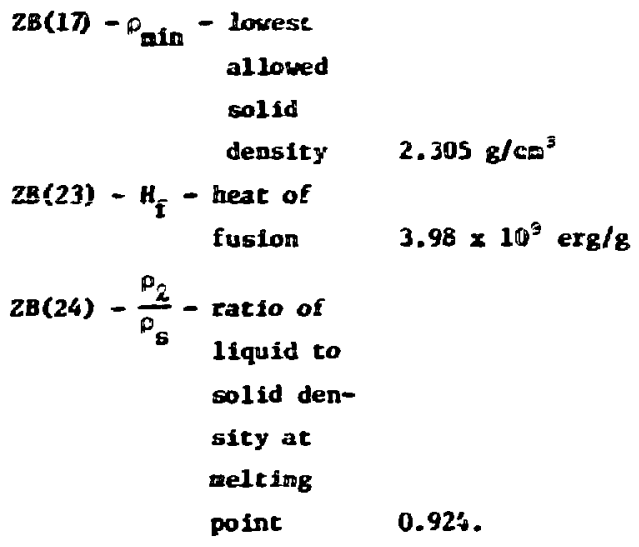

In addition to the above information, the torization potentials for all elements are stored in the code.

The calculated equations of state and fossland opacteles are shown graphically in Figs. 1, 2, anj 3. The opacities contain the therasl conductivity as described in Ref. 4.

Additional equation-of-state data used in thr elastic-plastic calculation are input into the YIELD array. These values are:

$Y_{0}=3.0$ kbax, $Y_{1}=0$

$\nu_{0}=0.333-$ Poisson's ratio at room temperature

$a=0.8 \quad-$ fraction of relt energy where the material starts to lose its strength
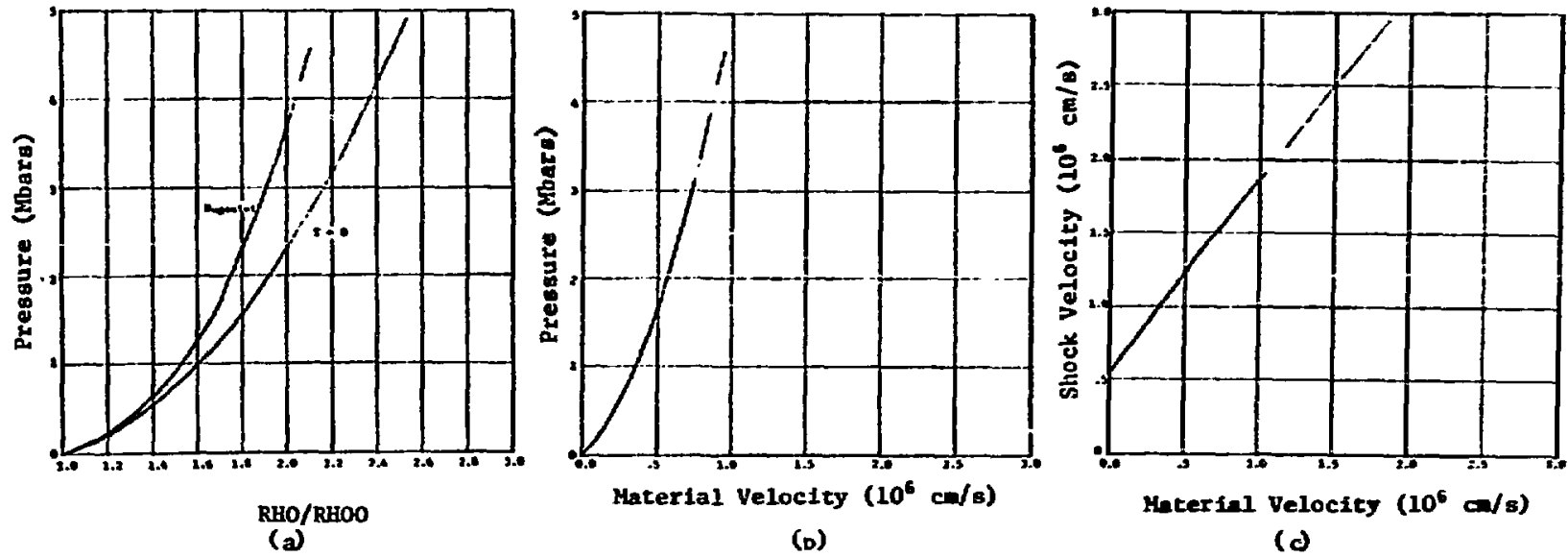

Fig. 1. Equations of state for aluninu - Hugoniot curves for pressure versus density (a), pressure versus material velocity (b), and shock velocity versus material velocity (c). 


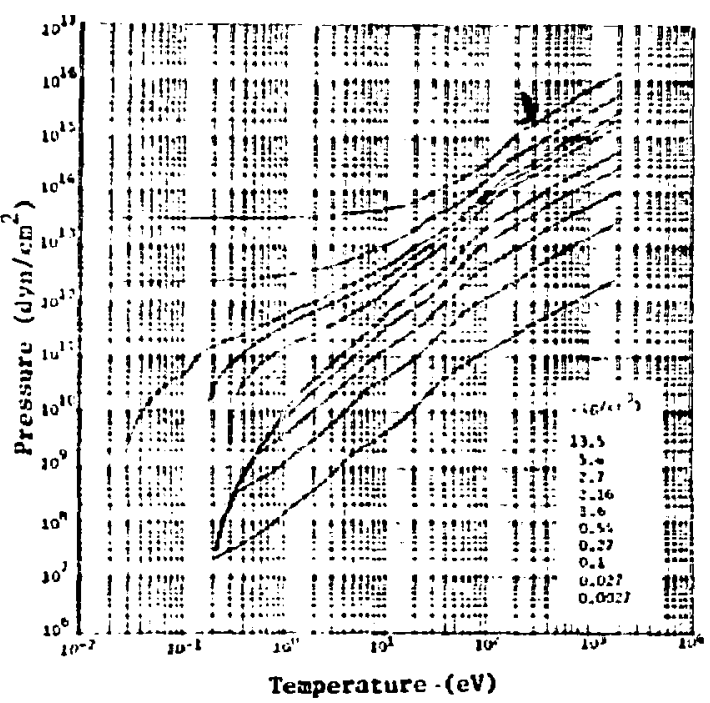

(a)

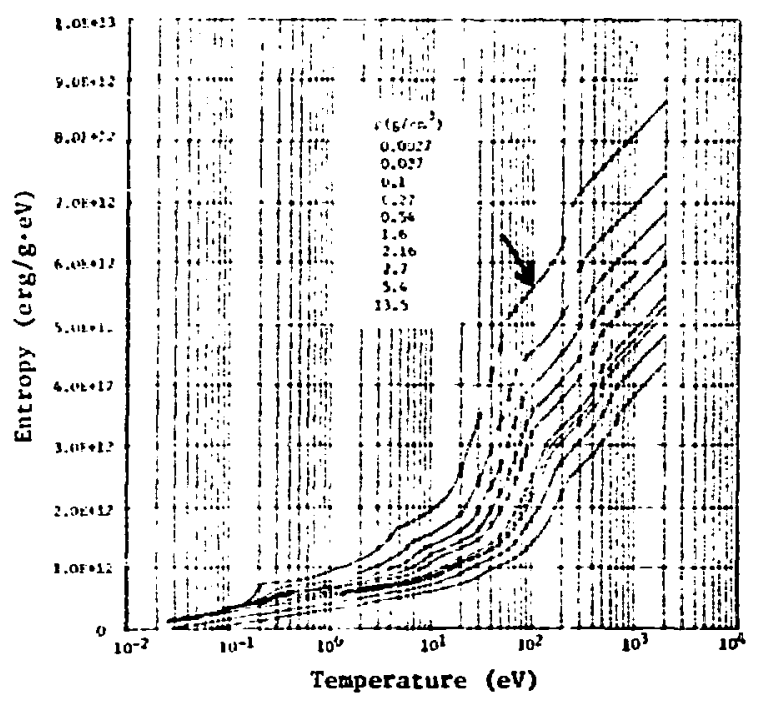

(c)

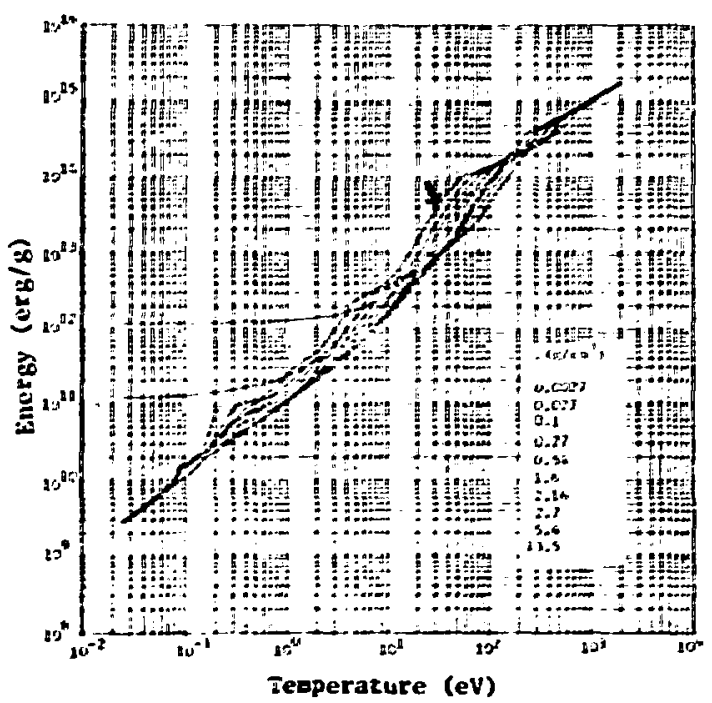

(b)

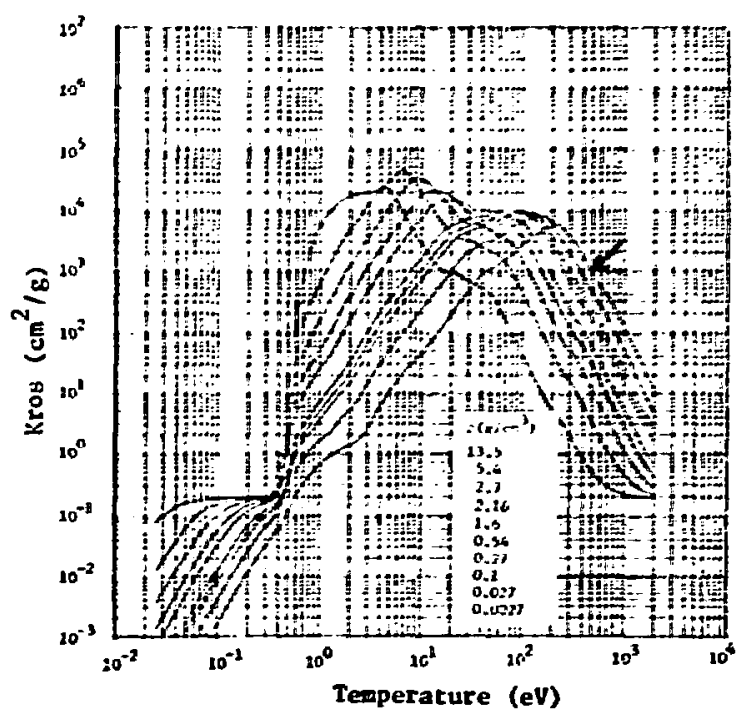

(d)

Fig. 2. Equations of state for aluminum. Pressure, energy, entropy, and Rossland opacity (a, b, c, and d, respectively) as a function of temperature and density. 


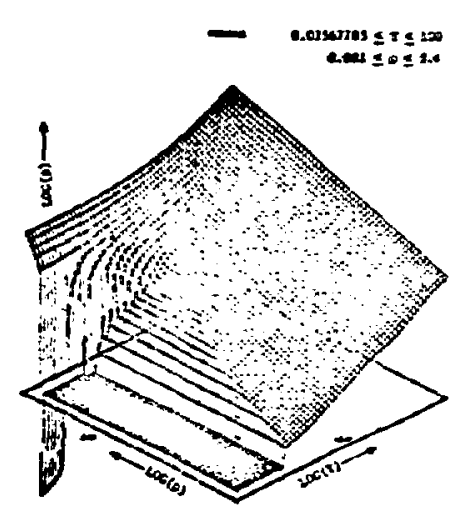

a

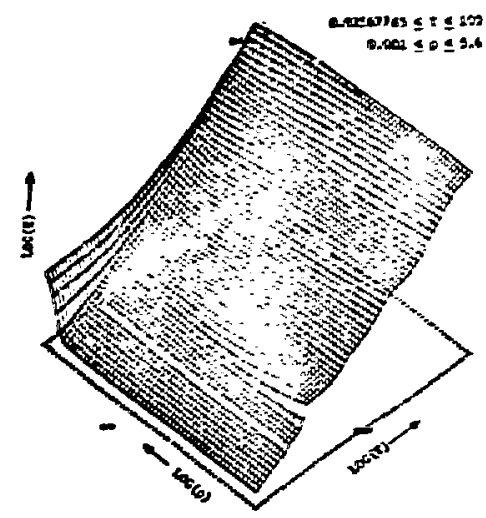

b

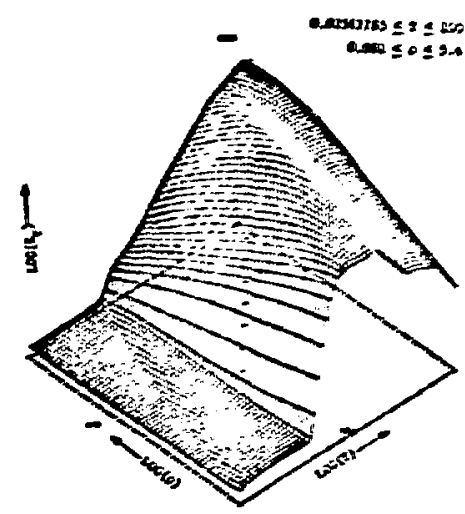

Fig. 3. Equations of state for aluminum - pressure, energy, and ofacity.

where

$Y=Y_{0}\left(1+Y_{1} \eta\right) F(E), \quad F(E)=\left\{\begin{array}{l}1, E \leq \alpha \varepsilon_{m} \\ \frac{1-E / \varepsilon_{m}}{1-\alpha}, \alpha \varepsilon_{m}<E<\varepsilon_{m} \\ 0, E \geq \varepsilon_{m}\end{array}\right.$.

The term $Y$ is a state function of the solid known as flow stress. It is used in the von Mises yield condition to find the pressure at wich the material starts to yield and exhibits plastic behavior; i.e., yleld occurs when

$$
E_{\ell}\left(\sigma_{l}{ }^{d}\right)^{2}>2 / 3 \mathrm{Y}^{2}
$$

where

$$
\begin{aligned}
E= & \text { specific internal energy } \\
E_{m}= & \text { specific energy at the melting point at } \\
& \text { zero pressure } \\
\eta= & 1-\frac{\rho}{o_{0}} \\
\sigma_{r}{ }^{d}= & P-\sigma_{l} \quad(l=x, y, z) .
\end{aligned}
$$

The von Newan-Richtmeyer artifictal viscosity, $Q,{ }^{3}$ is used to allow the finite-difference equations to treat shock waves in a continuous manner. The coefficient of the quadratic term $B_{q}$ is taken as 2 , which is approximately the number of zones orer which the shock is spread regardless of shock strength. Because -100 zones were used over $1.0 \mathrm{~cm}$, the shocks should be well-defined. A linear terw, $B_{f}$, Is included to give some damping to low-level oscillations. The value of $B_{\ell}$ was taken as 0.1 (default value in the code).

Stress waves are calculated by solving the finite-difference analogs of the conservation-of-mass, momentum, and energy equations. To determine whether or not fracture of the material occurs, the resulting stress is compared to a dynamic fracture criterion. For aluminum, the dynamic fracture criterion of Tuler and Butcher ${ }^{7}$ is used. This wodel calculates a quantity:

$$
K(t)=\int_{0}^{t} f(\theta) d t
$$

where

$$
f(\sigma)=\left\{\begin{array}{cc}
\left(-\sigma-\sigma_{0}\right)^{\lambda}, & 0<-\sigma_{0} \\
0, & \sigma \geq-\sigma_{0}
\end{array}\right\}
$$

The quantity $R(t)$ is calculaced at every zone for every time step. Spallation occurs when

$$
K(t)>K_{s}\left(\frac{T_{s}-T}{T_{s}-T_{o}}\right)^{c} \geq 0 .
$$

Values of input variables used, taken from Ref. 7 , were:

$$
\left.\begin{array}{rl}
K_{s} & =3.98 \times 10^{13} \\
\lambda & =2.02 \\
\sigma_{0} & =1.0 \times 10^{10}
\end{array}\right\} \text { cgs unics. }
$$

Tuler and Butcher state that these values are applicable to Type-1100 aluminum in the following sense: The abeve values of $k_{s}, \lambda$, and $\sigma_{0}=$ $4.25 \times 10^{9}$ dyne/ $\mathrm{cm}^{2}$ are from 6061-T6 aluminum data. The value of $\sigma_{0}=1.0 \times 10^{10}$ represents the asyrtotic value for long pulse durations indicated by experiments vith Type-1100 aluminum. The data vere used by the authors to predict spall layer thicknesses from fracture experiments with Type-1100 aluminum. 
The value of $T_{S}$ is taken to be $966 \%$ (the melt temperature of aluminns), and $c$ is taken to be 0.5 because Ref. 3 suggests that this value fits avallable data.

\section{LASER-TARGET INTERACTION AND TARGET RESPONSE}

Intense laser beams interacting with a metal target produce a plasma (by neating) near the target surface. This rapidly expanding plassa, in turn, produces shock waves that propagate frod the plasma into the solid target. As the shock wave traverses the homogeneous medium, dispersion occurs, 1.e., the amplitude of the wave derreases and the width increases. Dispersion occurs because the shock velocity for the rarifaction wive depends on the stress. Higher stress ioplies higher velocity; the top of the rarifaction wave therefore poves faster than the botton, with the resulc that a triangular stress wave is formed. After triangle formation the amplitude decreases because the rarifaction follows an isentropic curve, giving a higher shock velocity than the compression wave, which follows a Hugoniot line. When the shock wave reaches the back surface, the reflected portion of the wave (which is ncw an unloading wave) and the unreflected part of the wave interfere to give the stress distribution during reflection. After reflection the wave is an inverted mirror inage of the stress wave at the time reflection started; i.e., $\sigma^{\prime}(x)=-v\left(x_{0}-x\right)$ where $x_{c}$ is the width of the stress wave on the $x$-axis at the time reflection starts. This transformation of the stress wave results from the boundary condition, $\sigma\left(x_{t}\right)=0$, where $x_{t}$ is the position of the vacuun target interface. This phenomena is discussed on Page 720 of Ref. 8 .

The sequence of events which leads to spall is illustrated in Figs. 4, 5, and 6. The problem chosen for illustration represents a $7 \mathrm{~kJ} / \mathrm{cm}^{2}$ 'as ar pulse of $1.0-n s$ duration on $1.0 \mathrm{~cm}$ of aluminum (Problem 23, Appendix C). Figure 4, which presents a time sequence if stress, temperature, and velocity as a function of position, gives an overall picture of plasma-cloud formation and its interastion with the slab to form a stress wave. Figure 5 presents a similar sequence showing stress, tomperature, density, and source strength. The region near the plasea-solid boundary has been magnified to show the detalls of shock-save gereration. fis the source-strength ploss show, laser ener $j y$ is absorbed tin the plasea clost. and is cransportent from there to the woriflog surface by eleceronic heat conduction and radiative heat cransfer; the working surface is defined as that area at with the teeperature and densicy curves cross (see $\mathbb{F}$ ig. $5 c$ - tine at which the laser is turned off - 1or best illustration of this sequence). It can be seen that work can be dome on the high-densiey region by the low-density region as expressed by noting that the equation of state for a gas, $P=$ NokT, allows high pressure at low deasily dete to theat ing: there $N=$ particles/g and $k$ is the Boltman constant. The stress wave depicted in Fig. 5 is shown again in fig. 6. Only the solid region of the target is represented and the behavior of the stress wave craveling thrcugh the material is shown. The precursor of the stress wave is an elastic wave. It toves ahead of the plastic wave (which soves at thercodynabic sound speed) because the sound speed of the elastic material is

$$
c_{s,}=\left[\frac{3(1-v)}{1+v}\right]^{1 / 2} c_{t s}
$$

where $c_{t s}$ is the thersodynazic sound speed and bis Poisson's ratio. For aluginus the ratio of elastic to thermodynamic sound speed is 1.225. Fro= Fig. 6 (and Fig. 8 to be discussed later' it can be seen that the elastic disturbance runs ahead of the peaik of the stress wave by a factor of about 1.2.

The cagnitude of the precursor is given by

$$
\sigma_{E}=\frac{1-v}{1-2 v} Y_{0}
$$

where $Y_{o}$ is the elastic yield strength. Because a value of $Y_{0}=3$ kbar was used in the calculations, $\sigma_{\vec{E}}=6$ kbar. This correlates well with the nagnitudes in Figs. 6 and 8 .

Figure $6 f$ shows a stress wave produced by interference of a compression and rarifaction zave at the back of the slab target. This figure also shows that spallation occurs at 0.072 co fron the free surface, as a result of the negative stress acting on a plane for a period of time. The stress waves in Figs. 6d and $6 f$ are inverted mirror inages, except that the peak in Fig. Gf is missing because spall occurs before complete reflection. 


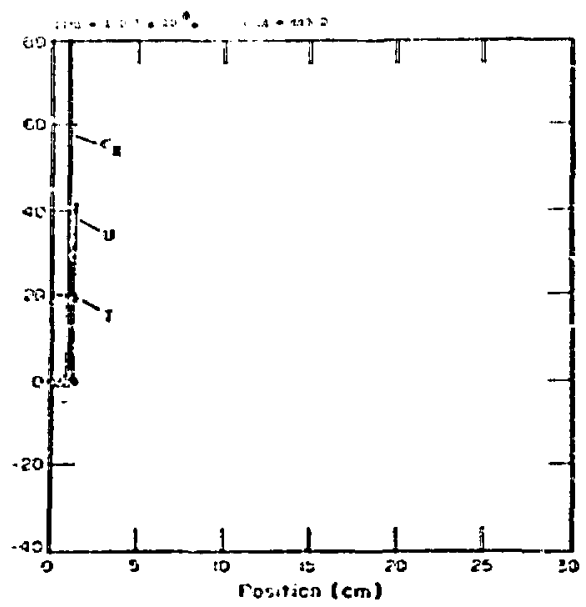

(a)

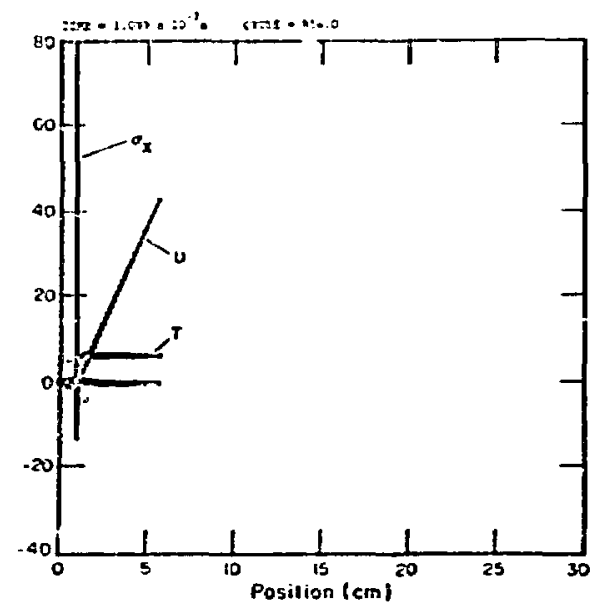

(c)

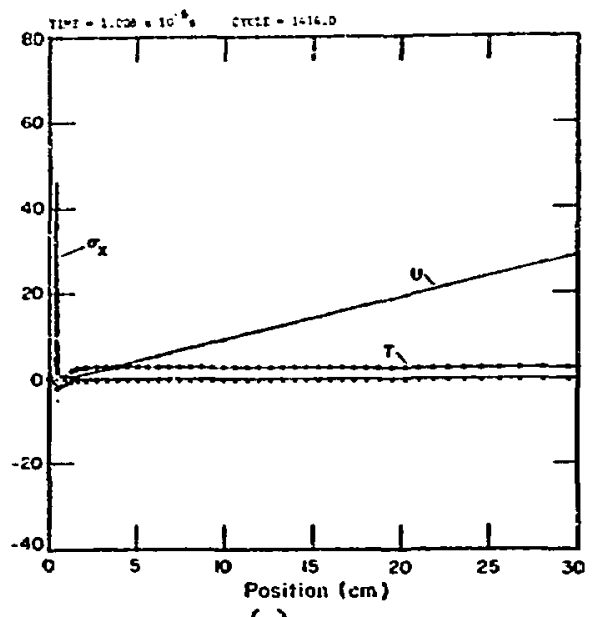

(e)

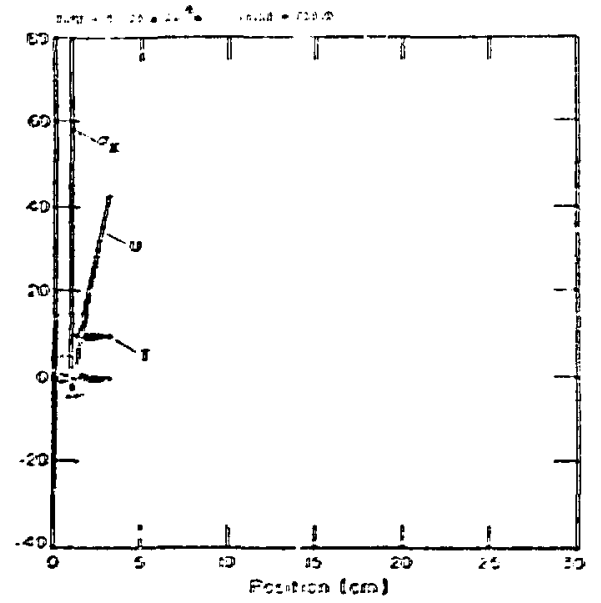

(b)

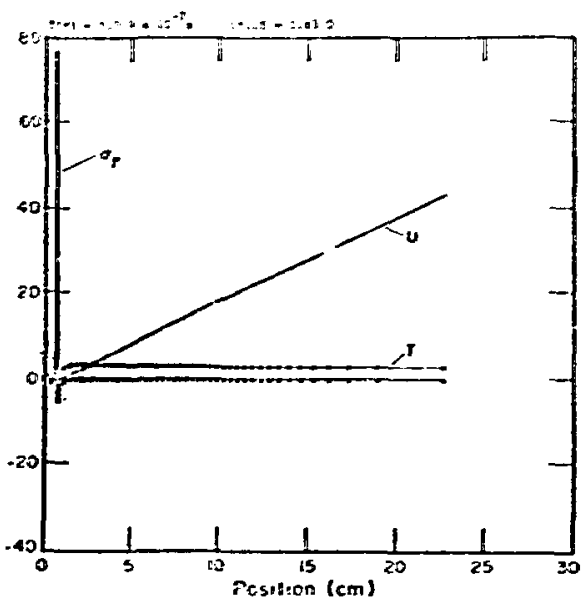

(d)

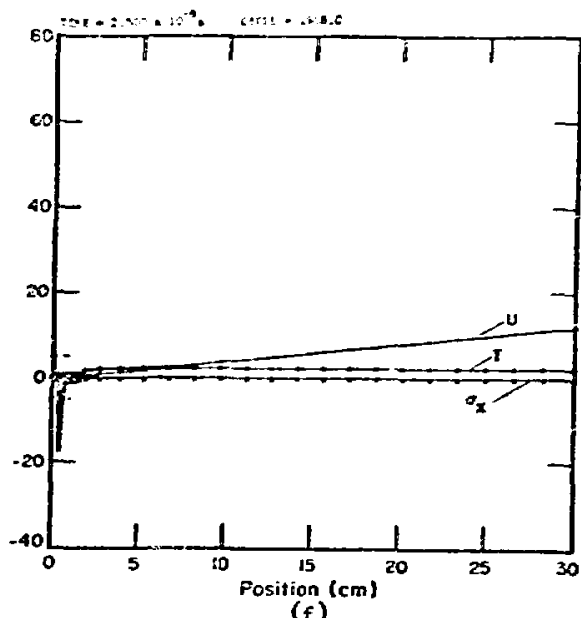

Fig. 4. Stress, temperature, and velocity in the plasma cloud as a function of position and tine. Laser energy, $7.0 \mathrm{~kJ} / \mathrm{cm}^{2}$. Pulse time, $10^{-9} \mathrm{~s}$. Aluminu thickress, $1.0 \mathrm{~cm}$. $\mathrm{r}$. . . Stress X (kbar $\mathrm{s}$ ), + Temperature (eV), -- Velocity $\left.\left(10^{+6} \mathrm{~cm} / \mathrm{s}\right)\right]$. 


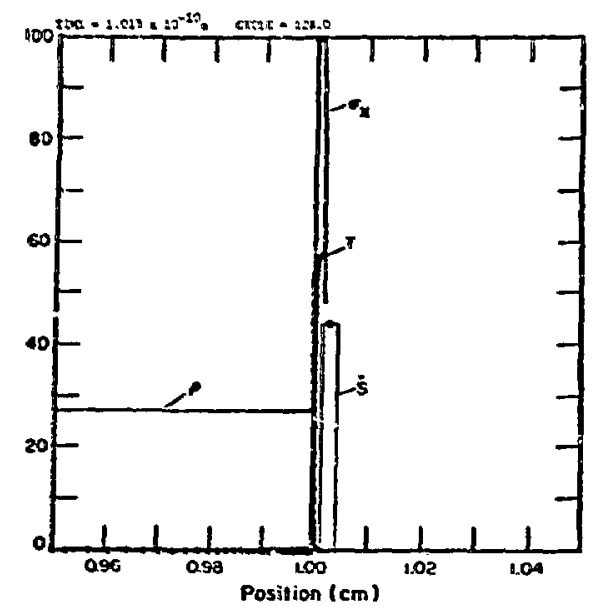

(a)

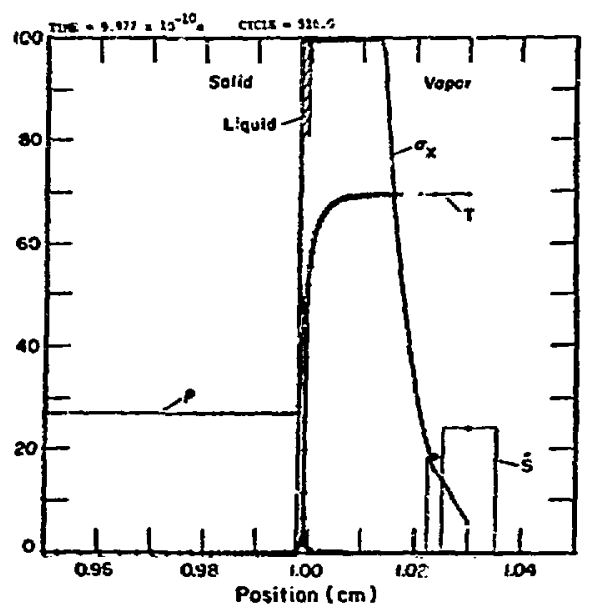

(c)

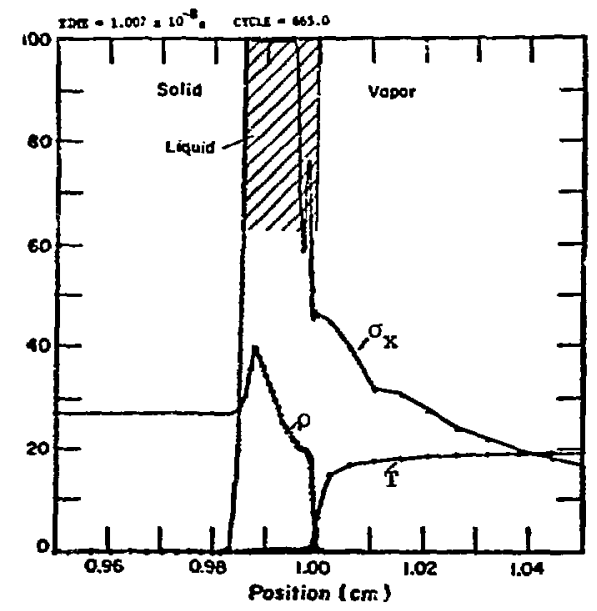

(e)

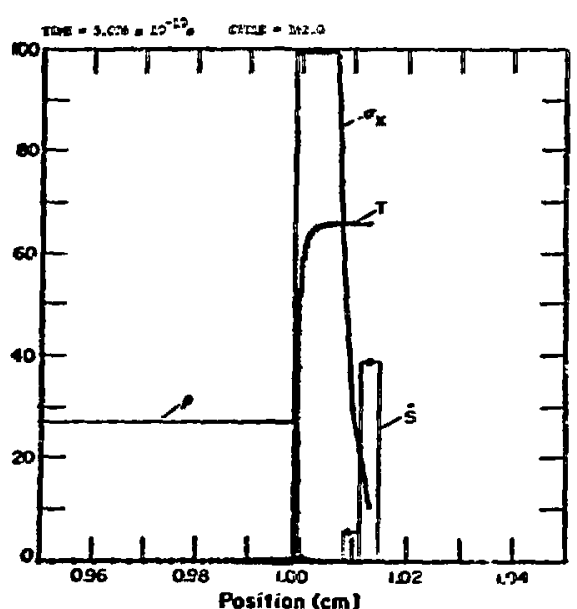

(b)

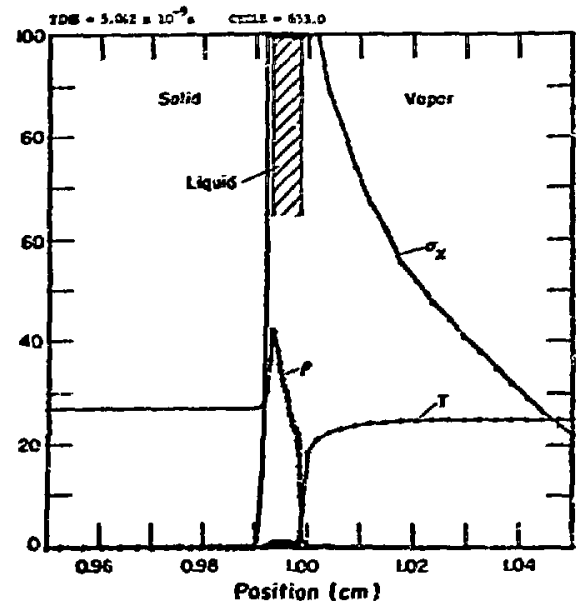

(d)

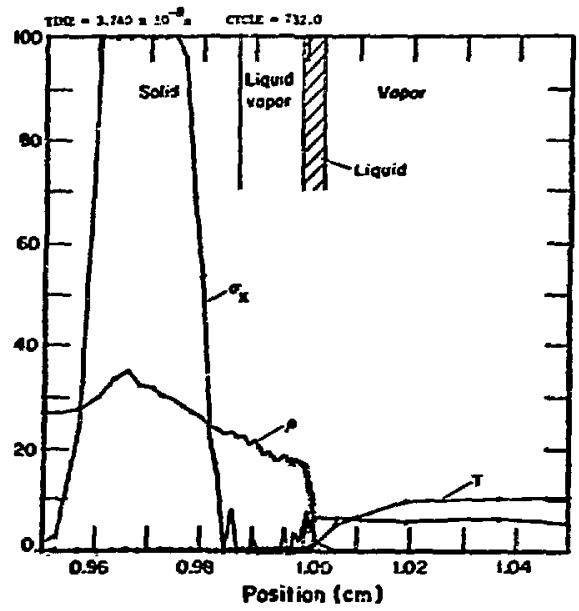

(f)

Fig. 5. Stress, temperature, density, and source strength at solid/plasma interface as a function of position and time. Laser energy, $7.0 \mathrm{~kJ} / \mathrm{cm}^{2}$. Pulse time, $10^{-9} \mathrm{~s}$. Aluminum thickness, $1.0 \mathrm{~cm}$. [...Stress $\mathrm{X}$ (kbars), ++ Temperature $(\mathrm{eV}),-$ Density $\left(10^{-1} \mathrm{~g} / \mathrm{cm}^{3}\right)$, , 

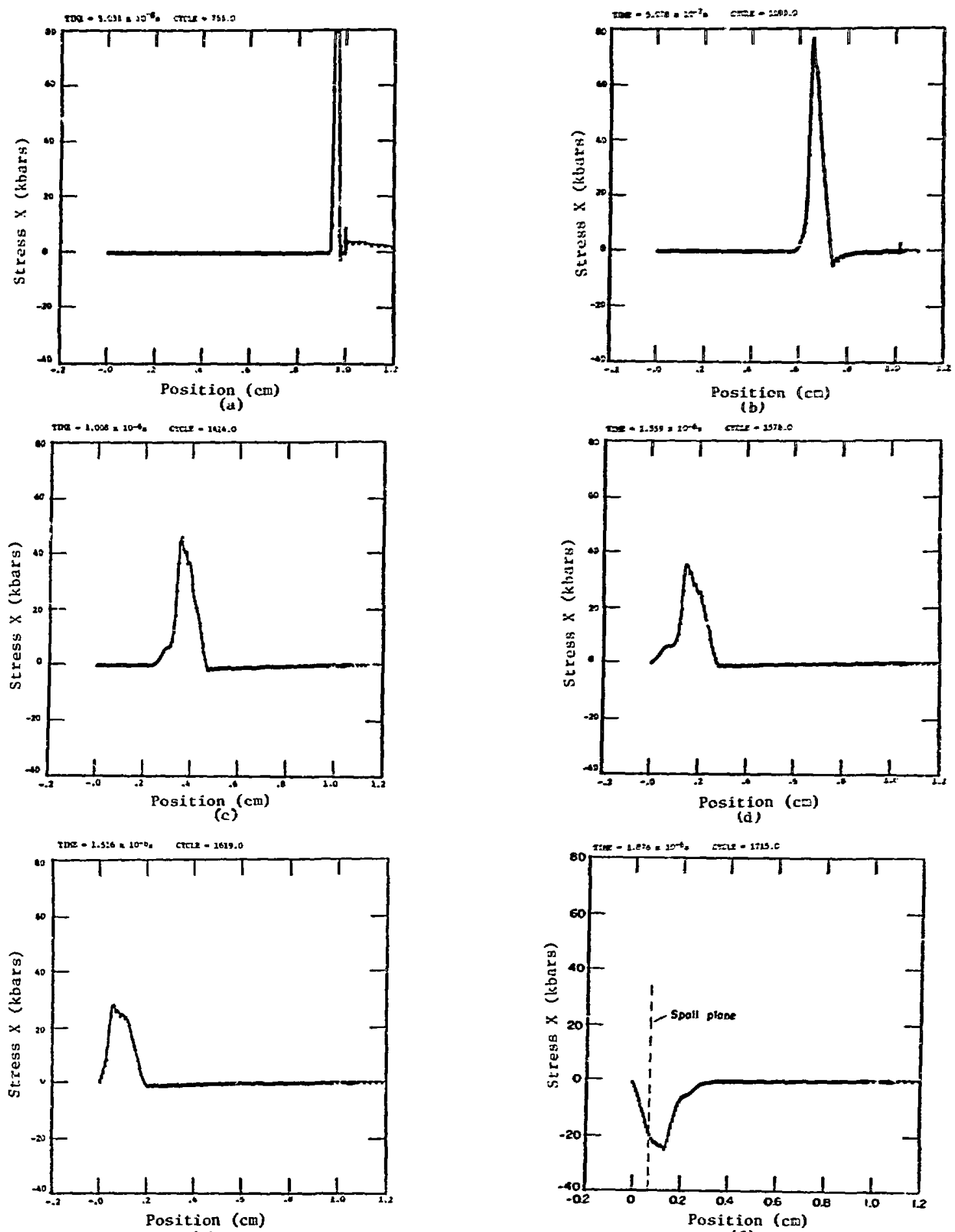

(e)

(f)

Fig. 6. Stress in solid material as a function of position and time. Laser energy, $7.0 \mathrm{~kJ} / \mathrm{cm}^{2}$. Pulsz time, $10^{-9} \mathrm{~s}$. Aluminum thickness, $1 \mathrm{~cm}$. 
The results shown in Figs. 4 through 6 are for a laser pulse width of 1.0 us, a tme much sthorter than the shock transit times. Berause different physical phenomena occur when pulse durations are near shcck transit times, we will consider such a case next. For a 1.0-cm-thick aluminum target with a 1.0-us pulse incident on it, the laser pulse widch is $66 \%$ of the shock transit time $(1.5 \mu \mathrm{s})$. The series of time-sequence plots in Figs. 7 througin 9 are the result of a computer calculation (Problem 76, Appendix c). The laser energy is $46 \mathrm{~kJ} / \mathrm{cm}^{2}$ and is sufficient to cause spall. Figure 7 shows the overall picture (as in Fig. 4) of plasma-cloud format.Ion and its interaction with the solid. In addition to the variables shown in Fig. 4, the source strength here indicates that the cloud becomes very large before the laser is turned cff. The time sequence of the resulting stress wave traveling through the medium is shown in Fig. 8. It can be seen that the stress wave is $66 \%$ across the material at $1.0 \mu \mathrm{s}$ when the laser is turned of $f$, but that work is done by the hot plasma for some time after that; i.e., the pressure pulse is considerably longer than the laser pulse. Figure 8c shows the stress at the time the plastic wave reaches the back surface $(\sim 1.8 \mu \mathrm{s})$. Figure $8 \mathrm{~d}$ shows the stress at a time when an $x-t$ diagram (to be discussed lacer) predicts that the entire target would be at zero stress if the stress wave were rectangular, and Fig. 8e shows the stress wave at the time of spall. Figures $8 \mathrm{c}$ and $8 \mathrm{e}$ are nearly inverted mirror images of each other. A late-time stress-wave configuration, Fig. 8f, shows that spall continues after the first breakage and illustrates some stress waves that result when free surface: are introduced into the problem. (Lines in these graphs are not drawn across spall planes.) Most interesting in this calculation is the fact that the target fractures in the middle rather than near the back face as it did with the 1.0-ns laser pulse.

Superimposed on the major stress wave (Fig. 8)

is a series of short-wavelength large-amplitude stress waves. The generation of one of these waves is shown in Fig. 9 by magnifying the plaswa/liquid/ solid boundary regions. This phenomenon, whether computational or physical, is not well understood. Because the waves are increasing in amplitude and period, they must be the result of an instability.
It can be seen from Pig. That each wave is defined by several computational zomes; also, that they do not grow to the point where the problew blows up. These are two indicacions that the waves are not the result of mucerical instability.

An umierstanding of some results of the copputer calculations just described may be desirable at this point; naceiy, chat 1.0-ms laser-pulse durations give a spall layer $0.072 \mathrm{~cm}$ thick at $1.85 \mathrm{gts}$, whereas 1.0-1s pulses produce tid-plane spall at 3.47 us. A look at an $x-t$ diagram may be helpful.

Two such diagrans are shown in Figs. 10 and 11. The two diagrams represent the two cases shown in Figs. 4 through 6 and 7 through 9, respectively, in the sense that they depict rectangular elastic-wave pulses that axe "equivalent" to the complex computergenerated pulses. The actual pulses (and their diagrams) would be Euch rore complicated, but Figs. 10 and 11 duplicate the general shape closely enough to illustrate the principle.

The solid lines show the time it takes for the compression wave, i.e., the front of the stress wave, to arrive at any position; whereas the dashec lines show these data for the rarifaction wave, i.e., the back side of the stress wave. The slope of the lines is $\pm 1 / c_{s}$ where $c_{s}$ is the sound speed of the elastic wave. Regions in space and time are shown where positive, negative, and zero stress exist. Crossing the solid line from left to right represents a rise in stress (compression wave), and crossing the dashed line from left to right represents a drop in stress (rarifaction wave). Hence, it is necessary to change the sign of the stress, $\sigma$, in the upper half of the diagram to Daintain the definitions of rarifaction and compression waves. Also, because the solid and dashed lines are inverted in space in the upper half of the figure, the transformation $\sigma^{\prime}(x)=-\sigma\left(x_{0}-x\right)$ as previously stated is valid for rectangular stress waves.

In Fig. 10 the time width of an equivalent rectangular stress pulse, $\Delta t_{J}$, is found by forcing the rarifaction wave and the reflected compression wave to cross at the caículated spall plane. The width across the equivalent rectangular pulse is $\Delta x_{\sigma}=c_{s} \Delta t_{\sigma}=0.13 \mathrm{cra}$, which is about the distance between the leading edge and the peak of the pulse in Fig. 6d. This width is much larger than the laser pulse width because of dispersion in the stress wave as it travels through the medium. 


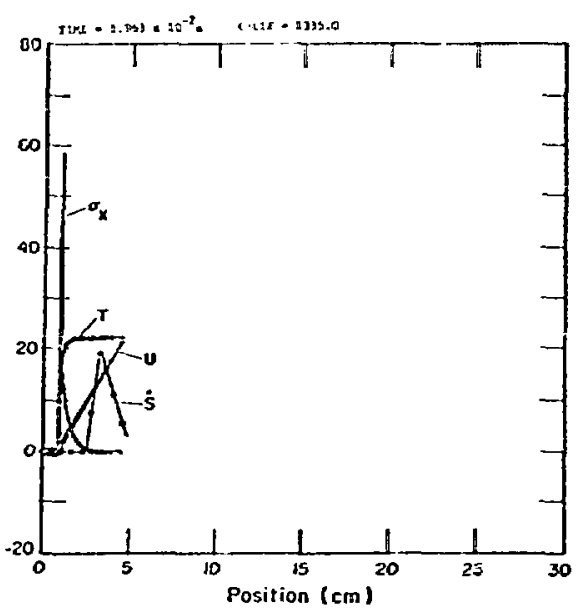

(a)

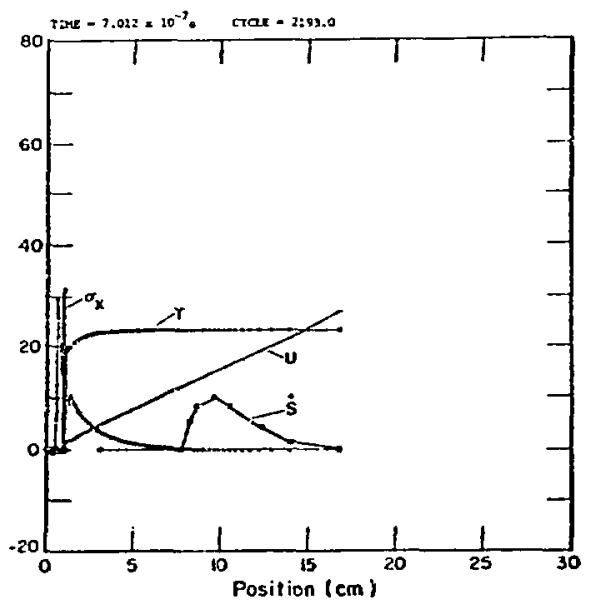

(c)

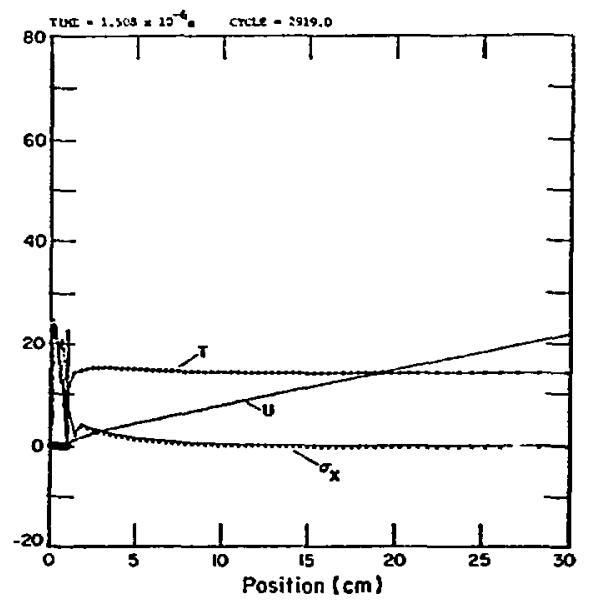

(e)

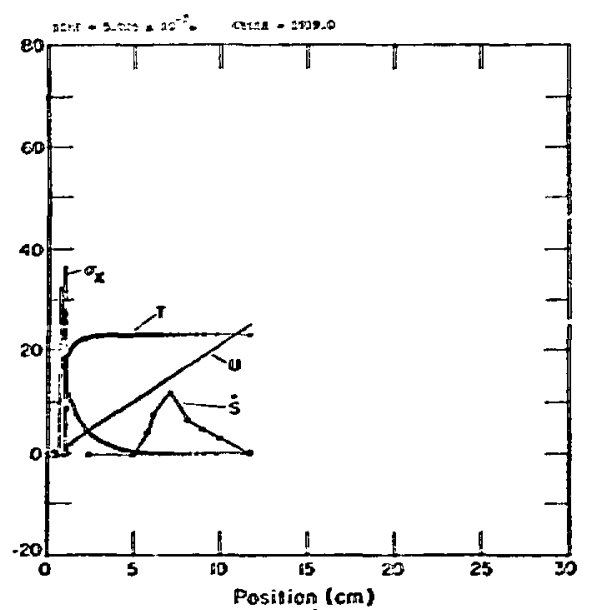

(b)

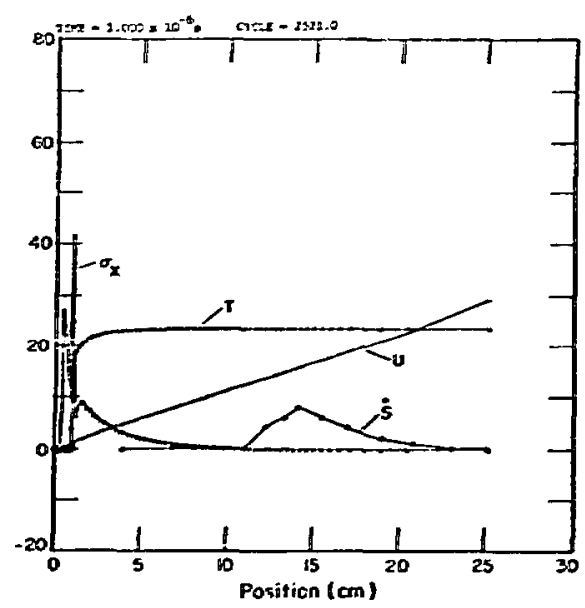

(d)

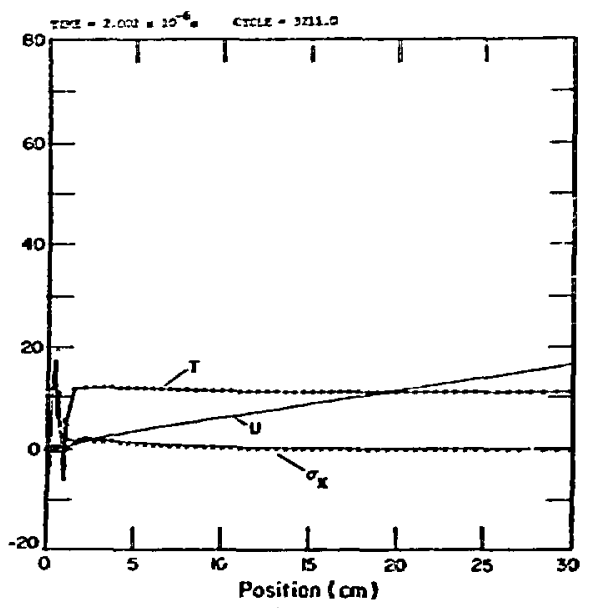

(E)

Fig. 7. Stress, temperature, velocity, and source strength in plasaa cloud as a function of position and time. Laser energy, $46.0 \mathrm{~kJ} / \mathrm{cm}^{2}$. Pulse time, $10^{-6} \mathrm{~s}$. Aluwinum thickness, $1.0 \mathrm{~cm}$. [. . Stress $X$ (kbars), ++ Temperature (eV), - Velocity $\left(10^{+6} \mathrm{~cm} / \mathrm{s}\right), \star \star \star$ Source $\left(10^{+24} \mathrm{erg} / \mathrm{g}^{\circ} \mathrm{s}\right) 1$. 

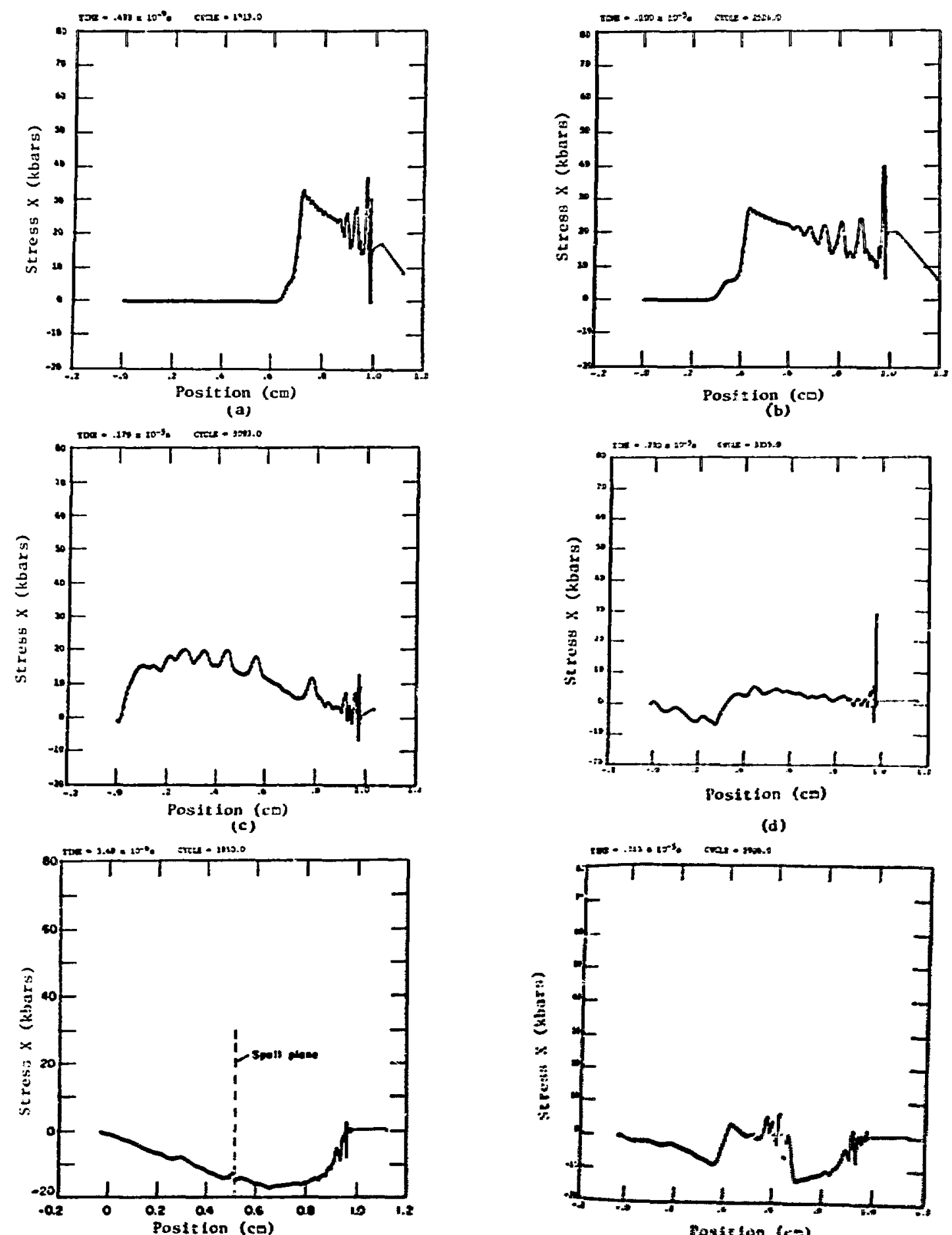

(d)

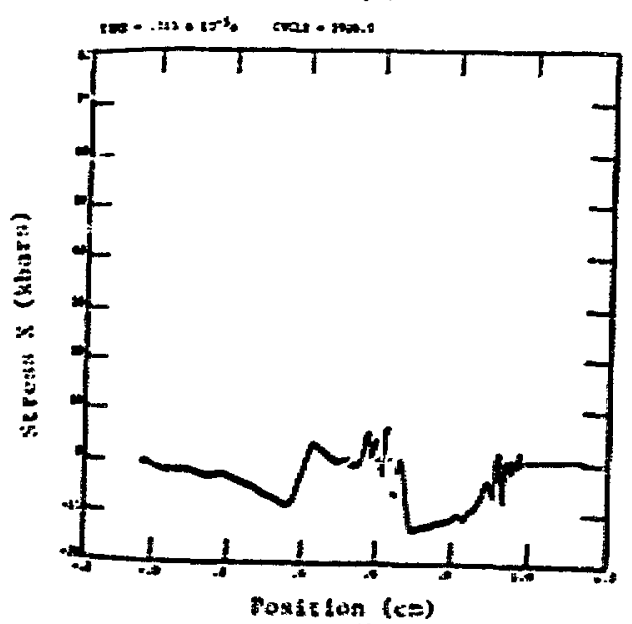

(c)

(I)

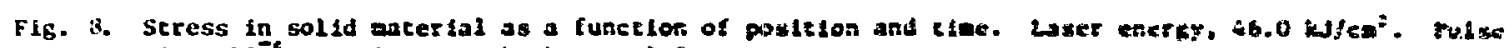
time, $10^{-6} \mathrm{~s}$. Aluelnu chickness, $1.0 \mathrm{~cm}$. 

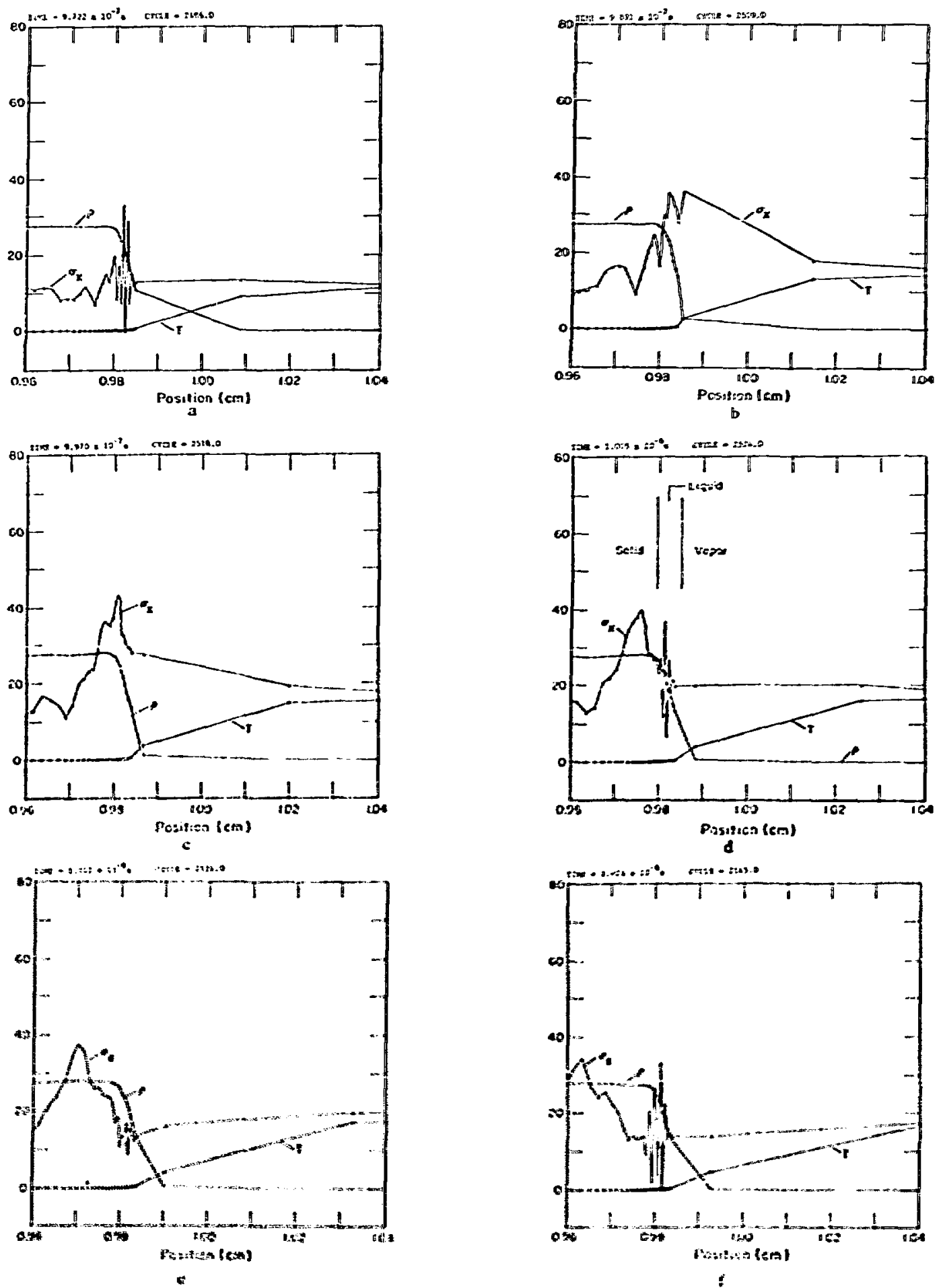

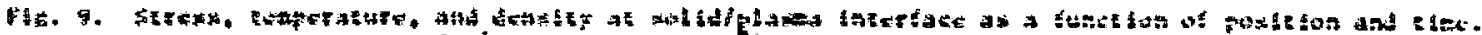

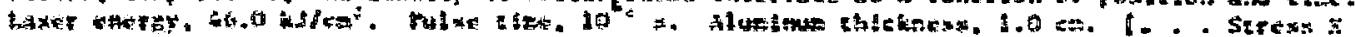
(Atatis). 


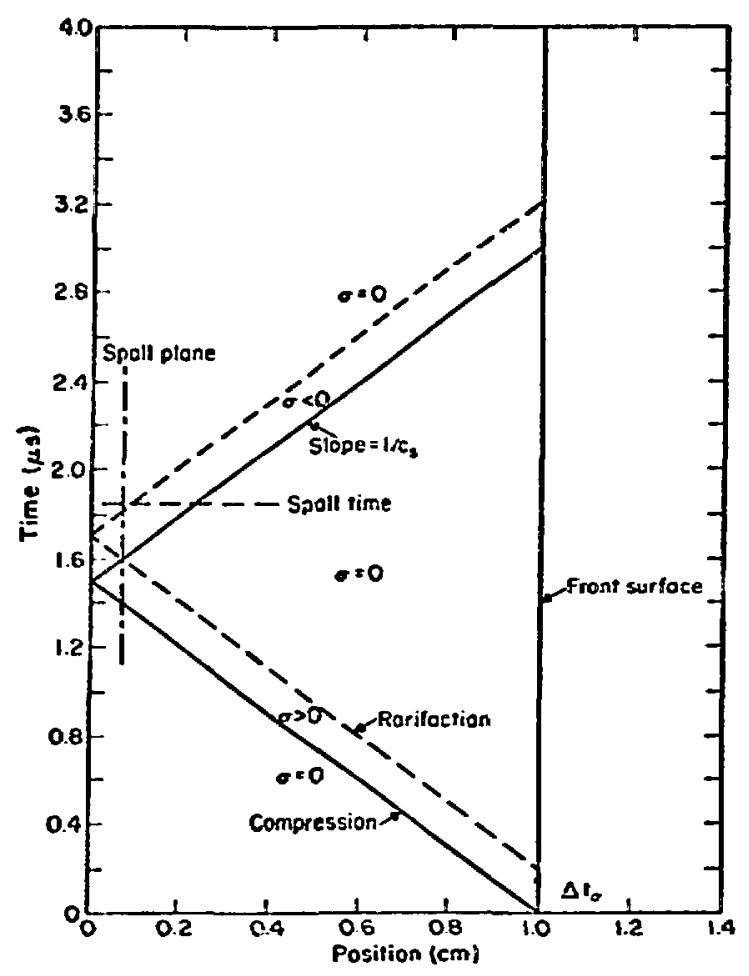

Fif. 10. $x-t$ diagram representative of a 1.0-ns laser pulse on $1.0 \mathrm{~cm}$ of aluminum. $E_{2}=$ $7.0 \mathrm{~kJ} / \mathrm{ca}^{2} . c_{s}=0.665 \mathrm{ca} / \mathrm{.s}$.

A sirular exercise is shown in Fig. 11 for a 1.0-hs pulse. For this case $\Delta t_{\sigma}$ is 1.54 is, giving an equivalent stress-pulse width of $1.02 \mathrm{~cm}$ which is about the thickness of the target. The calcuLated spall time of 3.47 us is somewhat less than $3.73 \mathrm{is}$, the time at which the stress goes back to zero at the spall plane. This behavior is expected because the stress has to becone less than $-10 \mathrm{kbar}$ betore the $t$ ime integration in the Tuler-Butcher criterton starts, and the tine integral is thereiore not carried out along the whole tine line where the stress is negat ive in the spall plane. The vilue of it, exceeds $1.0 \mathrm{us}$, the laser pulse width, beciause the hot plasa cloud continues to work on the solid target after the laser is turned off and the plasmo is cooling. It appears that the rarifaction wive in this case is generated when the cumpression wave reflects.

Our simple codel indicates tinat a laser pulse with a width of $2 x_{t} / c_{s}$ (where $x_{t}$ is the target dimension) bould not cause spall because the conpression and rarifaction waves would never cross to

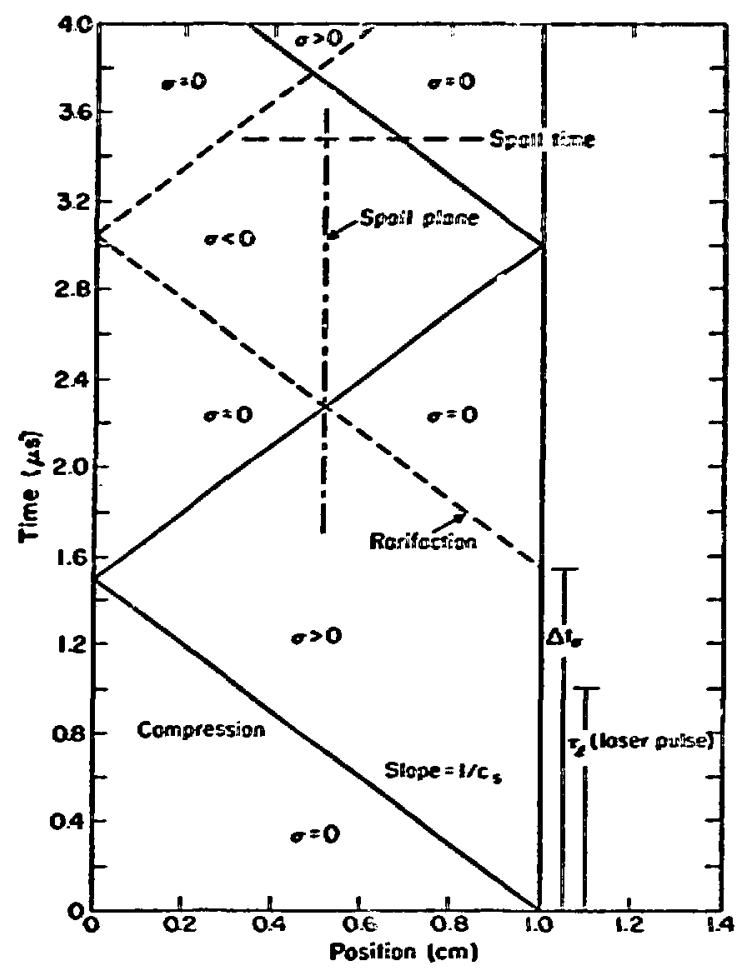

Fig. 11. $x-t$ diagram representative of a 1.0-is laser pulse on $1.0 \mathrm{~cm}$ of aluminum. $E_{2}=$ $46 \mathrm{~kJ} / \mathrm{cm}^{2} . C_{s}=0.665 \mathrm{~cm} / \mu \mathrm{s}$.

produce negative stress. It will be show in the next section that the energy required for spall becomes very large when $t_{2}=2 x_{t} / c_{s}$. Time-sequence plots of the stress waves for a problem (Problem 66, Appendix C) that is near these conditions (0.3-cathick aluminum target and a 1.0-us laser pulse) is shown in Fig. 12. It can be seen that, indeed, the negative stress wave does not develop well. The laser energy is $40 \mathrm{~kJ} / \mathrm{cm}^{2}$. Figure $12 \mathrm{a}$ shows the stress wave at the time its front reaches the back. surface; and Fig. 12b shows the wave at a time when the reflected wave should reach the front surface. The laser is still on, preventing a rarifaction wave from developing. At 1.61 is (Fig. 12c), the front of the compression wave reaches the back surface again, and a rarifaction wave has developed. At 2.10 us a negative stress wave is finally formed; however, its magnitude is not sufficient to cause spall. At this time the target has moved $-0.05 \mathrm{~cm}$ away from the laser, thus providing a mechaniso for absorbing monentum without producing enough negative stress to cause spall. One more cycle of oscillation 

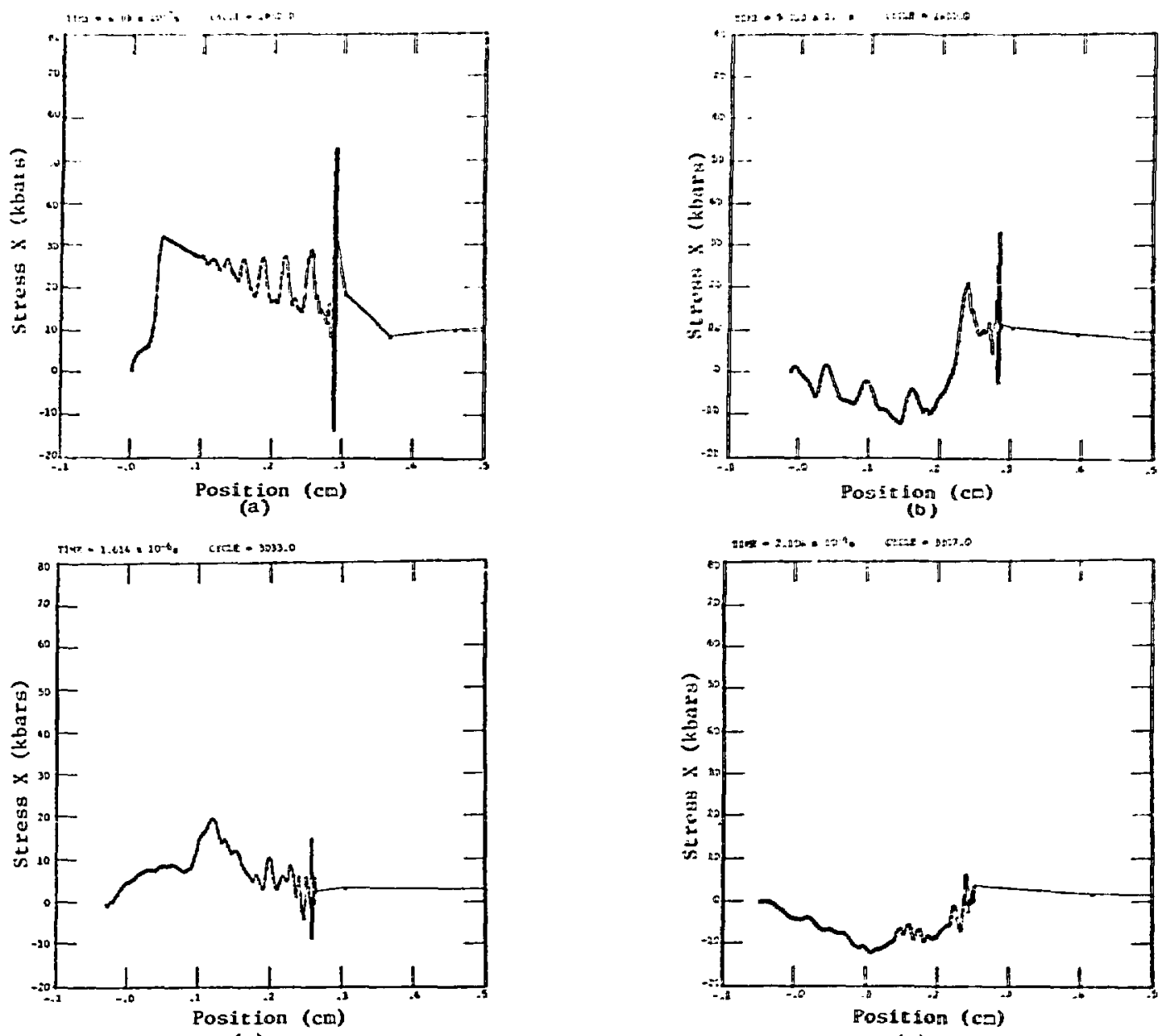

(c)

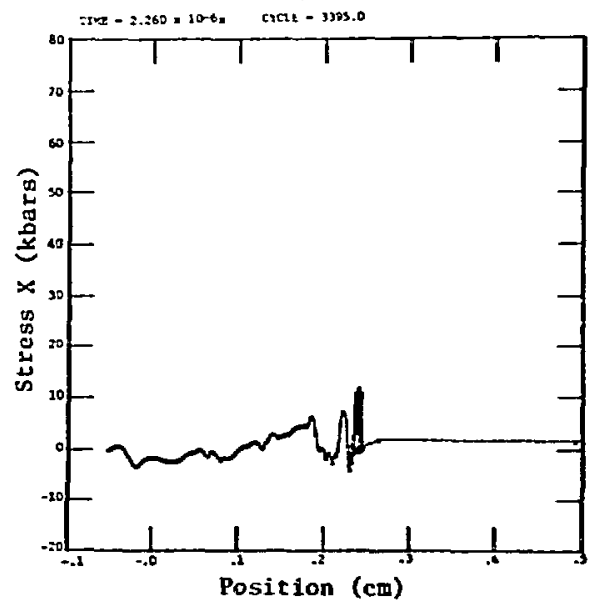

(d)

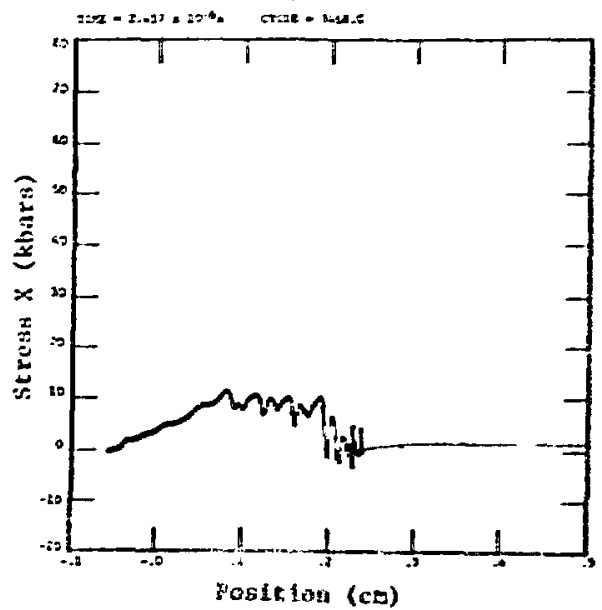

(e)

(f)

Fig. 12. Stress as a function of position and time. Laser energ\%, $40 \mathrm{~kJ} / \mathrm{cm}^{2}$. Pulse tiese, $10^{-6} \mathrm{~s}$. Aluminum thickness, $0.3 \mathrm{~cm} . \tau_{\hat{\chi}}=2.2 x_{t} / c_{s}$. 
is show in Figs. $12 \mathrm{e}$ and 12f, with 12e plotting the tioe at which the stresses are all nearest zerc. Figures $12 \mathrm{c}$ and $12 \mathrm{~d}$ are inverted mircor inages, as are F1gs. $12 d$ and $12 f$.

As a result of dispersion, the stress wave created by a short laser pulse suffers a significant loss in amplitude as it traverses the medium; however, wost of the l.oss occurs rear the front surface. As an example, Fig. 13 shows stress-wave amplitude for a 1.0-ns puise as a function of the position of peak stress.

\section{v. PARAMETER VARLATIONS}

Most of the data accumulated while running problems to establish energy thresholds for spall in aluminum are presented in this section and in Appendix $C$, which is a rabular summary. Several dependent variables of interest exist; however, because of the large volume of data generated we will present selerted data only, in graphic form. Independent variables to which the attention of this study has been directed include material thickness, time duration of constant power pulses, vavelengtin of laser IIgh:, ani energy absorbed by the target.

The viriable of greatest interest is the threshold energy requira! to cause spall in targets

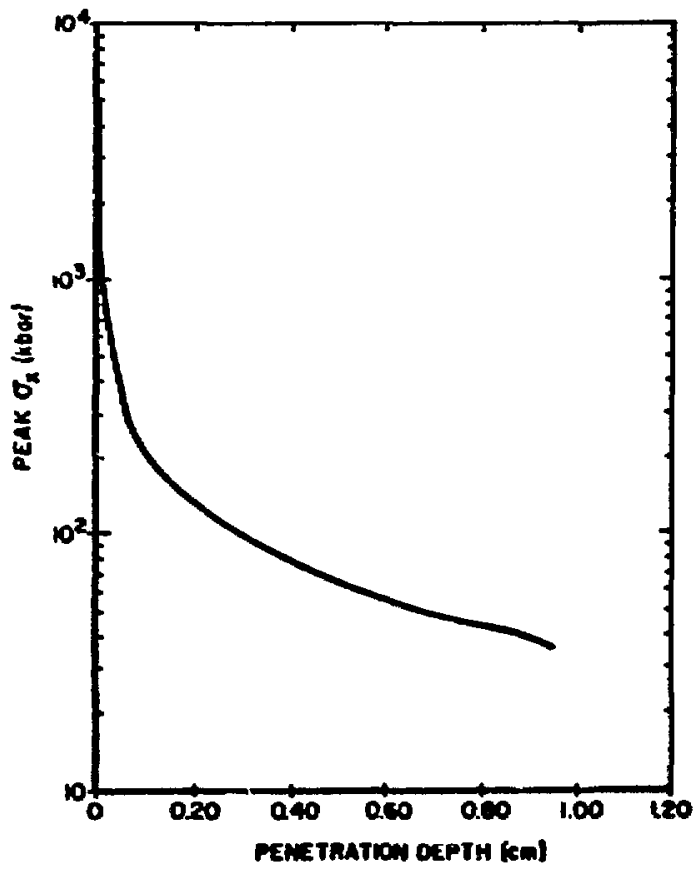

F18. 13. Decay of strass-wave peak as te travermes the target. Laser-11ght wavelength, 1.06 in. Pulse tin, $10^{-5}$. Laser mersy, 0.0 $\mathrm{kJ} / \mathrm{cm}^{2}$. Aluninu enickness, $1.0 \mathrm{~cm}$. (Problen in Appendix C.) of varying thickness at constamt laser power and pulse duration. These results are presented graptrically in Fig. 14. Laser pulse durations of 1.0 ms to 1.0 fus and alumint target tinicknesses of 0.1 to 1.0 core considered. Because computer calculations can only predict whether or not spall occurs for a given set of conditions, several computer runs may be necessary to establist: a spall threshold energy to some desfred degree of accuracy. The error bars in Fig. 14 represent the lowest emergy where spall was observed and the highest energy where no spall was observed. The spall threshold for $x_{t}=0.1 \mathrm{~cm}$ and $\tau_{2}=1.0 \mathrm{us}$ requires sone explanation: It is believed that the spall threshold should be lower than shown in the figure. in energy level of $15 \mathrm{~kJ} / \mathrm{cm}^{2}$ did not cause spall as normally seen in the form of solid-saterial separation, although the shock waves pass repeatedly through the waterial utile the laser is on, causing the material to melt in some places as a result of shock-heating. The power level at this point (15 $\mathrm{GH} / \mathrm{cos}^{2}$ ) is about the losest at wich CHART $\mathrm{L}$ can be run with the present ansorption schene. Below this pouer level, there is absorption in the liquid layer by the few free electrons predicted by the Saha-type ionization calculation. Light gets to the liquid because a critical density region (w - $\omega_{\rho}$, see Appendix A) is not formed at these power levels. An improved absorption wodel would have provision for partial reflection and absorption at the liquid/gas Interface and therefore would allow calculacions at lower porer levels.

Two energy thresholds for spall are shoun in F18. 16 for $\tau_{l}-100 \mathrm{nb}$ and $x_{2}=0.1 \mathrm{~cm}$. The higher

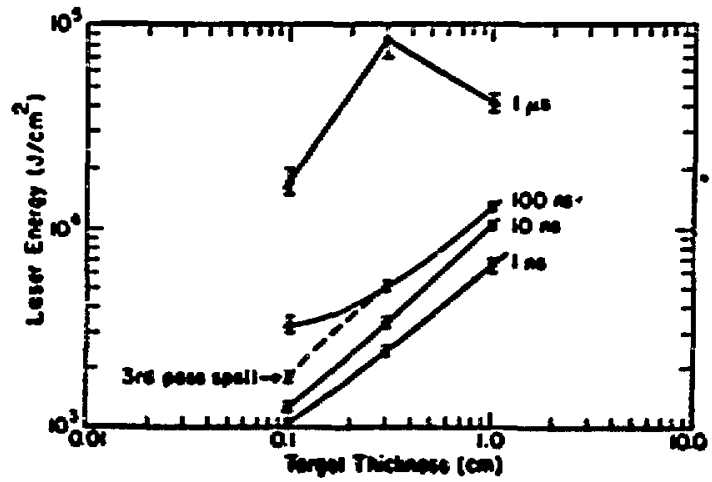

Fis. 14. Energy threshold for spall as a fusction of eluatiou target thicknese and tine duration of constant power pulses. Leserlight welengeh, 2.7 un. 
occured shorlly after the first stress-wave reflection at 0.373 's. As energy decreases, spall continues to occul:, but only after the cotpression wave has made 3.5 passes through the target at $1.01 \mathrm{fs}$. This can be visualized in an $x-t$ diagram (Fig. 15). Whether or not spall occurred after multiple stresswave reflections is questionable because the applicability of the Tuler-Butcher criteriom to multiple passes of a negative stress wave is not certain.

The data in Fig. 14 can be plotted in a manner that combines the effect of pulse tire and target thickness into a single variable. This is done in Fig. 16, where $\varepsilon_{\ell}=E_{\ell} / \rho x_{t}(\mathrm{~kJ} / \mathrm{g})$ is plotted as a function of $\tau=\tau_{\ell} c_{s} / x_{t}$. Plotted in this ranner, the energy thresholds for spall of all thicknesses fall near a smooth curve that has a large maxinum around $\tau=2$, as analysis from Section IV would lead one to expect.

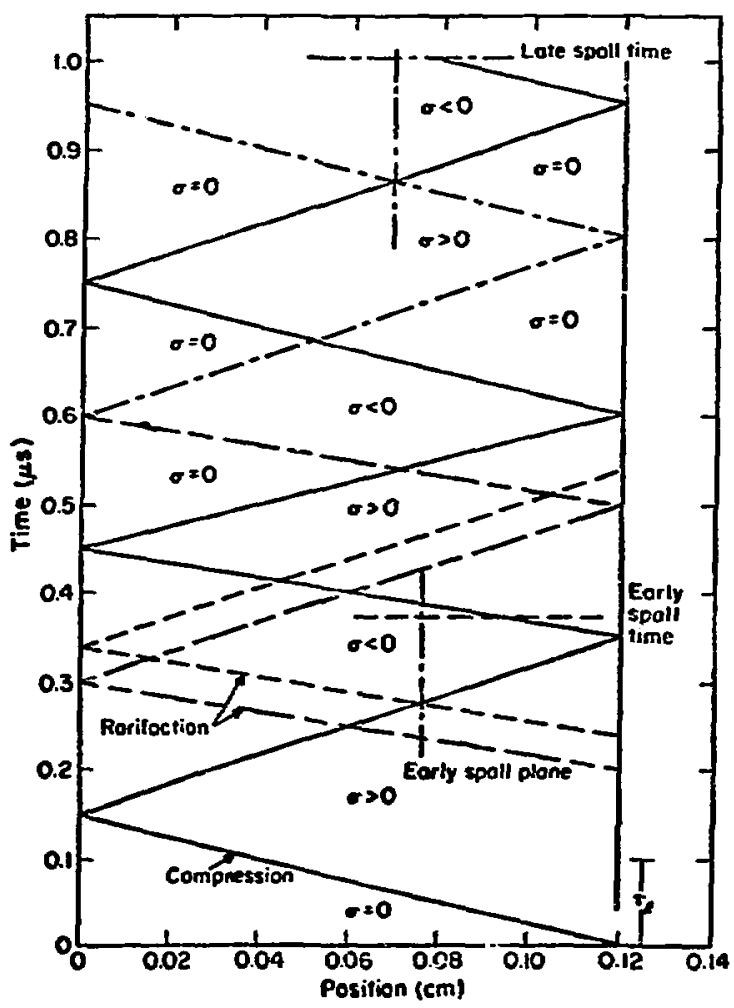

Fig. 15. $x-t$ diagram showing near uid-plane spall after one period of negative stress and after three periods of negative stress.

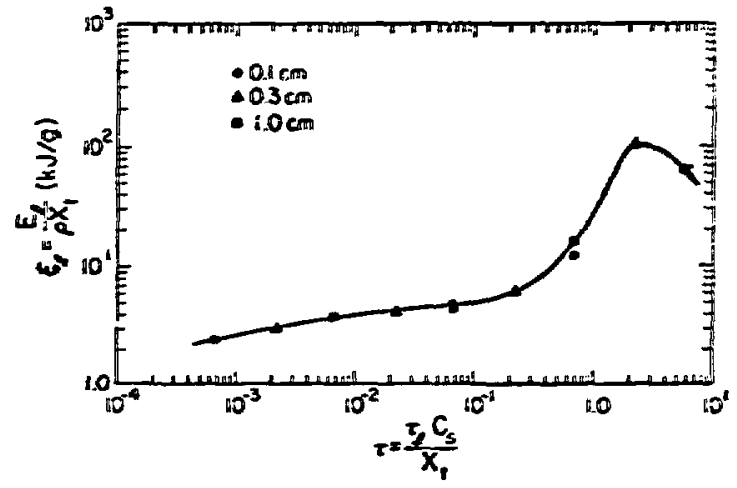

Fig. 16. Spall threshold energy per unit nass as a function of laser pulse tice (in units of shock transit tine) for all carget thicknesses.

The same phemomenon exists when electron beass are used as the source of energy for producing spall, as indicated by experinental results of threshold energies as a function of 6061-T6 alubinum target thickness (Ref. 9, D. 22). The electrom-bean pulse time in ticke expericents is $6 \times 10^{-e} \mathrm{~s}$ (full widch at half maxima) for all data points. The target thickness corresponding to the point there the shock transit tine is equal to the pulse tice is $0.04 \mathrm{cs}$, and a thickness $0 \equiv 0.02 \propto$ corresponds to a case in which the pulse width is trice the shock transit tice. Data presented in Ref. 9 indicate that the energy per unit Dass required for spall increases rapidly as the tarzet gets thinner beyond a target thickness of $0.04 \mathrm{co}$. Extrapolation indicates that the spall energy threshold is very large at

$$
\tau=\frac{\tau_{e b} c_{s}}{x_{t}}=2,
$$

where $\tau_{e b}$ is the electron-bean-source on time.

Two quantities, fuportant in deterefning whether or not a laser pulse will cause spall, are the aagnitude of the peak of the generated stress vave and the amount of ispulse delivered to the solid saterial. Both have to be suffictencly high if spall is to occur. The inpulse is determined largely by the anount of moterial resoved fros the surface of the target; f.e., the inpulse is $I=\sqrt{2 M} E$ where $M$ is the ass resoved and $\varepsilon$ is the deposited energy. 
Mass removal-versus-time plots tor some representa:ive problems are given in Figs. 17 through 20.

Each figure represents a different order of magnitude in laser pulse time, $\tau_{\ell} ;$ all are for laser energies of $10 \mathrm{~kJ} / \mathrm{cm}^{2}$ except the $\tau_{2}=1.0 \mathrm{us}$ case where $E_{\ell}=30 \mathrm{~kJ} / \mathrm{co}^{2}$; the wavelength in all cases is 2.7 w. Only for $\tau_{\ell}=1.0 \mathrm{~ns}$ do the total wassremoval rates approach asymtotic values as time grows. This allows one to plot mass removal per unit energy vs laser energy for $\tau_{R}=1.0 \mathrm{~ns}$ as shown in Fig. 21. These curves suggest that the amount of melt per unit energy remains nearly constant as energy increases, but that the amount of vapor per unit energy decreases. The vapor is the most important factor in determining inpulse, because it absorbs most of the energy. A change in wavelength (to 1.06 $\mu \mathrm{m})$ has a negligible effect on mass removal.

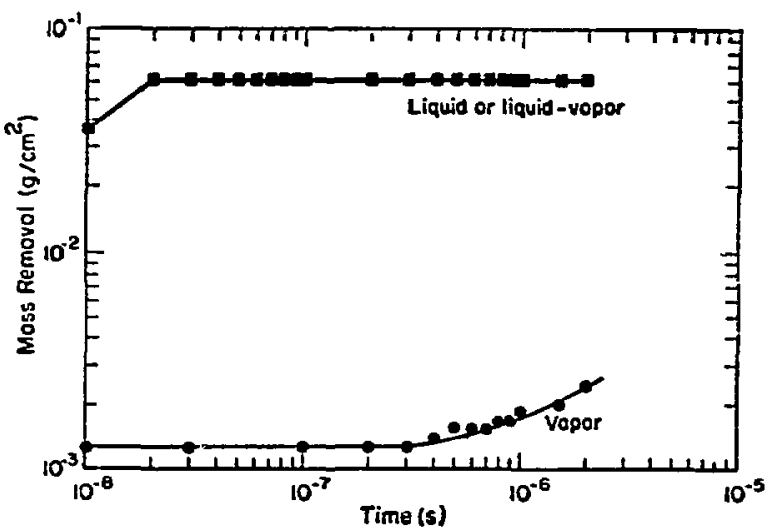

Fig. 17. Mass removal as a function of time. Laser light wavelength, $2.7 \mathrm{\mu m}$. Laser energy, $10 \mathrm{~kJ} / \mathrm{cm}^{2}$. Pulse time, $10^{-9} \mathrm{~s}$.

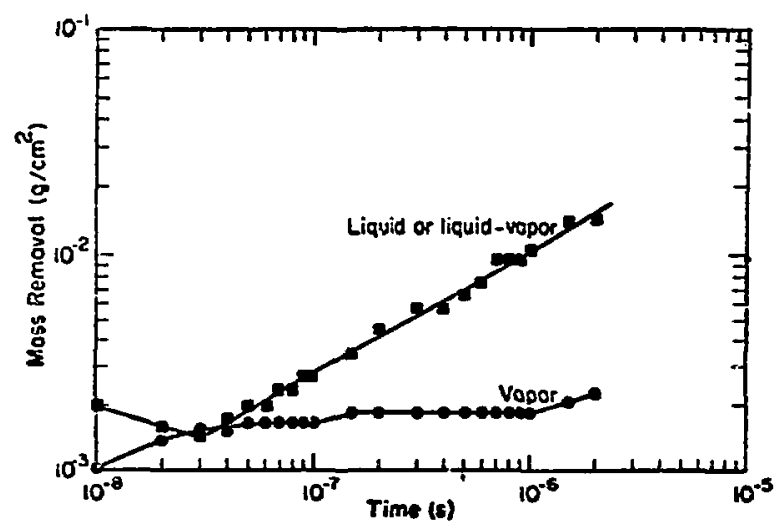

Fig. 18. Mass removal as a function of time. Laser light wavelength, $2.7 \mathrm{um}$. Laser energy, $10 \mathrm{~kJ} / \mathrm{cm}^{2}$. Pulse time, $10^{-\mathrm{a}} \mathrm{s}$.

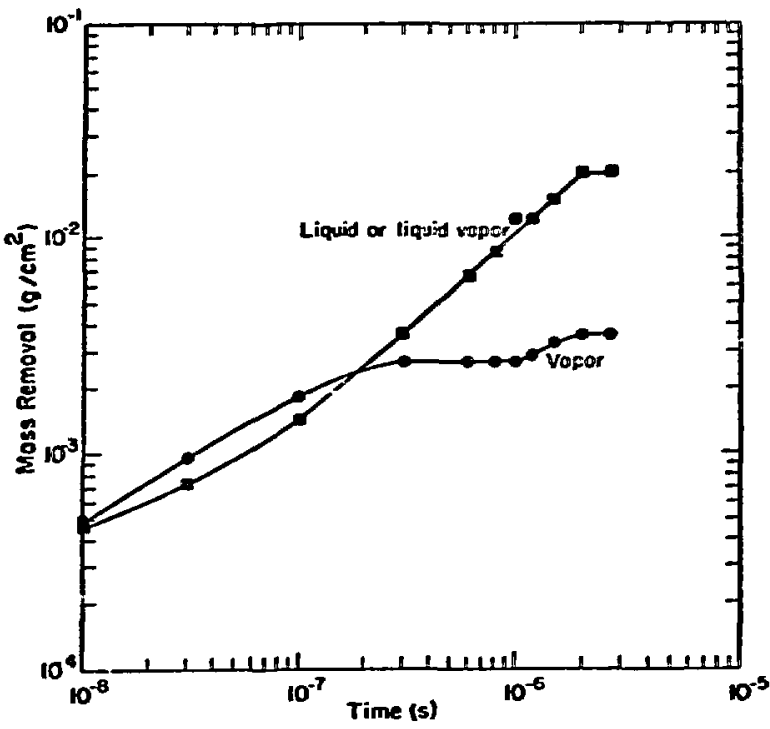

Fig. 19. Mass removal as a function of tine. Laser light wavelength, $2.7 \mathrm{frc}$. Laser energy, $10 \mathrm{~kJ} / \mathrm{cm}^{2}$. Pulse tine, $10^{-7} \mathrm{~s}$.

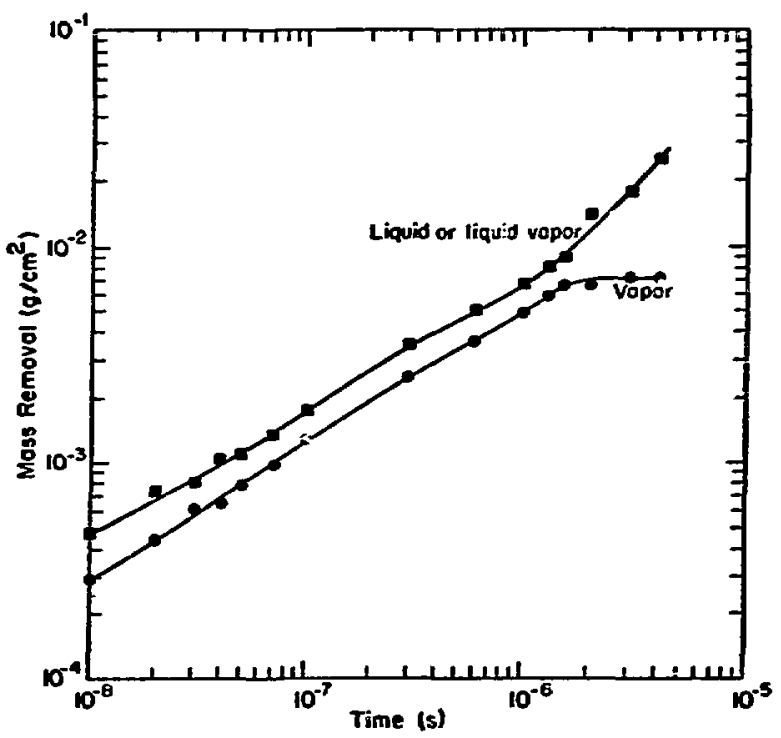

Fig. 20. Mass removal as a function of tine. Laser light wavelength, $2.7 \mathrm{jm}$. Laser energy, $30 \mathrm{~kJ} / \mathrm{cm}^{2}$. Pulse time, $10^{-\frac{6}{6}} \mathrm{~s}$. 


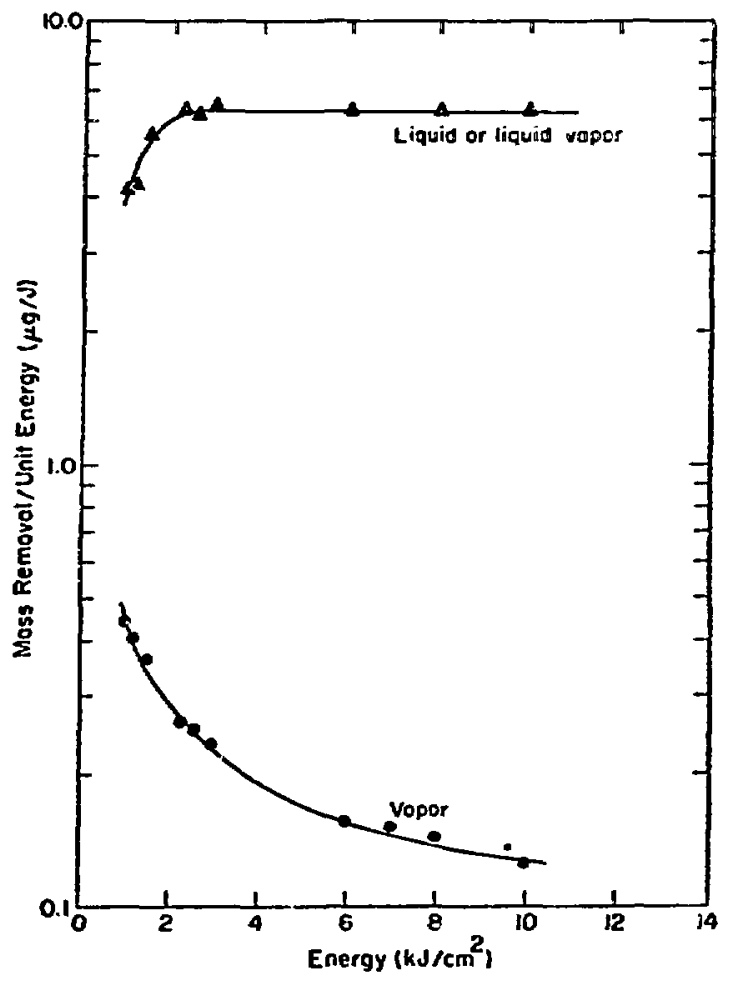

Fig. 21. Efficiency of mass removal as a function of laser energy. Wavelength, $2.7 \mu \mathrm{m}$. Values at $t, 0.2$ us. Pulse time, $10^{-9} \mathrm{~s}$.

Graphs of generated impulse vs time for several problems are shown in Fig. 22. By generated impulse we mean the maximum value of $\Sigma_{i} m_{i} v_{i}$ where $m_{i}$ is the mass and $v_{i}$ the velocity of zone $i$. Because asymtotic values are reached for most problems within run times, a plot of generated impulse per unit energy vs laser energy can be made as in Fig. 23. The asymtoric value of generated impulse and the maximum value of the impulse delivered to the solid layer are usually nearly the same.

Gregg and Thomas ${ }^{10}$ have measured some values of impulse delivered to solid targets by using a ruby laser with a pulse width of $7.5 \mathrm{~ns}$ (full width at inalf maximum). They also present an analytical fit to their data (solid line in Fig. 23; the dashed line is an extrapolation of their data). Cosparison of calculations to experiment shows that the calculated values have the correct slope, but are $\sim 387$ high. The difference seems to be acceptable.
The laser pulse shape must be frown in greater detall before conparisom calcolations can be atzempted. The data in Fig. 23 imtlicate that low-energy pulses are more efficient at gemerating ingulse (down to a point, as Gregg-amd-Thomas ${ }^{10}$ experiments show) and that puse duration has ittlle ffect on inpulse. The latcer is show fin a core explicit manner in Fig. 24.

The thickmess of the material broken away by the first spall varies wish several parameters, e.g., with energy-keeping all other condicions constiant-as seen in Appendix $C$. However, the thichness as a function of laser pulse $t$ ice, $\bar{t}_{2}$, presents the most interestimg ptenozenon. Using in eacin case the thickness for the lowest energy at thict spall occurred, we plotted in Fig. 25 the (difensionless) spal1 thickness ( $\left.x_{s p}=x_{s p} / x_{t}\right)$ as a function of (dimensionless) tice $\left(\tau=\tau_{i} c_{s} / x_{t}\right)$ for all three target thicknesses. This figure displavs a sinar? rise in the spalled-layer thickness when $:=2$, in agreement with some conclusions reached froJ an $x-t$ diagram analysis which is discussed in Section IV.

At energy levels slightly above the threshold for spall, the spalled layer has considerable comentum. The efficiency of generatiog nomentus in the spalled layer is illustrated in Figs. 26 through 28 which plot the wosentum per unit energy vs laser energy. The data for an Nd:glass laser are shown in Fig. 26, whereas those for an HF laser are shown in Figs. 27 and 28. Target thicknesses are 0.1 and $1.0 \mathrm{~cm}$. Some conclusions drawn from these figures are: (a) laser energies 50 to $100 \%$ above the spall-threshold eritgy are most efficient at delivering womentuw to the spalled layer and (b) the impulse decreases as laser pulse tine increases until pulse widths begin to match shock transit times, when momentur appears to increase wost 1 y because of an increase in mass removed.

When calculating laser interaction problems with CHART $L$, the free-free absorption =echaniso causes the energy to be absorbed at greater depths into the plasma if light of shorter wavelength is used. The only noticeable effect of such light is a small increase in impulse delivered to the spalled layer. The fractional increase appears to depend on target thickness and laser energy. 

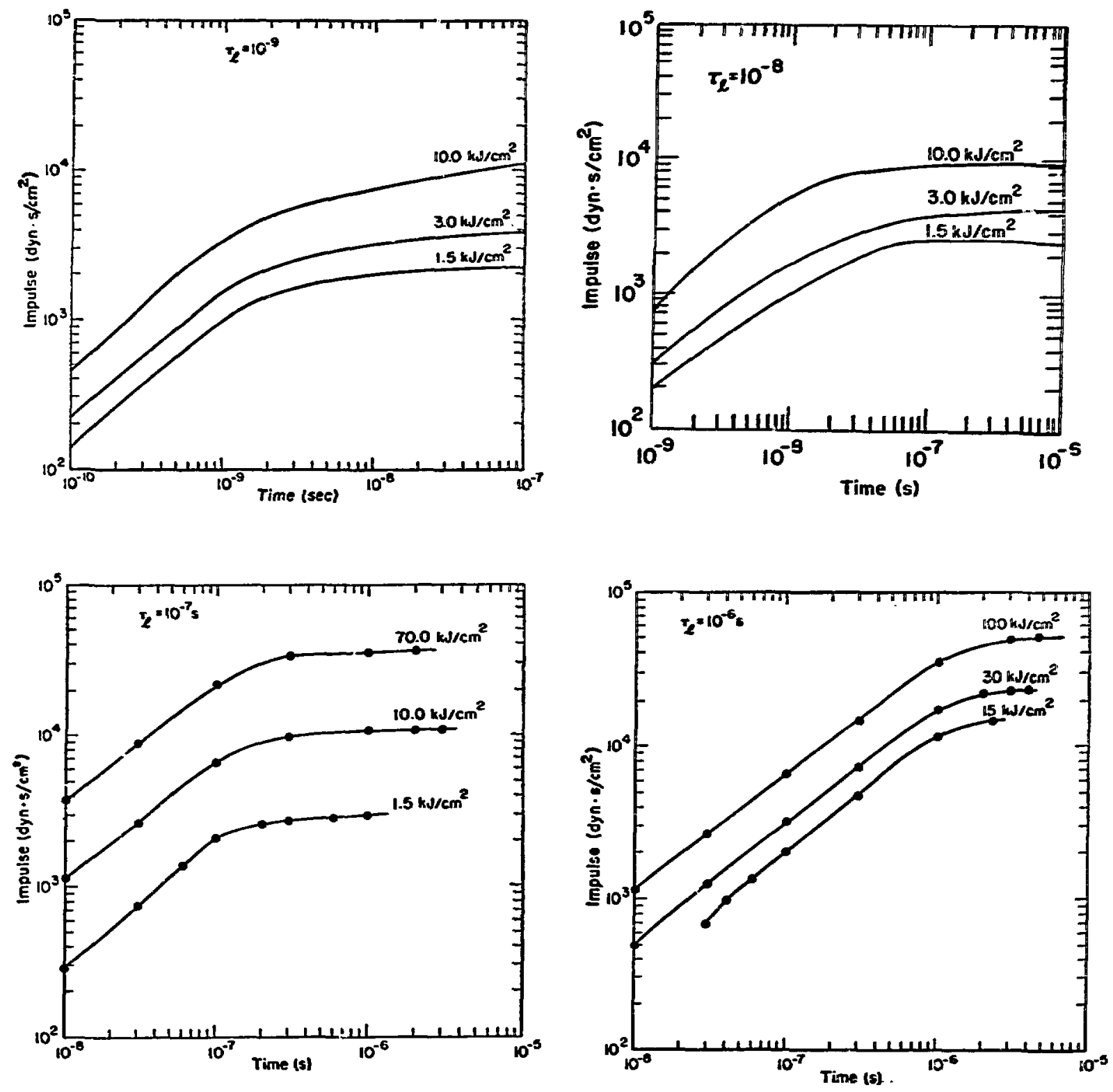

Fig. 22. Impulse generated in aluminum as a function of time, energy, and laser-pulse tine duration. 


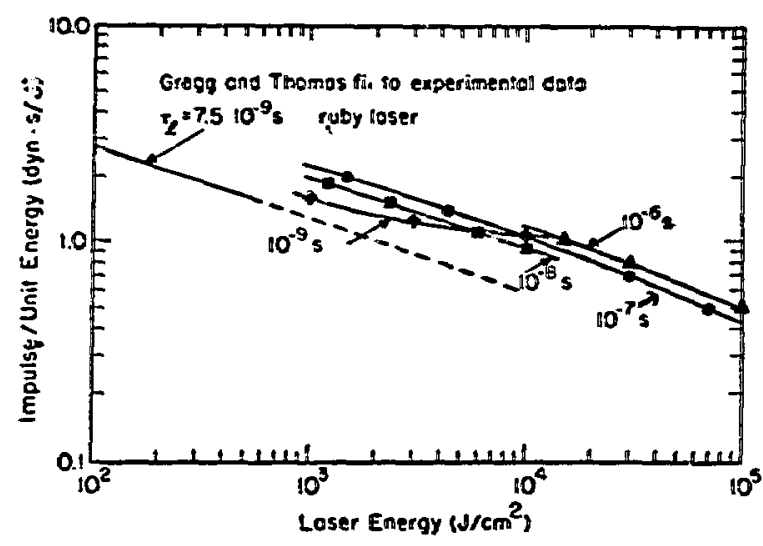

Fig. 23. Calculated impulse per unit enercy as a function of Iaser energy and pulse time compared to a fit to experimental data.

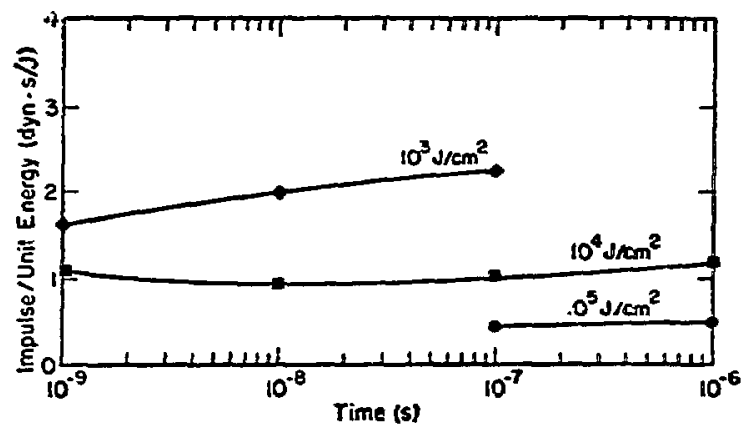

Fig. 24. Impulse per unit energy generated in aluminum as a function of laser-pulse duration and laser energy.

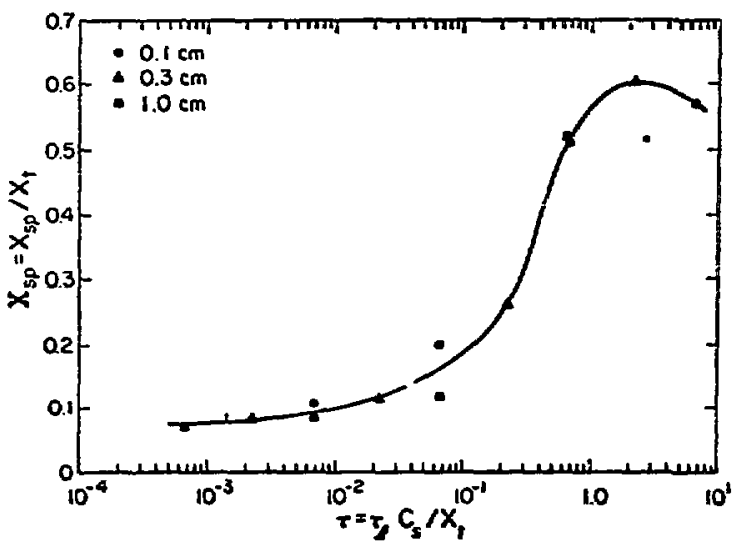

Fig. 25. Spa11 layer thickness (in units of target thickness) as a function of laser pulse time (in units of shock transit time).

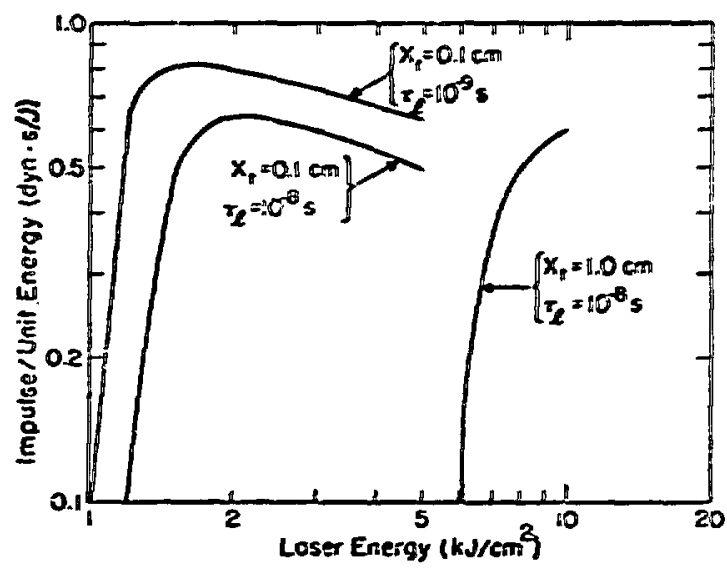

Fig. 26. Effictency of generating inpulse in spalled layers as a function of laser energy, target thickmess, and laser pulse time. Laser wavelength, $1.06 ; .0$.

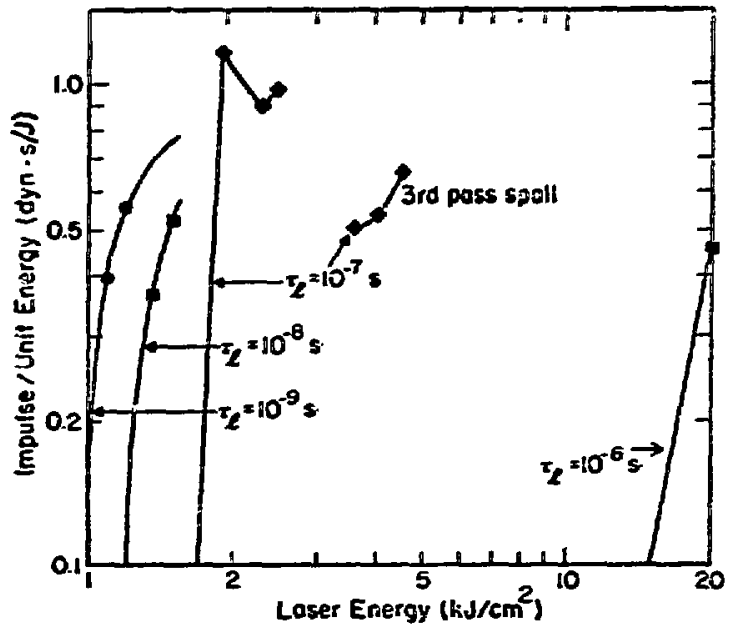

Fig. 27. Efficiency of generating inpulse is spalied layers as a function of laser energy and laser pulse time. Laser wavelength, 2.7 Do. Target thickness, $1.0 \mathrm{cr}$. 


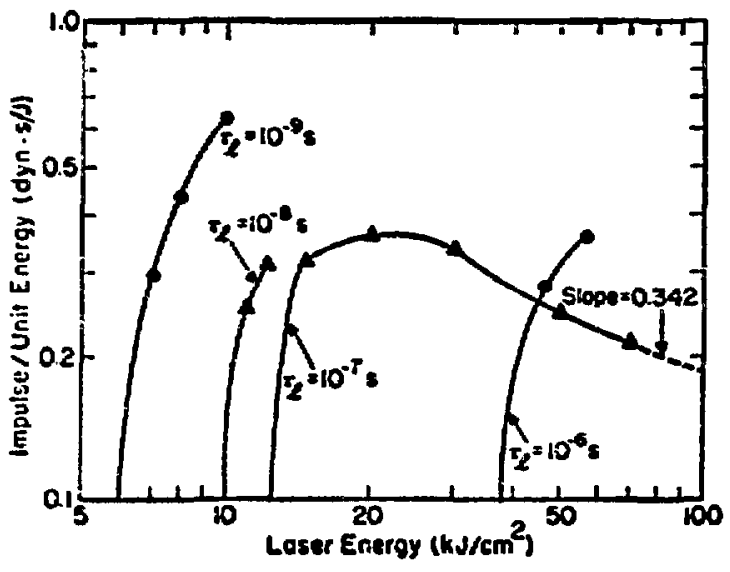

Fig. 28. Efticlency of generacing impulse in spalled layers as a function of laser energy and laser pulse time. Laser wavelongth, 2.7 wh. Target thickness, $1.0 \mathrm{co}$.

Sone results from Appendix c are sumarized below to show this effect.

\begin{tabular}{|c|c|c|c|}
\hline $\begin{array}{l}x_{t} \\
(\mathrm{~cm}) \\
\end{array}$ & $\begin{array}{c}E \\
\left(k J / \mathrm{cm}^{2}\right)\end{array}$ & 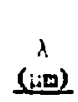 & $\left(\begin{array}{c}I \\
\frac{k d y n \cdot s}{c m^{2}}\end{array}\right)$ \\
\hline 0.1 & 1.2 & 1.06 & 0.734 \\
\hline 0.1 & 1.2 & 2.7 & 0.675 \\
\hline 0.1 & 1.5 & 1.06 & 1.20 \\
\hline 0.1 & 1.5 & 2.7 & 1.12 \\
\hline 1.0 & 1.5 & 1.06 & 0.816 \\
\hline 1.0 & 1.5 & 2.7 & 0.804 \\
\hline 1.0 & 1.1 .0 & 0.30 & 3.11 \\
\hline 1.0 & 11.0 & 2.7 & 2.80 \\
\hline
\end{tabular}

Some effects of varying the time between two successive laser pulses are studied in Appendix D. vI. COMPARISON WITH EXPERINENT

Af experiment was recently reported by Fox and Barr in which $0.1 \mathrm{~cm}$ of 6061 -T6 aluminum was successiully spalled by a laser. ${ }^{2}$ One of our calculafions (Problem 6, Appendix C) had input parameters that correspond to the conditions of the experiment, so that a comparison of results is possible.*

The out line of a spalied, sectioned taiget (traced from a photugraph) is shown in Fig. 29. The scale factor of $47: 1$ is based on the assumption that the thickness of the material on the left side of the photogr $3 \mathrm{ph}$ is $1.0 \mathrm{~mm}$. The diameter of the beam for a fluence of $5 \times 10^{3} \mathrm{~J} / \mathrm{cm}^{2}$ corresponding "The value of $\sigma_{0}$ used in the calculations was that for 1100 aluminum instead of 6061-T6, but the effect should be negligible because $\sigma_{s} \gg \sigma_{0}$ for thin ( $1.0 \mathrm{~mm}$ ) targets.

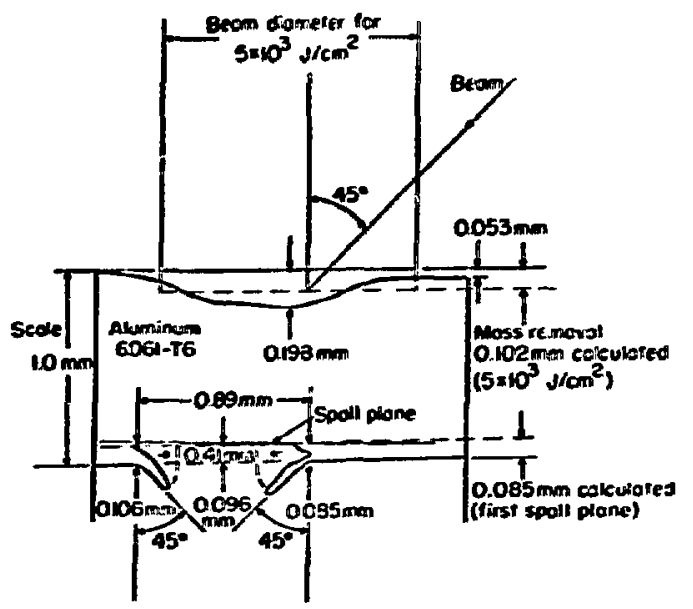

Fig. 29. Outline of section of aluninue spalled by a laser pulse in Fox and Barr ${ }^{2}$ expericent. Measured values of mass removal and spalled layer thickness are compared to calculations.

to a laser energy of $75.3 \mathrm{~J}$ is shown along wich several other dimensions inferred from the scale factor. Also shown are calculated tass-removal thickness (0.0991 mof of liquid plus 0.0033 of yapor) and the distance from the back surface of the material to the plane were the first spall occurs. Agreement between theory and experiment seems to be good.

For short pulses, the data in Afpendix $C$ indicate that depth of the spall ad layer is deterained largely by type and thickness of the waterial. Variations in spall layer thickness due to laser-energy variations are not large enough to be affected very much by uncertainties in fluence $\left(2 \mathrm{bJ} / \mathrm{cm}^{2}\right)$.

VII. EFFECTS OF AIR ON SPALL CALCULATIOKS

A11 calculations reported thus far are for targets in a vacuum. The calculations indicate that 0.1 - to 1.0-cm-thick alusinum can be spalled with short-pulsed lasers. The shorter the laser pulse ( $<1.0 \mu \mathrm{s})$ the higher the peak pressures, mainly due to the fact that hydrodynamic motion is slower while the laser is on. Consequently, the energy required for spall becomes less as the time width of a constant-energy laser pulse is decreased, i.e., the peak of the stress wave is an important factor in achieving spall. This phenonenon dictates that power in the laser pulse be as high as possible. However, high laser powers are incompatible with transmission of laser pulses through air, which 
would ingly that spall experinents sfould be performed in a vacuu chamber. The question has therefore been raised whether some intermediate laser pulse width combined with sose laser-light wavelength would cause spall in a reasomable thickness of alusinum in air. Resules of spall calculations shown in Fig. 14 are replotted in Fig. 30. The energy required for spall is plotted as a function of the tine width of constant power pulses.

For laser pulses longer than $1.0 \mathrm{~ns}$, the threshold power (in $\mathrm{W} / \mathrm{co}^{2}$ ) for air breakdown can be wrtiten as a simple function of laser-light wavelength: 11,12

$$
P_{\mathrm{B}}=3.2 \times 10^{12} \frac{1}{\lambda^{2}}
$$

where $\lambda$, the wavelength, is $\geq 0.7 \mathrm{Lm}$. The value of the coeficient (for air) of

$$
\frac{1}{\lambda^{2}}
$$

is taken from Kroll and Watson. 11 A fit to the data of D. B. Henderson ${ }^{12}$ gives a value of $2.8 \mathrm{x}$ $10^{11}$; but if S. D. Rockwood's formula is used (see Appendix E for derivation) we obtain $3.5 \times 10^{11}$ for this coefficient.

The formula discussed above applies to clean air only; therefore, the question arises how many particulates can be tolerated before breakdown occurs. Air breakdown due to the presence of minute foreign particles is caused by gas-dynamic expansion of the particles after they have absorbed light. Therefore, the gas-dynamic expansion time

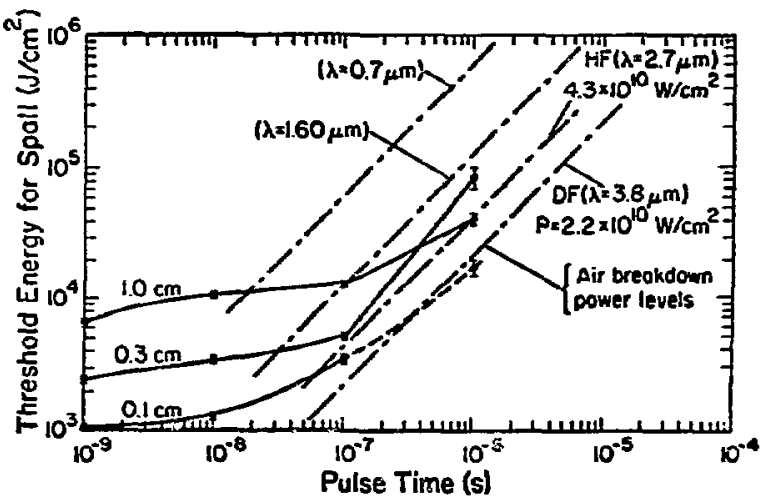

Fig. 30. Spail thresholds for three thiclknesses of aluminum compared to air-breakdown power levels. of the speck stould be large compared ith line pulse

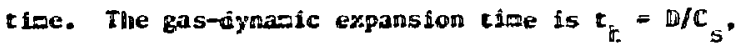

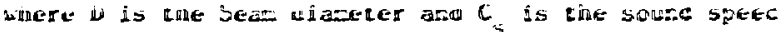

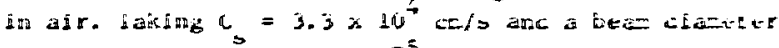

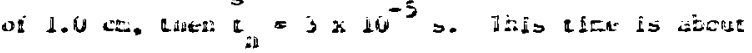

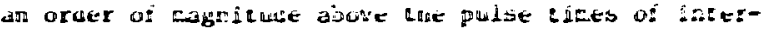
sit.

Brealdown fowers fros our forcula are illustrated in fig. 30 to show that it may be possible to get laser light energy with a vavelength of $=1$ to the target in azoursts sufficient to cause spall (assuring spall thresholds are not affected by air).

In addition to the afr breakdown, one has to be concerned with the transoitsance of tine $1 \mathrm{ight}$ through the atmospinere. Spectral transaittance curves (Ref. 13, Pp. 7-2 and 7-3) show that an HF laser $(2.7$ a) does not penetrate air very bell. However, the DF laser $(\lambda=3.8 ; 0)$ does have good transoittance and its power level at which air breakdown occurs is shown in Fig. 30. Because there is a window at $\lambda=1.6 \mathrm{\mu m}$, the power levels for air breakdown with this wavelength are also showm as well as the power level for $\lambda=0.7$ w-the shortest wavelength to which this theory applies.

Our analysis thus indicates that enough ligint can be transuitted to the target to cause spall. However, the heated aluminum surface reradiates energy toward the laser and starts ionizing the air next to the aluminum surface, and this causes problems. The thickness of the ionized layer of air continues to grow back toward the laser, foraing a laser-supported absorption vave; i.e., the laser energy is absorbed in an ever-increasing nass of air. As a result, the temperature which drives the heat-conduction wave is lowered and the resulting stress waves are degraded in amplitude. Temperature and laser-energy absorption as a function of position are shown in Fig. 31 for two different problens to illustrate these effects. Problens run on CHART $L$ to study the effects of a laser-supported absorption wave are summarized in Table $I$. Results shown in Fig. 31 are from Problems 1 and 2 in Table I. Laser-supported absorption waves similar to the one shown in Fig. 31 are presented in Ref. 14, p. 3-38. However, because the pouer level for the results in Ref. 14 is less by a factor of 100 than the level for the results in Fig. 31, the 


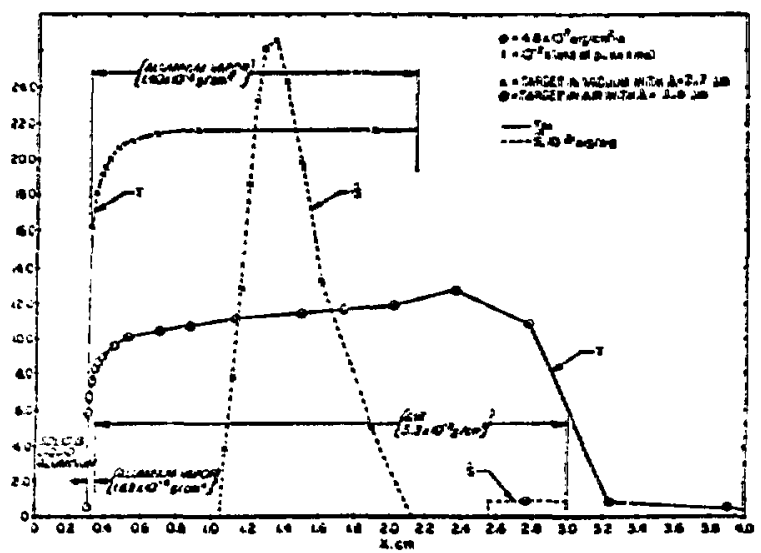

FIg. 31. Comparison of temperatures and source strengths to Hlustrate generation of laser-supported absozption wave in air.

TABLE I

CONPUTER CALCULATIONS OF THE EFEECTS OF AIR ON IMPULSE AND STRESS

\begin{tabular}{|c|c|c|c|c|c|}
\hline $\begin{array}{l}\text { Wave- } \\
\text { length } \\
\text { 표 }\end{array}$ & Air? & $\begin{array}{l}\text { Air } \\
\text { Zoning }\end{array}$ & $\begin{array}{l}\text { Energy } \\
\text { Flow }\end{array}$ & $\begin{array}{l}\text { Inpulse } \\
\text { Generattu } \\
\begin{aligned} & \text { at } t=0.4 \mathrm{~s} \\
&=(0.6 \mathrm{~s}) \\
& \mathrm{kdyn} \cdot \mathrm{s} / \mathrm{cm}^{2}\end{aligned}\end{array}$ & $\begin{array}{l}\text { Peak } \\
\text { Stress*, } \\
\text { kbar }\end{array}$ \\
\hline 2.7 & no & --- & $\begin{array}{l}\text { rad \& } \\
\text { elect }\end{array}$ & $\begin{array}{c}6.17 \\
(6.31)\end{array}$ & 36.7 \\
\hline 1.6 & yes & Coarse & $\begin{array}{l}\text { rad \& } \\
\text { elect }\end{array}$ & 1.54 & 4.23 \\
\hline 0.7 & yes & coarse & $\begin{array}{l}\text { rad \& } \\
\text { elect }\end{array}$ & $\begin{array}{c}3.76 \\
(4.80)\end{array}$ & 49.1 \\
\hline 0.7 & yes & fine & $\begin{array}{l}\text { rad \& } \\
\text { elect }\end{array}$ & $\begin{array}{c}3.17 \\
(4.32)\end{array}$ & 16.6 \\
\hline 0.7 & yes & fine & elect & 6.03 & 15.7 \\
\hline
\end{tabular}

* Just before wave reflection at $t=0.4 \mathrm{us}$ ** Problem 50 in Appendix C

Laser energy, $4.8 \mathrm{~kJ} / \mathrm{cm}^{2}$; Pulse time, $100 \mathrm{~ns}$.

absorption wave for the former level does not progress as rapidly as shown here.

Comparison of Problems 1 and 2 in Table $I$

shows the large degradation of both impulse and peak stress as a result of adding air to the problem.

The fact that the first problem uses a wavelength of $2.7 \mathrm{um}$ instead of $1.6 \mathrm{jm}$ is not pertinent to this comparison because wavelength has very little effect when air is not present. This conclusion is reached on the basis of previous runs, and is also seen to be plausible from Fig. 31, 1.e., changing the vavelength would merely shift the position of absorption within an isothermal region. 24
A comparison of Probless 2 and 3 will illustrate the effect of light wavelength on inpulse and peak stress: As expected, both are increased. The peak stress appears to be high enough to cause spall, but the acconpanying inpulse is insufficient.

The effects of zoning in the alr layer are clearly seen then comparing Problens 3 and 4. This comparison is pronoted by the observation that all the energy is absorbed in one zone at the end of the pulse for Problen 2 (see Fig. 31). The distinction between coarse and fine zoning in Table $I$ is expressed by the zone wass ratio, which is 1.2 moving avay frow the thimen for coarse zoning, and is 1.1 for fine :oning. The finer zoning appears to lower the pedi pressure considerably, f.e., the laser absorption rave propagates beter with fine zoning.

To study the effect of black-body radiation flow, compare Problens 4 and 5. Problen 5 was run with the black-body radiation flow turned off, but with the electronic-conduction ter left on. The effect sees to be an increase in inpulse.

We conclude that sufficient anounts of laser light could je sent through air to cause spall in aluinum if the proper vavelength of the light could be chosen, but laser-supported absorption waves generated at the aluninu surface would lower the gentrated inpulse and peak stress far below that which the target conld experience in vacuun at the sane power level.

VIII. CONCLUSIONS AW RECOMERDATIONS

\section{A. Conclustions}

The results of the cork reported herein indcate that:

- Short-pulse lasers provide an effective means for producing spall in metal targets;

- The vavelength of the laser light used has little effect on generated impulse;

- The wave-cancelling effects that oce or when the laser pulse with is twice the shock transit tine can cause large increases in the energy required for spall;

- Tuning of laser pulse vidths can be used to vary spall-layer thickness and mentum in the spalled layer;

- Achleving spall in air is much more difficult than in vacuu; and 
The computer model is in reasonably good agreement with experimental spall thickness and blowoff mass; generated impulse is correct to within - 40\%. The latter result could be improved by introducing nonequilibrium effects into the plasma-physics part of the calculation.

\section{B. Recommendations}

- Further experiments should be conducted so that a more careful comparison between theory and experiment can be made and to verify some of the longer pulse results presented here.

- If better experiments warrant it, calculations could be improved to sone extent by the introduction of a multitemperature or nonequllibrium model for the low density plasma cloud. reducing peak power requirements by breaking the pulse into a train of separated pulses should be done. Each pulse in the train would have a time duration less than $x_{t} / C$ and they would be spaced $2 x_{t} / C$ seconds apart (leading edge to leading edge): i.e., the shock wave could possibly be reinforced after each complete transition from front to back and to front again.

\section{ACKONLEDGEHENTS}

The author vishes to thank $R$. W. Bussard, Los Alawos Scientific Laboracory, wo concelved this program, for his guidance and assistance during the early phases of the cork.

Special recognition is given to the work of Evelyn $I$. Heck whose efforts in coupter prograsing. running of problems, and data analysis were esseatial to the coupletion of this report and the work reported therein. The cosputer-generated graphical displays used in this report and in analysis of the data are all the result of her work because the plotting routines of CHART $D$ as received fros Sandia Laboracories had to be essentially reutitten to be compatible with the LASL conputer systen.

This work benefited from discussions and suggestions from several people, including $R$. L. Yorse, who was project dizector, H. C. Lyons, R. Pollock. R. S. Thurston, W. L. Mudd, S. D. Reckwood, E. I. Whitced, J. R. Bobbitt, and H. Flicker of Los Alasos Scientific Laboratory, and S. L. Thompson and H. L. Lauson of Sandia Laboratories, Albuquerque, Siev Mexico.

APPENDIX A

\section{ABSORPTION OF LASER LIGHT}

The cross section which is used to calculate

laser light absorption in the ChART L code is calculated from the free-free absorption mechanism. This method allows free electrons in a partially ionized plasma to absorb laser light by being accelerated by the electromagnetic fillds. The form of the cross section is taken from Page 148 of Ref. 5.

$$
k_{v}=\frac{4}{3}\left(\frac{2 \pi}{3 k T}\right)^{1 / 2} \frac{n_{e} n_{i} z^{2} e^{6}}{h c m_{e}^{3 / 2} v^{3}} g_{f f}
$$

where

$$
\begin{aligned}
& T=\text { plasma temperature } \\
& n_{e}=\text { electrons } / \mathrm{cm}^{3} \\
& n_{\hat{i}}=\text { ions } / \mathrm{cm}^{3} \\
& z=\text { ionization number } \\
& e=\text { charge of electron }
\end{aligned}
$$

$$
\begin{aligned}
& c=\text { speed of light } \\
& m_{e}=\text { mass of electron } \\
& v=\text { light frequency } \\
& g_{f}=\text { Gaunt factor. }
\end{aligned}
$$

Equation (A-1) is the result of averaging spectral absorption over a Maxwell distribution of electrons. This is consistent with the assumption of lusal thermodynamic equilibrium in ChaRT $D$.

Reference 5 also gives

$g_{\mathrm{ff}}=\frac{\sqrt{3}}{\pi} \frac{\mathrm{v}}{\mathrm{C}}\left[\ln \frac{(2 \mathrm{kT})^{习 / 2}}{\pi 2 \mathrm{e}^{2} V_{\mathrm{m}_{e}}}-\frac{5 Y}{2}\right]$ for $\begin{array}{r}\text { hv } \ll k T \\ \omega \ll \omega_{\rho}\end{array}$

where

$v \quad \rightarrow$ phase velocity of the light wave

$v / C=n=$ index of refraction

$\gamma=0.5772=$ Euler"s constant . 


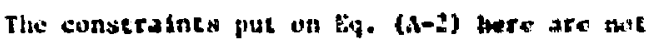
coo severe because kT appears in a tepartefelto enrs. For $U / C$ the disporsion relackan

$$
\frac{y}{i} \cdot \frac{1}{\sqrt{1+i}}
$$

1s usied, shere

L plassa ircquency

: - Iiphl fruquency (radf tict).

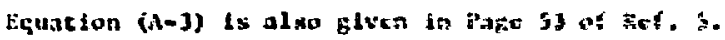

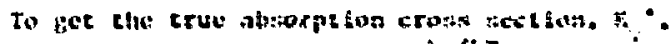

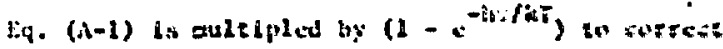
for indued cessidon; l.e.

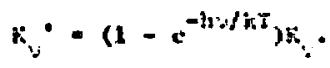

Adutionally:

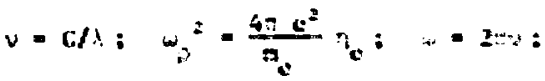

$$
\begin{aligned}
& \eta_{c}=z_{1}: \quad n_{1}-\frac{m x^{2}}{n}
\end{aligned}
$$

where

$$
\begin{aligned}
& \text { - density } \\
& \lambda=\text { atomic weight } \\
& \lambda=\text { suvelength. }
\end{aligned}
$$

After combining Eqs. (a-1) chrough $(d-5)$ and inserting cgs nunet lcal values for the constants. we following three equations resule, which can bo used ia sequence to calculate an effective cross section:

$$
\left(\frac{\omega_{\rho}}{\omega}\right)^{2}=5.410 \times 10^{20} \frac{\lambda^{2}}{\lambda} 02
$$

$$
\mathrm{g}_{\mathrm{ff}}=\frac{0.5513}{\left[1-\left(\frac{\omega_{\mathrm{o}}}{\omega}\right)^{2}\right]^{1 / 2}}|\ln | \frac{(k)^{3 / 2} \lambda}{2}|+7.63|
$$

$$
\begin{aligned}
& K^{\prime}=4.645 \times 10^{22} \frac{\left\langle Z>\left\langle Z^{2}>\mathrm{q}^{2} \lambda^{3}\right.\right.}{\mathrm{A}^{2} \sqrt{\mathrm{kT}}} \\
& \left(1-\mathrm{e}^{-\frac{1.2406 \times 10^{-}}{\lambda \mathrm{kT}}}\right)_{\mathrm{B}_{\mathrm{ff}}}
\end{aligned}
$$

where $\left\langle Z^{2}\right\rangle=$ average value of $2^{2}$ when mixtures are used.

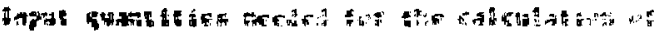

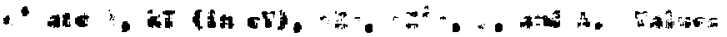
w) 27 .

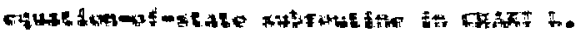

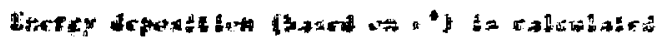

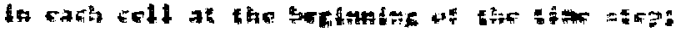

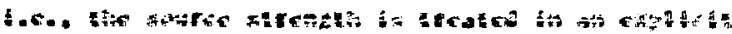

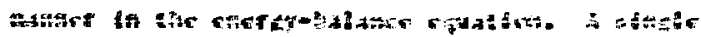

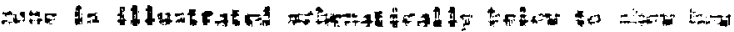

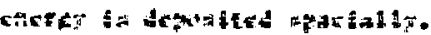

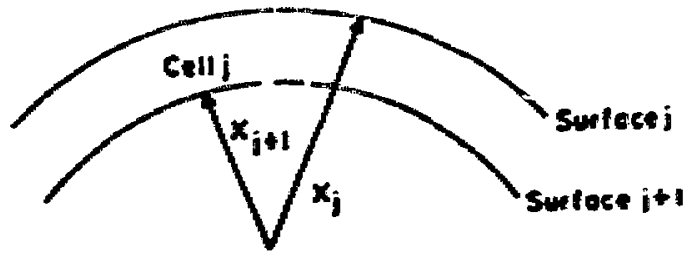

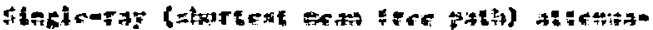

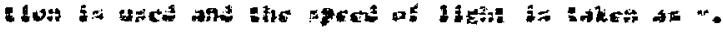
risers,

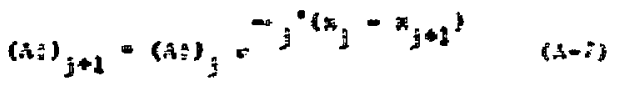

Aisto

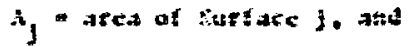

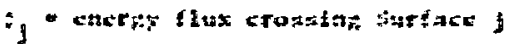

$$
\begin{aligned}
& (\mathrm{eth} / \mathrm{cm} \cdot \mathrm{sec}) \text {. }
\end{aligned}
$$

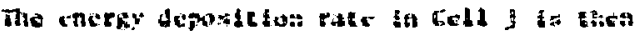

$$
\dot{s}_{j}-(n a)_{j}-\left(x_{i}\right)_{j+1}
$$

The outer (lux (A:), chack (rob cable labity or analyte furwulde. Absorption pete* are calculaced inuard by liqu, $(A-6),(A-7)$, and $(A-8)$ une al a point is reacised where fis 1 . Elassically the 11ght reflects lwere. Also, this fs the point where curbulent freating would oceur. As an uption in Chlakt $L$ one can efther assuox that curbulent beacing; accurs and dump all the reasining energ: in che first zone bivere of $/ 2 \geq 1$, or lat the 1 gith ceflect at this point and be absorbed on the way back out. The aethod used here was first developed by $R$. Pollock of Lisl in tnpubl fsited work. 


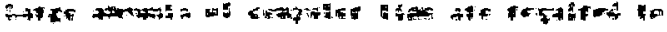

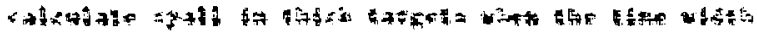

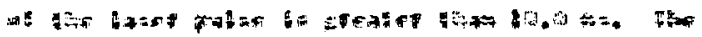

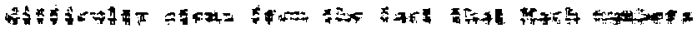
دest

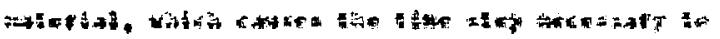

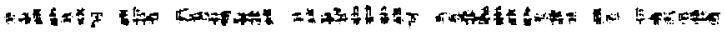

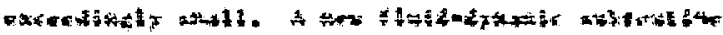

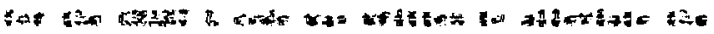

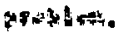

INo

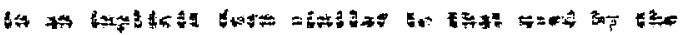

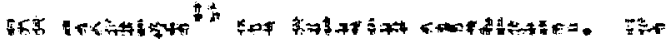

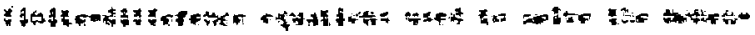

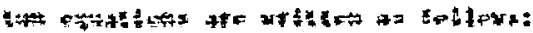

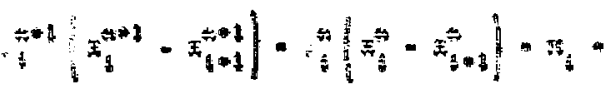

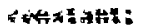

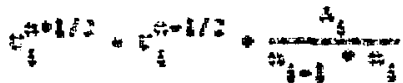

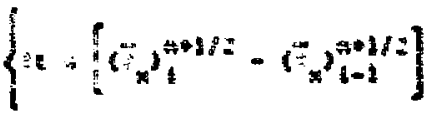

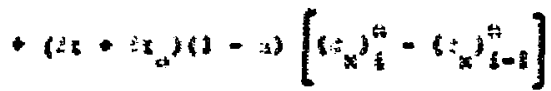

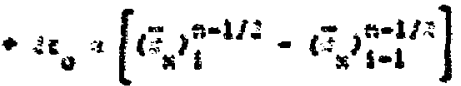$$
\left.+\left(\operatorname{se}+\operatorname{se}_{4}\right)\left(q_{1}^{n-1 / 2}-q_{t-1}^{n-2 / 2}\right)\right\}
$$

$$
\begin{gathered}
x_{t}^{n+1}-x_{t}^{n}+t_{1}^{n+1 / 2} \text { se } \\
\left(x^{3} y^{n+1 / 2}\right.
\end{gathered}
$$$$
\left(0_{x}\right)_{1}^{n}+\left(c_{1}^{n}\right)^{2}=\left(x_{1}^{n+1 / 2}-n_{1}^{n}\right)
$$

$(s-s)$

The supersetipin refer to etme points and the subserspte to position in che space-elae azth. Thit chakt 1 space wahl lus 1 increasing an $x$ decreswe: and is atwow eraphically as follows.

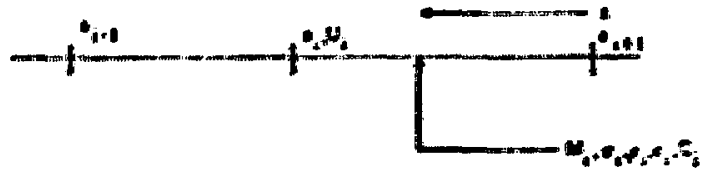

TE =

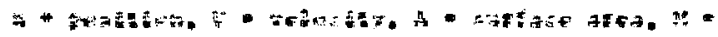

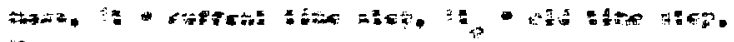

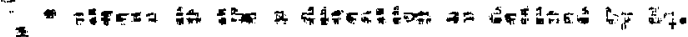

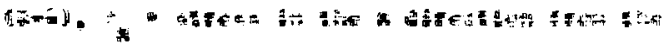

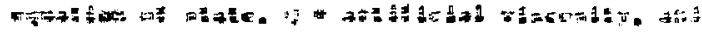

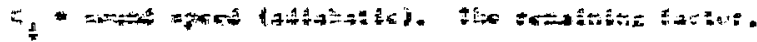

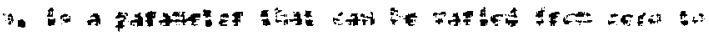

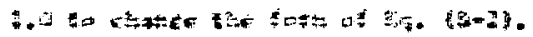

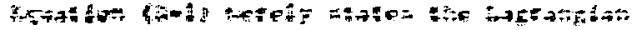

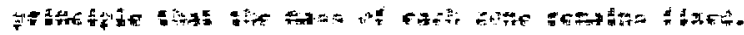

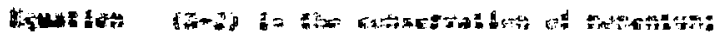

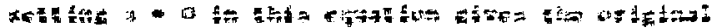

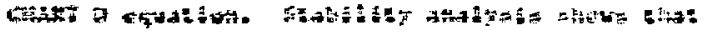

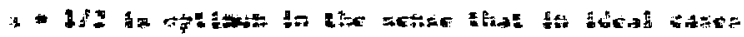

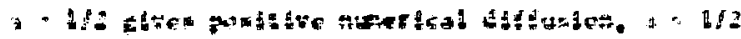

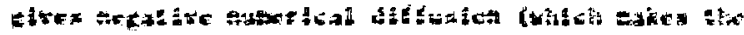

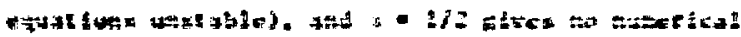

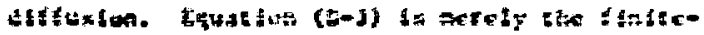

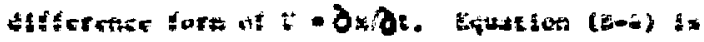

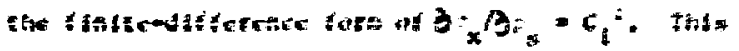

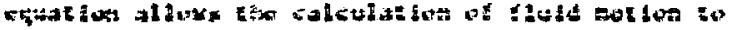

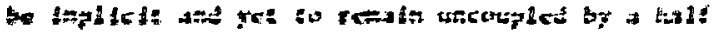

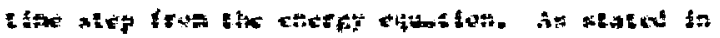

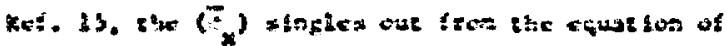

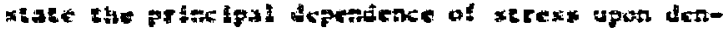

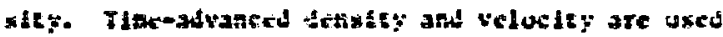

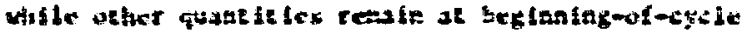
valuex. Igutation (E-4) siwuld two bu faterprect ax anclecting the effece of internal eners: varsa-

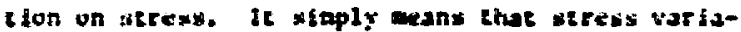

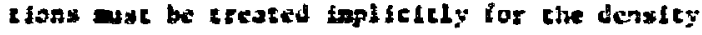
but can tomin purely explicit for the inceral enersy.

The accuracy and speed of tive andfied ChLRT code described here to liustrated is Figs. 8-1. B-2. and y-3. Nesulcs Irom the original version of chakt 0 (lateled as Explacit on the fleures) are compared to results from the subroutine descelbed 


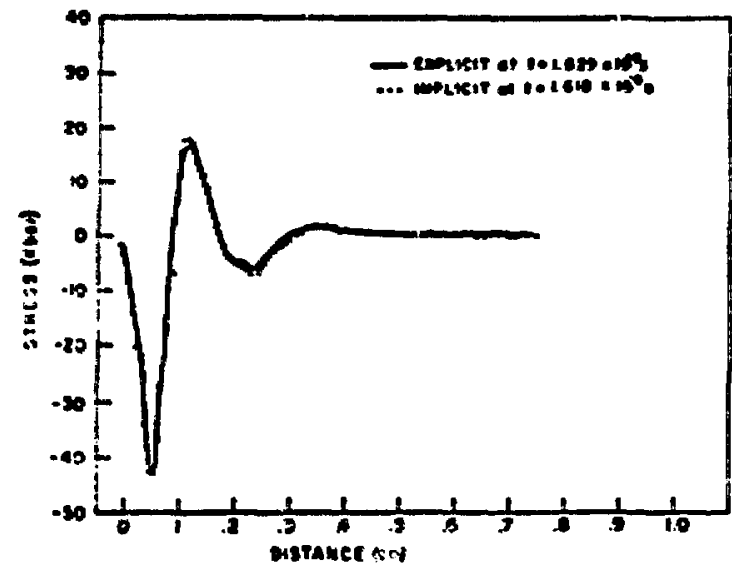

Fity. a-1. Compariton of otress waves calculated by tho explicit and implicte fluiddynable aethods. Laser energy, $3 \times 10^{5}$ $J / c a^{2}$. Pulse tjae, $10 \mathrm{~ns}$. Alueinum thicknísis, $1.0 \mathrm{ca}$, So radiative heat cranster.

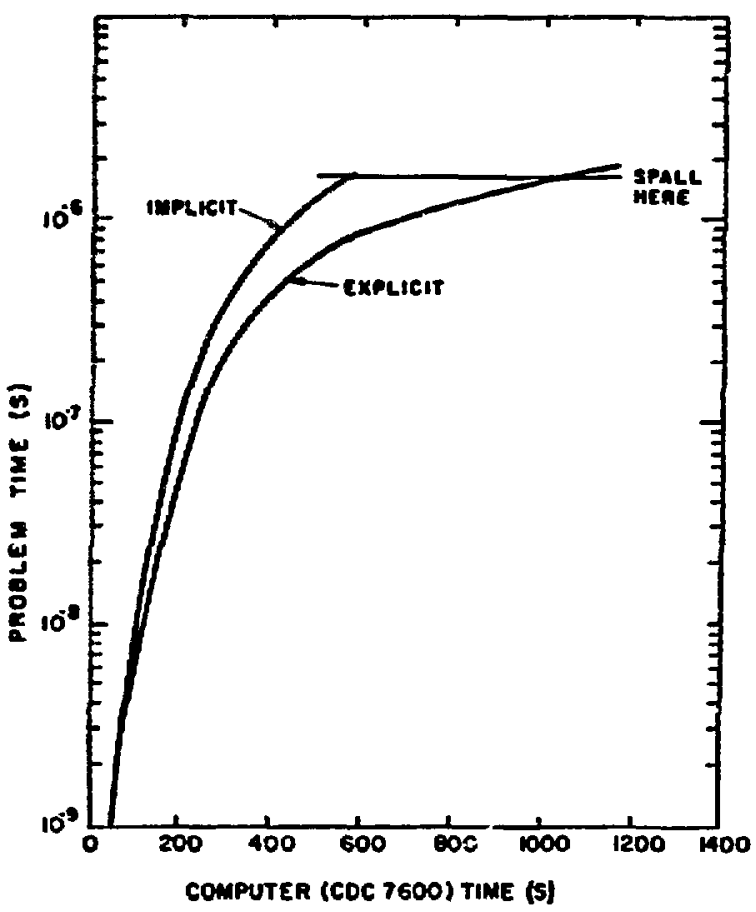

FEB. B-2. Comparison of computer time required by the explicit and Implicit fluid-dynamic methods. Laser energy, $3 \times 10^{5} \mathrm{~J} / \mathrm{cm}^{2}$. Pulse tine, 10 ns. Aluminum thickness, $1.0 \mathrm{~cm}$. No radiative heat transfer.

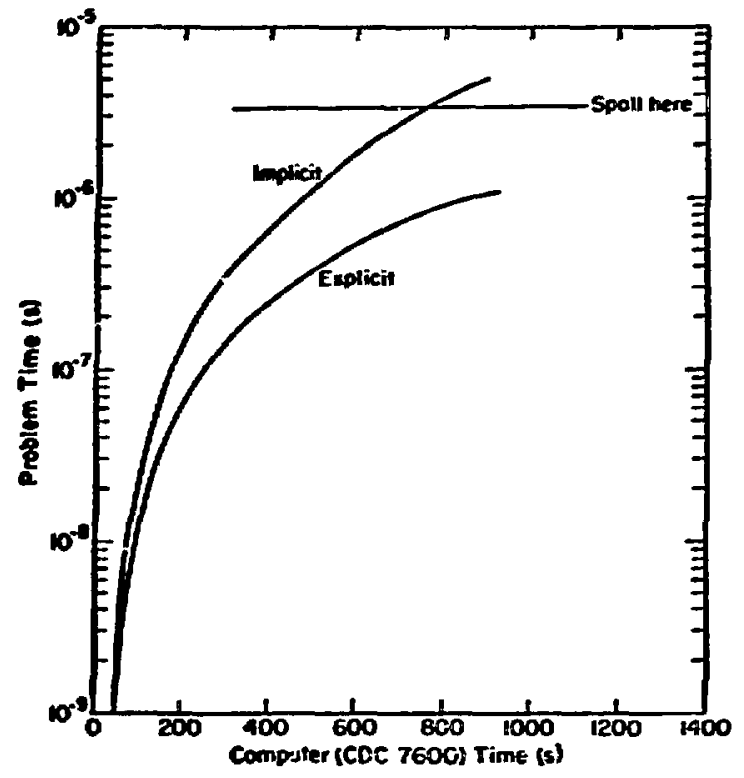

Fig. B-3. Comparison of coaputer time required by explicit and inplicit fluid-dynamic sethods. Laser energy, $4.6 \times 10^{4} \mathrm{~J} / \mathrm{cm}^{2}$. pulse time, 1.0 his. Aluminu thickness, $1.0 \mathrm{~cm}$.

here (labeled as IMPLICIT). The stress wave from a 10.0-ns, $3 \times 10^{5}-\mathrm{J} / \mathrm{cm}^{2}$ laser pulse on $1.0 \mathrm{~cm}$ of aluminum is calculated. Figure B-1 shous that the stress vaves on the first cycle where spall occurs are essentially the same. Figure $\mathrm{B}-2$ shows that - 802 savings in computer tine was realized for this calculation. Fron the shape of the curve, it is expected that even greater savings will be realized for thicker targets or lower laser intensities. A plot show In Fig. B-3, similar to that in Fi8. B-2, for the proble where $46 \mathrm{~kJ} / \mathrm{cm}^{2}$ in a 1.0us pulse was incident on $1.0 \mathrm{~cm}$ of aluminum (Problem 76 in Apperdix C), indlcates that the explicit method would have taken a very long time to obtain time of spall, whereas only 13 minutes were sufficient with the implicit nethod. 
APPENDIX C

VALUES OF INDEPENDENT VARIABLES USED IN THE PARAMETER STUDY OF ALUMINUM AN ) CORRESPONDLNG RESULTS OF THE CALCULATIONS

\begin{tabular}{|c|c|c|c|c|c|c|c|c|c|c|c|}
\hline $\begin{array}{l}\text { Prob- } \\
\text { lem }\end{array}$ & $\begin{array}{l}\text { Laser } \\
\text { Light } \\
\text { Wave- } \\
\text { Length, } \\
\text { um } \\
\end{array}$ & $\begin{array}{l}\text { Laser } \\
\text { Pulse } \\
\text { Dura- } \\
\text { tion, } \\
\text { B } \\
\end{array}$ & $\begin{array}{l}\text { Target } \\
\text { Thick- } \\
\text { ness, } \\
\text { cm } \\
\end{array}$ & 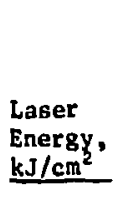 & $\begin{array}{l}\text { Mass } \\
\text { Removal } \\
\text { In Gas } \\
\text { Form at } \\
0.2 \text { us, } \\
\mathrm{g} / \mathrm{cm}^{2}\end{array}$ & $\begin{array}{l}\text { Mass } \\
\text { Removal } \\
\text { In LIquid } \\
\text { Form at } \\
0.2 \mu \mathrm{s}, \\
\mathrm{s} / \mathrm{cm}^{2}\end{array}$ & $\begin{array}{l}\text { Impulse } \\
\text { to } \\
\text { Solid, } \\
\frac{\mathrm{kdyn} \cdot \mathrm{s}}{\mathrm{Cm}^{2}} \\
\end{array}$ & $\begin{array}{l}\text { Time of } \\
\text { First } \\
\text { Spall, s }\end{array}$ & $\begin{array}{l}\text { Distance } \\
\text { From Back } \\
\text { Face to } \\
\text { Plane of } \\
\text { First Spall, } \\
\text { cm }\end{array}$ & $\begin{array}{l}\text { Impulse } \\
\text { Delivered } \\
\text { to Plane at } \\
\text { First Spall, } \\
\text { kdyn:B } \\
\mathrm{Cm}^{2}\end{array}$ & $\begin{array}{l}\text { Com- } \\
\text { puter- } \\
7600 \\
\text { Time, } \\
\text { ain } \\
\end{array}$ \\
\hline 1 & 0.3 & $10^{-8}$ & 1.0 & 11.0 & -- & $\cdots$ & 10.0 & $1.84 \times 10^{-6}$ & .0723 & 3.11 & 10 \\
\hline 2 & 1.06 & $10^{-9}$ & 0.1 & 1.0 & $4.48 \times 10^{-4}$ & $3.76 \times 10^{-3}$ & 1.56 & $-\infty$ & -- & $\ldots$ & 4 \\
\hline 3 & 1.06 & $10^{-9}$ & 0.1 & 1.2 & $4.94 \times 10^{-4}$ & $5.12 \times 10^{-3}$ & 1.74 & $1.84 \times 10^{-7}$ & .0103 & .734 & 8 \\
\hline 4 & 1.06 & $10^{-9}$ & 0.1 & 1.5 & $5.45 \times 10^{-4}$ & $9.47 \times 10^{-3}$ & 2.10 & $1.77 \times 10^{-7}$ & $.0103-.0109$ & $1.17-1.23$ & 8 \\
\hline 5 & 1.06 & $10^{-9}$ & 0.1 & 2.0 & -- & --- & 2.67 & $1.70 \times 10^{-7}$ & .00971 & 1.59 & 5 \\
\hline 6 & 1.06 & $10^{-9}$ & 0.1 & 5.0 & $\cdots$ & -- & 5.46 & $1.50 \times 10^{-7}$ & .00850 & 3.14 & 5 \\
\hline 7 & 1.06 & $10^{-9}$ & 1.0 & 6.0 & $9.45 \times 10^{-4}$ & $3.81 \times 10^{-2}$ & 6.70 & -- & -- & -- & 10 \\
\hline 8 & 1.06 & $10^{-9}$ & 1.0 & 8.0 & $1.05 \times 10^{-3}$ & $5.08 \times 10^{-2}$ & 8.67 & $1.79 \times 10^{-6}$ & .0723 & 3.80 & 10 \\
\hline 9 & 1.06 & $10^{-9}$ & 1.0 & 10.0 & $1.27 \times 10^{-3}$ & $6.15 \times 10^{-2}$ & 10.6 & $1.74 \times 10^{-6}$ & .0723 & 5.99 & 15 \\
\hline 10 & 1.06 & $10^{-6}$ & 0.1 & 1.0 & -- & -- & 1.87 & --- & $-\infty$ & $\cdots$ & 5 \\
\hline 11 & 1.06 & $10^{-9}$ & 0.1 & 1.2 & -- & -- & 2.11 & --- & $-\infty$ & -- & s \\
\hline 12 & 1.06 & $10^{-6}$ & 0.1 & 1.5 & $-\infty$ & -- & 2.46 & $2.10 \times 10^{-7}$ & $.0146-.0151$ & $.793-.839$ & s \\
\hline 13 & 1.06 & $10^{-8}$ & 0.1 & 2.0 & $-\infty$ & -- & 3.00 & $1.95 \times 10^{-7}$ & $.0120-.0127$ & $2.26-2.33$ & 4 \\
\hline 14 & 1.06 & $10^{-8}$ & 0.1 & 5.0 & -- & -- & 5.55 & $1.72 \times 10^{-7}$ & $.00910-.00971$ & $2.37-2.54$ & 4 \\
\hline 15 & 2.7 & $10^{-9}$ & 0.1 & 1.0 & $4.48 \times 10^{-4}$ & $4.18 \times 10^{-3}$ & 1.57 & $\cdots$ & 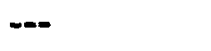 & -- & 3 \\
\hline 16 & 2.7 & $10^{-9}$ & 0.1 & 1.1 & $4.05 \times 10^{-4}$ & $4.23 \times 10^{-1}$ & 1.66 & $1.91 \times 10^{-7}$ & $.0103-.0109$ & $.427-.459$ & 5 \\
\hline 17 & 2.7 & $10^{-3}$ & 0.1 & 1.2 & $4.94 \times 10^{-4}$ & $5.12 \times 10^{-3}$ & 1.73 & $1.86 \times 10^{-7}$ & $.0103-.0109$ & $.669-.702$ & 5 \\
\hline 18 & 2.7 & $10^{-9}$ & 0.1 & 1.5 & $5.45 \times 10^{-4}$ & $8.54 \times 10^{-3}$ & 2.10 & $1.78 \times 10^{-7}$ & $.0103-.0109$ & $1.09-1.16$ & 5 \\
\hline 19 & 2.7 & $10^{-9}$ & 0.3 & 2.3 & $5.94 \times 10^{-4}$ & $1.49 \times 10^{-2}$ & 3.01 & -- & $-\infty$ & $-\cdots$ & 10 \\
\hline 20 & 2.7 & $10^{-9}$ & 0.3 & 2.6 & $6.48 \times 10^{-4}$ & $1.64 \times 10^{-2}$ & 3.30 & $5.51 \times 10^{-7}$ & $.0237-.0256$ & $1.03-1.15$ & 10 \\
\hline 21 & 2.7 & $10^{-9}$ & 0.3 & 3.0 & $7.29 \times 10^{-4}$ & $1.99 \times 10^{-2}$ & 3.72 & $5.37 \times 10^{-7}$ & .0256 & 1.73 & 10 \\
\hline 22 & 2.7 & $10^{-9}$ & 1.0 & 6.0 & $9.45 \times 10^{-4}$ & $3.81 \times 10^{-2}$ & 6.72 & --- & -- & -- & 10 \\
\hline 23 & 2.7 & $10^{-9}$ & 1.0 & 7.0 & $1.05 \times 10^{-3}$ & $4.61 \times 10^{-2}$ & 7.63 & $1.85 \times 10^{-6}$ & .0723 & 2.08 & 10 \\
\hline 24 & 2.7 & $10^{-3}$ & 1.0 & 8.0 & $1.16 \times 10^{-3}$ & $5.07 \times 10^{-2}$ & 8.68 & $1.79 \times 10^{-6}$ & .0723 & 3.47 & 10 \\
\hline 25 & 2.7 & $10^{-9}$ & 1.0 & 10.0 & $1.27 \times 10^{-3}$ & $6.15 \times 10^{-2}$ & 1.06 & $1.74 \times 10^{-6}$ & $.0723-.0789$ & $6.04-b .52$ & 10 \\
\hline 26 & 2.7 & $10^{-6}$ & 0.1 & 1.20 & -- & -- & 2.13 & -- & -- & -- & 5 \\
\hline 27 & 2.7 & $10^{-8}$ & 0.1 & 1.35 & $-\infty$ & -- & 2,30 & $2.36 \times 10^{-7}$ & .0200 & .491 & 5 \\
\hline 28 & 2.7 & $10^{-0}$ & 0.1 & 1.50 & $\ldots$ & $\ldots$ & 2.48 & $2.12 \times 10^{-7}$ & .0152 & .804 & 5 \\
\hline
\end{tabular}




\begin{tabular}{|c|c|c|c|c|c|c|c|c|c|c|c|}
\hline $\begin{array}{l}\begin{array}{l}\text { Prob- } \\
\text { lem }\end{array} \\
\end{array}$ & $\begin{array}{l}\text { Laser } \\
\text { IIght } \\
\text { Wave- } \\
\text { length, } \\
\text { 쑈 } \\
\end{array}$ & $\begin{array}{l}\text { Laser } \\
\text { Pulse } \\
\text { Dura- } \\
\text { tion, } \\
\\
\end{array}$ & $\begin{array}{l}\text { Target } \\
\text { Thick- } \\
\text { ness, } \\
\text { c표 }\end{array}$ & $\begin{array}{l}\text { Laser } \\
\text { Energy, } \\
\mathrm{kJ} / \mathrm{cm}^{2}\end{array}$ & $\begin{array}{l}\text { Mass } \\
\text { Removal } \\
\text { in Gas } \\
\text { Form at } \\
0.2 \mathrm{\mu s}, \\
8 / \mathrm{cm}^{2}\end{array}$ & $\begin{array}{l}\text { Mass } \\
\text { Removal } \\
\text { in Liquid } \\
\text { Form at } \\
0.2 \mu 8, \\
\text { / } \text { cm }^{2}\end{array}$ & $\begin{array}{l}\text { Impulse } \\
\text { to } \\
\text { Solid, } \\
\text { kdyn*g } \\
\mathrm{cm}^{2} \\
\end{array}$ & $\begin{array}{l}\text { Time of } \\
\text { Firet } \\
\text { Spe12, }\end{array}$ & $\begin{array}{l}\text { Distance } \\
\text { From back } \\
\text { Face to } \\
\text { Plane of } \\
\text { Firge Spald, } \\
\text { ca }\end{array}$ & 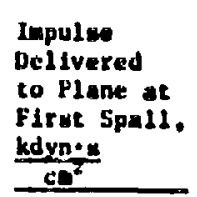 & $\begin{array}{l}\text { Con- } \\
\text { puter- } \\
7600 \\
\text { Time, } \\
\text { cln }\end{array}$ \\
\hline 29 & 2.7 & $10^{-6}$ & 0.3 & 2.3 & -- & -- & 3.47 & $\cdots$ & $\cdots$ & -- & 10 \\
\hline 30 & 2.7 & $10^{-8}$ & 0.3 & 2.6 & --- & -- & 3.73 & $\cdots$ & $\cdots$ & -- & 10 \\
\hline 31 & 2.7 & $10^{-8}$ & 0.3 & 3.0 & $-\infty$ & $\cdots$ & 4.25 & -- & --- & $\cdots$ & 10 \\
\hline 32 & 2.7 & $10^{-0}$ & 0.3 & 3.2 & -- & -- & 4.30 & $\ldots$ & $\cdots$ & -- & 6 \\
\hline 33 & 2.7 & $10^{-0}$ & 0.3 & 3.6 & -- & $\cdots$ & 4.66 & $5.87 \times 10^{-7}$ & .0335 & 1.54 & 6 \\
\hline 34 & 2.7 & $10^{-0}$ & 1.0 & 6.0 & -- & $m$ & 6.70 & -- & -- & -.. & 10 \\
\hline 35 & 2.7 & $10^{-0}$ & 1.0 & 8.0 & -- & -- & 7.93 & --- & --- & $\cdots$ & 10 \\
\hline 36 & 2.7 & $10^{-0}$ & 2.0 & 9.0 & --- & -- & 8.80 & -- & -- & $\cdots$ & 10 \\
\hline 37 & 2.7 & $10^{-p}$ & 1.0 & 10.0 & -- & --- & 9.25 & $-\infty$ & $\cdots$ & $\cdots$ & 12 \\
\hline 38 & 2.7 & $10^{-0}$ & 1.0 & 11.0 & -- & $\cdots$ & 9.90 & $1.88 \times 10^{-6}$ & $.0789 m .0855$ & $2.64-2.96$ & 10 \\
\hline 39 & 2.7 & $10^{-8}$ & 1.0 & 12.0 & -- & -- & 10.3 & $1.84 \times 10^{-6}$ & .0789 & 3,69 & 10 \\
\hline 40 & 2.7 & $10^{-7}$ & 0.1 & 1.5 & --- & --- & 2.92 & $\cdots$ & --- & $\ldots$ & $\bullet$ \\
\hline 41 & 2.7 & $10^{-7}$ & 0.1 & 1.65 & $\cdots$ & $\cdots$ & 2.89 & -- & $\ldots$ & $\ldots$ & $s$ \\
\hline 42 & 2.7 & $10^{-7}$ & 0.1 & 1.70 & -- & -- & 3.14 & $\infty$ & $\infty$ & -- & 8 \\
\hline 43 & 2.7 & $10^{-7}$ & 0.1 & 1.90 & --- & -- & 3.39 & $1.0 \mathrm{i} \times 10^{-6}$ & $.0479 \ldots .0503$ & $2.17-2.25$ & 8 \\
\hline 44 & 2.7 & $10^{-7}$ & 0.1 & 2.30 & $\cdots$ & $\cdots$ & 3.88 & $9.90 \times 10^{-7}$ & $.045 s$ & 2.02 & 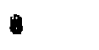 \\
\hline 45 & 2.7 & $10^{-7}$ & 0.1 & 2.50 & -- & $\cdots$ & 4.14 & $9.95 \times 10^{-7}$ & .0467 & 2.43 & 8 \\
\hline $45 a$ & 2.7 & $10^{-7}$ & 0.1 & 3.00 & -- & -- & 4.62 & $9.40 \times 10^{-7}$ & $.0455-.046$ & $3.60-3.65$ & 10 \\
\hline 46 & 2.7 & $10^{-7}$ & 0.1 & 3.60 & $-\infty$ & $-\infty$ & 5.14 & $3.73 \times 10^{-7}$ & $.0566-.0582$ & $1.74-1.92$ & 7 \\
\hline 47 & 2.7 & $10^{-7}$ & 0.1 & 4.00 & -- & $\cdots$ & 5.42 & $3.47 \times 10^{-7}$ & $.0467-.0497$ & $2.03-2.21$ & 7 \\
\hline 48 & 2.7 & $10^{-7}$ & 0.1 & 4.5 & -- & -- & 5.79 & $3.26 \times 10^{-7}$ & $.0673-.0503$ & $2.79-3.00$ & 5 \\
\hline 49 & 2.7 & $10^{-7}$ & 0.3 & 4.4 & $--\infty$ & --- & 6.11 & --- & --- & $\cdots$ & 10 \\
\hline 50 & 2.7 & $10^{-7}$ & 0.3 & 4.8 & -- & --- & 6.5 & -- & --- & -- & 10 \\
\hline 51 & 2.7 & $10^{-7}$ & 0.3 & 5.4 & -- & -- & 6.96 & $7.64 \times 10^{-7}$ & $.0750-.0789$ & $2.41-2.60$ & 10 \\
\hline 52 & 2.7 & $10^{-7}$ & 1.0 & 8.0 & -- & $\cdots$ & 9.32 & $\cdots$ & $-\infty$ & $\cdots$ & 10 \\
\hline 53 & 2.7 & $10^{-7}$ & 1.0 & 10.0 & $\ldots$ & -- & 10.8 & $-\infty$ & $\cdots$ & -- & 10 \\
\hline 54 & 2.7 & $10^{-7}$ & 1.0 & 11.5 & $-\infty$ & -- & 11.7 & $\cdots$ & $\cdots$ & $-\infty$ & 10 \\
\hline 55 & 2.7 & $10^{-7}$ & 1.0 & 12.5 & -- & --- & 12.5 & $\cdots$ & $-\infty$ & -- & 12 \\
\hline 56 & 2.7 & $10^{-7}$ & 1.0 & 13.5 & $\cdots$ & --- & 12.9 & $2.06 \times 10^{-6}$ & .128 & 4.22 & 10 \\
\hline
\end{tabular}




\begin{tabular}{|c|c|c|c|c|c|c|c|c|c|c|c|}
\hline $\begin{array}{l}\text { Prob- } \\
\text { lem }\end{array}$ & $\begin{array}{l}\text { Laser } \\
\text { Light } \\
\text { Wave- } \\
\text { length, } \\
\text { Hm } \\
\end{array}$ & $\begin{array}{l}\text { Laser } \\
\text { Pulse } \\
\text { Dura- } \\
\text { tion, } \\
s \\
\end{array}$ & $\begin{array}{l}\text { Target } \\
\text { Thick- } \\
\text { ness, } \\
\text { cm }\end{array}$ & $\begin{array}{l}\text { Laser } \\
\text { Energy, } \\
\mathrm{kJ} / \mathrm{cm}^{2} \\
\end{array}$ & $\begin{array}{l}\text { Mass } \\
\text { Removal } \\
\text { In Gas } \\
\text { Form at } \\
0.2 \mathrm{Hs}^{\mathrm{s}}, \\
\mathrm{g} / \mathrm{cm}^{2} \\
\end{array}$ & $\begin{array}{l}\text { Mass } \\
\text { Removal } \\
\text { In Liquid } \\
\text { Form at } \\
0.2 \mathrm{Hs} \\
\mathrm{g} / \mathrm{cm}^{2} \\
\end{array}$ & $\begin{array}{l}\text { Impulse } \\
\text { to } \\
\text { Solid, } \\
\text { idyneg } \\
\underline{c a^{2}} \\
\end{array}$ & $\begin{array}{l}\text { Time of } \\
\text { First } \\
\text { Spell, }\end{array}$ & $\begin{array}{l}\text { Olstance } \\
\text { Fron back } \\
\text { Face to } \\
\text { Plane of } \\
\text { Firut Spal1, } \\
\text { cE }\end{array}$ & $\begin{array}{l}\text { Itapulae } \\
\text { Delivered } \\
\text { to Plane at } \\
\text { firut Spall, } \\
\text { kdyne } \\
\text { cet }\end{array}$ & $\begin{array}{l}\text { Con- } \\
\text { puter- } \\
7600 \\
\text { tere. } \\
\text { an } \\
\end{array}$ \\
\hline 57 & 2.7 & $10^{-7}$ & 1.0 & 11.5 & - & -- & 14.0 & $2.02 \times 10^{-6}$ & .105 & 4.75 & 10 \\
\hline 58 & 2.7 & $10^{-7}$ & 1.0 & 20.0 & $-m$ & -- & 16.7 & $1.92 \times 10^{-6}$ & .0910 & 7.20 & 10 \\
\hline 59 & 2.7 & $10^{-7}$ & 1.0 & 30.0 & -- & -- & 21.5 & $1.83 \times 10^{-6}$ & .07a9-.08ss & $9.73-10.5$ & 10 \\
\hline 60 & 2.7 & $10^{-7}$ & 1.0 & 50.0 & - & - & 24.8 & $1.73 \times 10^{-6}$ & .0658 & 12.4 & 10 \\
\hline 61 & 2.7 & $10^{-7}$ & 1.0 & 70.0 & $-\infty$ & - & 36.5 & $1.67 \times 10^{-6}$ & $.0592-.0658$ & $14.2-15.6$ & 10 \\
\hline 62 & 2.7 & $10^{-6}$ & 0.1 & 15.0 & $m$ & -- & 14.8 & -- & --- & $-\infty$ & 16 \\
\hline 63 & 2.7 & $10^{-6}$ & 0.2 & 20.0 & --- & -- & 16.8 & $1.47 \times 10^{-6}$ & .0570 & 9.14 & 15 \\
\hline 64 & 2.7 & $10^{-6}$ & 0.3 & 20.0 & $\cdots$ & -- & 17.9 & -- & $\cdots$ & -- & 15 \\
\hline 65 & 2.7 & $10^{-6}$ & 0.3 & 30.0 & --- & -- & 22.9 & -- & -- & $\cdots$ & 15 \\
\hline 66 & 2.7 & $10^{-6}$ & 0.3 & 40.0 & -- & -- & 27.4 & --- & $\cdots$ & $\cdots$ & 15 \\
\hline 67 & 2.7 & $10^{-6}$ & 0.3 & 46.0 & -- & -- & 30.0 & -- & $\cdots$ & -.. & 16 \\
\hline 68 & 2.7 & $10^{-6}$ & 0.3 & 54.0 & -- & -- & 33.4 & $-\cdots$ & -- & -- & 16 \\
\hline 69 & 2.7 & $10^{-6}$ & 0.3 & 68.0 & -- & -- & 38.1 & $\cdots$ & -- & -.- & 15 \\
\hline 70 & 2.7 & $10^{-6}$ & 0.3 & 100.0 & -.- & -- & 48.3 & $1.99 \times 10^{-6}$ & $.179-.183$ & $28.5-29.1$ & 15 \\
\hline 71 & 2.7 & $10^{-6}$ & 1.0 & 15.0 & -- & -- & 15.3 & $-\cdots$ & $\cdots$ & -- & 10 \\
\hline 72 & 2.7 & $10^{-8}$ & 1.0 & 18.0 & -- & -- & 17.7 & --- & -- &.- & 17 \\
\hline 73 & 2.7 & $10^{-6}$ & 1.0 & 22.0 & -- & -- & 19.9 & -- & -- & -- & 17 \\
\hline 74 & 2.7 & $10^{-6}$ & 1.0 & 26.0 & -- & -- & 21.7 & -- & -.. & $-\infty$ & 15 \\
\hline 75 & 2.7 & $10^{-6}$ & 1.0 & 38.0 & -- & -- & 27.8 & --- & -- & -- & 15 \\
\hline 76 & 2.7 & $10^{-6}$ & 1.0 & 46.0 & -- & --- & 31.0 & $3.47 \times 10^{-6}$ & $.513-.520$ & $12.8-13.0$ & 15 \\
\hline 77 & 2.7 & $10^{-6}$ & 1.0 & 56.0 & $\cdots$ & $\cdots$ & 35.0 & $3.03 \times 10^{-6}$ & $.460-.473$ & $19.7-20.3$ & 15 \\
\hline
\end{tabular}


ARPaIx o

\section{LASE FULSE SPACIEC:}

Calculations were performed to investleate the effecte of pules-spactins on carzet responce. As a base set of conditions we aswaed 1 ch of 1100 aluwinum and a laner wavelength of $2.7 \mathrm{\mu m}$. Two pulses of 2 na width were incldent with apacing, $\Delta t$, measured froe the tralling edge of the first pulse to the leading edge of the second.

The spall threshold was calculated at epacings of 1, 10, and $100 \mathrm{~ns}$. The results and the data for a single 1-na pulse are coupared in Table $D-I$. It can be seen that for $\Delta t<100$ ns the energy per pulse is less than for the single-pulse case, whlle the total energy deposited is 10 and $20 \%$ greater in the 1- and 10-ne cases, respectively. At $100 \mathrm{ng}$ spacing the energy per pulse is sufficlent to cause spall with a single pulse. Both the impulse and the thickness of the spalled layer are doubled in this case.

The effects of pulee-spacing alone were evaluated with two 1-ns pulses, each with an incident enersy of $8 \mathrm{~kJ} / \mathrm{es}^{2}$. The results and the data for a single pulve are compared in Table D-II. Because the speed of sound $1 \mathrm{~s}$ greater outside than inside a atress wave, there is a tendency of the stress wave of the second pulse to coslesce vith the first. Coalescing occurs then $\Delta t$ is less than the shock transit tine for the target, and produces a varlablelength, single stress wave dependent on $\Delta t$. For $\Delta t<100 \mathrm{~ns}$ the effect is a wore peaked stress wave wth a short tine to spall. For $\Delta t \geq 100$ ns the resulting Btress we is longer with a longer tine to spall.

TABLE D-I

RESULTS OF CHART L CALCULATIONS

LASER PULSE SPACING - SPALL THRESHOLD

Wavelength, $\lambda, 2.7$ un; Fulse Width, 1 ns; Aluninum Thickness, 1 ca; Two Pulses Incident

\begin{tabular}{|c|c|c|c|c|c|c|c|}
\hline \multirow[b]{2}{*}{$\begin{array}{c}\text { Pulse } \\
\text { Spacing, } \\
\mathbf{s} \\
\end{array}$} & \multicolumn{2}{|c|}{ Laser Energy, $\mathrm{J} / \mathrm{cm}^{2}$} & \multicolumn{2}{|c|}{ Impulse, dyn-s/cm } & \multicolumn{2}{|c|}{ Thickness, $c$} & \multirow[b]{2}{*}{$\begin{array}{c}\text { Tine to } \\
\text { Spall, } \\
\end{array}$} \\
\hline & $\begin{array}{c}\text { Total } \\
\text { Deposited } \\
\end{array}$ & $\begin{array}{c}\text { Per } \\
\text { Pulse } \\
\end{array}$ & $\begin{array}{c}\text { Maxinua } \\
\text { Generated } \\
\end{array}$ & $\begin{array}{c}\text { In Spalled } \\
\text { Layer } \\
\end{array}$ & $\begin{array}{l}\text { Bloroff } \\
\text { Cas \& } \\
\text { Liguld }\end{array}$ & $\begin{array}{l}\text { Spalled } \\
\text { Layer }\end{array}$ & \\
\hline $1 \times 10^{-3}$ & 9. $\times 10^{3}$ & $4.5 \times 10^{3}$ & $8.48 \times 10^{3}$ & $2.37 \times 10^{3}$ & $1.09 \times 10^{-2}$ & 0.145 & $1.84 \times 10^{-6}$ \\
\hline $1 \times 10^{-8}$ & 10. $\times 10^{3}$ & $5 \times 10^{3}$ & $9.94 \times 10^{3}$ & $2.41 \times 10^{3}$ & $1.2 \times 10^{-2}$ & 0.092 & $1.9 \times 10^{-6}$ \\
\hline $1 \times 10^{-7}$ & 16. $\times 10^{3}$ & $8 \times 10^{3}$ & $14.6 \times 10^{3}$ & $6.53 \times 10^{3}$ & $1.92 \times 10^{-2}$ & 0.151 & $1.97 \times 10^{-6}$ \\
\hline $\begin{array}{l}\text { Base } \\
\text { Case }\end{array}$ & $8 \times 10^{3}$ & $\begin{array}{c}\text { One-Pulse } \\
\text { Case }\end{array}$ & $9.2 \times 10^{3}$ & $3.74 \times 10^{3}$ & $1.75 \times 10^{-2}$ & 0.072 & $1.79 \times 10^{-6}$ \\
\hline
\end{tabular}

*Prepared by Major J. R. Bobbitt, U. S. Arny, Los Alanos Scientific Laboratory Military Staff Menber. **At time of spall. Kore will boll off later. 
TABLE D-II

RESULTS OF CHART L CALCULATIONS

LASER PULSE SPACIKG - IYPULCE

Wavelength, $\lambda, 2.7$ wa Pulse Width, 1 as; Aluninum Thickness, 1 ca; Two Pulses Incident Laser Energy Depostted, $16 \times 10^{3} \mathrm{~J} / \mathrm{cm}^{2}: 8 \times 10^{3} \mathrm{~J} / \mathrm{cm}^{2} /$ Pulse

\begin{tabular}{|c|c|c|}
\hline \multirow{2}{*}{$\begin{array}{c}\text { Pulse } \\
\text { Spac Ing, } \\
\mathrm{g}\end{array}$} & \multicolumn{2}{|c|}{ Impulce, $d y n-s / c n^{2}$} \\
\hline & $\begin{array}{c}\text { Maximun } \\
\text { Generated } \\
\end{array}$ & $\begin{array}{c}\text { In Spalled } \\
\text { Laver }\end{array}$ \\
\hline $1 \times 10^{-9}$ & $13.1 \times 10^{3}$ & $9.6-7.43 \times 10^{3}$ \\
\hline $1 \times 10^{-6}$ & $14.0 \times 10^{3}$ & $8.25-5.76 \times 10^{3}$ \\
\hline $1 \times 10^{-7}$ & $14.6 \times 10^{3}$ & $6.53 \times 10^{3}$ \\
\hline $\begin{array}{c}\text { Base } \\
\text { Case** }\end{array}$ & $9.2 \times 10^{3}$ & $3.74 \times 10^{3}$ \\
\hline
\end{tabular}

*At time of spall. More will boll off later.

\begin{tabular}{|c|c|c|}
\hline \multicolumn{2}{|c|}{ Thickness, cn } & \multirow[b]{2}{*}{$\begin{array}{c}\text { Tise to } \\
\text { Spall, } \\
\mathrm{s}\end{array}$} \\
\hline $\begin{array}{l}\text { Blowoff } \\
\text { (gas \& } \\
\text { Liguid) }\end{array}$ & $\begin{array}{c}\text { Spalled } \\
\text { Layer }\end{array}$ & \\
\hline $2.56 \times 10^{-2}$ & $0.112-0.072$ & $1.71 \times 10^{-6}$ \\
\hline $1.52 \times 10^{-2}$ & $0.112-.066$ & $1.75 \times 10^{-6}$ \\
\hline $1.92 \times 10^{-2}$ & 0.151 & $1.97 \times 10^{-6}$ \\
\hline $1.75 \times 10^{-2}$ & 0.072 & $1.79 \times 10^{-6}$ \\
\hline
\end{tabular}

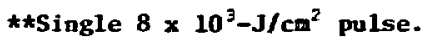

APPENDIX E

DERIVATION OF LASER POWER LEVEL FOR BREAKDOWN OF CLEAN AIR

This derivation of the laser power level for breakdown of clean air (taken from notes by S. D. Rockwood) ${ }^{16}$ applies to large volumes where electron diffusion effects are not important.

The time rate of change of the number of electrons per cubic centimeter is taken to be

$$
\dot{n}_{e}=R_{i} N_{e}-R_{a} N_{e}
$$

where

$$
\begin{aligned}
N & =\text { number of atoms } / \mathrm{cm}^{3} \\
R_{i} & =\text { rate of ionization }\left(\mathrm{cm}^{3} / \mathrm{s}\right) \\
R_{a} & =\text { rate of attachment }\left(\mathrm{cm}^{3} / \mathrm{s}\right) .
\end{aligned}
$$

The time rate of electron temperature change comes from the conservation of energy:

$$
\begin{array}{r}
k \dot{T}_{e}=2 / 3\left[\frac{\alpha P}{n_{e}}-R_{i} N\left(I+3 / 2 k T_{e}\right)-\right. \\
\left.X R_{x} N\right]
\end{array}
$$

where

$$
\begin{aligned}
& T_{e}=\text { the electron temperature } \\
& P=1 \text { ight flux }\left(\mathrm{erg} / \mathrm{cm}^{2} \cdot \mathrm{s}\right)
\end{aligned}
$$

$$
\begin{aligned}
& a=\begin{array}{l}
\text { absorption coefficient for light by free } \\
\text { electrons }
\end{array} \\
& I=\text { ionization energy per electron per atom } \\
& X=\text { excitation energy per electron per aton } \\
& R_{X}=\text { rate of atom excitation. }
\end{aligned}
$$

Let:

$$
\begin{aligned}
& R_{i}=c \cdot e^{-I / k T} e \\
& R_{a}=d \cdot e^{-A / k T} e \\
& R_{x}=b \cdot e^{-X / k T} e
\end{aligned}
$$

The two-body attachment rate $\left(R_{a}\right)$ is all right for $p \leq 2 \mathrm{~atm} ; c, d$, and $b$ are constants. The continuous wave $l i m i t$ is defined by the condition $R_{i}=R_{a}$. For this condition Eqs. (E-3) and $(E-4)$ give

$$
k T_{e}=\frac{I-A}{\ln (c / d)}
$$

Because the electron temperature is rapidly established, take $\dot{T}_{e}=0$. The excitation term is the dominant loss term in $\mathrm{Eq} .(\mathrm{E}-2)$; hence:

$$
\frac{a P}{n_{e}} \approx X_{X} n
$$


The absorption coefficient is taken from werowave theory.

$$
a_{N W}=\left(\frac{4 e^{2}}{e^{c} 2}\right) \frac{v}{v^{2}+\omega^{2}} n_{e}
$$

where $\omega$ is the electromagnetic wave frequency and $v$ is the collision frequency of electrons. Let:

$$
\alpha^{\prime} \equiv \frac{4 e^{2}}{m^{c} 2}
$$

and

$$
v^{\prime}=\frac{v}{N} ;
$$

in the region of interest $v \ll \omega$, then,

$$
\alpha=\alpha^{\prime} \frac{v^{\prime}}{w^{2}} \mathrm{n}^{\alpha}
$$

Equating $R_{x}$ from Eq. (E-7) and Eq. (E-5) using Eq. $(E-8)$ and solving for the resulting temperature, we obtain

$$
k T_{e}=\frac{x}{\ln \left(\frac{b x w^{2}}{\alpha^{\top} v^{\top} P}\right)}
$$

Equations (E-6) and (E-9) give two expressions for the temperature which can be eliminated on combination to give the continuous-wave power level for air breakdown as

$$
P_{B}=\left[\frac{b x}{a^{2} v^{0}}\left(\frac{d}{c}\right)^{x / 1-A}\right] \omega^{2} .
$$

The coefficient of $\omega^{2}$ is a constant for a given nedium.

Sone typical values that can be used to evaluate this coefficient for air are, in cgs units:

$$
\begin{aligned}
& b x=6.4 \times 10^{-21} \\
& \alpha^{\prime}=0.106 \\
& d=2.0 \times 10^{-9} \\
& I-A=12.5 \mathrm{eV} \\
& c \quad=2.0 \times 10^{-7} \\
& v^{\prime}=2.0 \times 10^{-8} \\
& x=3 \mathrm{eV} .
\end{aligned}
$$

Substituting these values into Eg.(E-10) and changing fron light frequency to wavelength gives

$$
P=3.55 \times 10^{11} / \lambda^{2} \mathrm{~W} / \mathrm{cm}^{2}(\lambda \text { in } \mu \mathrm{m}) .
$$

For light of a $\mathrm{CO}_{2}$ laser $(10.6 \mathrm{~mm})$,

$$
P=3.16 \times 10^{9} \mathrm{~W} / \mathrm{cm}^{2} \text {. }
$$

\section{REFERENCES}

1. N. C. Anderholm, "Laser Generated Spal1," Sandia Laboratories Report SC-TM-69-735, (November 1969).

2. J. A. Fox and D. N. Barr, "Laser Induced Shock Effects in Plexiglas and 6061-T6 Aluminum," Appl. Phys. Lett., 22, 594 (1973)

3. S. I. Thompson and H. L. Lauson, "Improvements in the CHART D Radiation Hydrodynamic Code II: A Revised Program," Sandia Laboratories Report SC-RR-70-0713, (February 1972).

4. S. L. Thompson and H. L. Lauson, "Improvements in the ClaRT D Radiation Hydrodynamic Code III: Revised Analytic Equations of State," Sandiz Laboratories Report SC-RR-0714 (March 1972).

5. L. Spitzer, Jr., Physics of Fully Ionized Gases (Interscience Publishers, liew York, 1962).

6. R. Gentry, lecture notes from "Physics 500 Fluid Dynamics," Presented at UNM Graduate Center, Los Alamos, NM (1972).

7. F. R. Tuler and B. M. Butcher, "A Criceria for the Time Dependence of Dynamic Fracture," Int. J. Fract. Mech. 4, 431 (1968).

8. Ya. B. Zel'dovich and $y$ P. Raizer, Physics of Shock Waves ano $\mathrm{Hi}$ mperature Hydrodymamic Phenomena, Vol. II (Acacemic Press, New York, 1967).
9. T. Stefansky and J. H. Shea, "Dynamic Fracture Experiments Using High-Energy Pulsed Electron Beams," Proceedings of Physics Int. Col,, San Leandro, CA, DASA-PIFR-108 (Apri1 1971).

10. D. W. Gregg and S. J. Thomas, Momentum Iransfer Produced by Focused Laser Giant Pulses," J. Appl. Phys. 37, 2787 (1966).

11. N. Kroll and K. M. Watson, "Theoretical Study of Ionization of Air by Intense Laser Pulses," Institute for Defense Analysis, JASON, Arlington, VA (December 1970).

12. D. B. Henderson, "Transmic ion of a Train of Short, Intense Laser Pulses," Los Alamos Scientific Laboratory Report LA-5102-MS (December 1972).

13. "Electro-Optics Handbook," RCA, Burlington, MA (1968).

14. N. F. Harmon (Ed.), "DoD Effects Heeting, August 14-18," MITRE-Y73-78, Vol. II.

15. F. H. Harlow and A. A. Amsden, "A Numerical Fluid Dynamics Calculation Hethod for all Flow Speeds," J. Comp. Phys. ㅇ, 197 (1971).

16. S. D. Rockwood, LASL, Private Commication. 


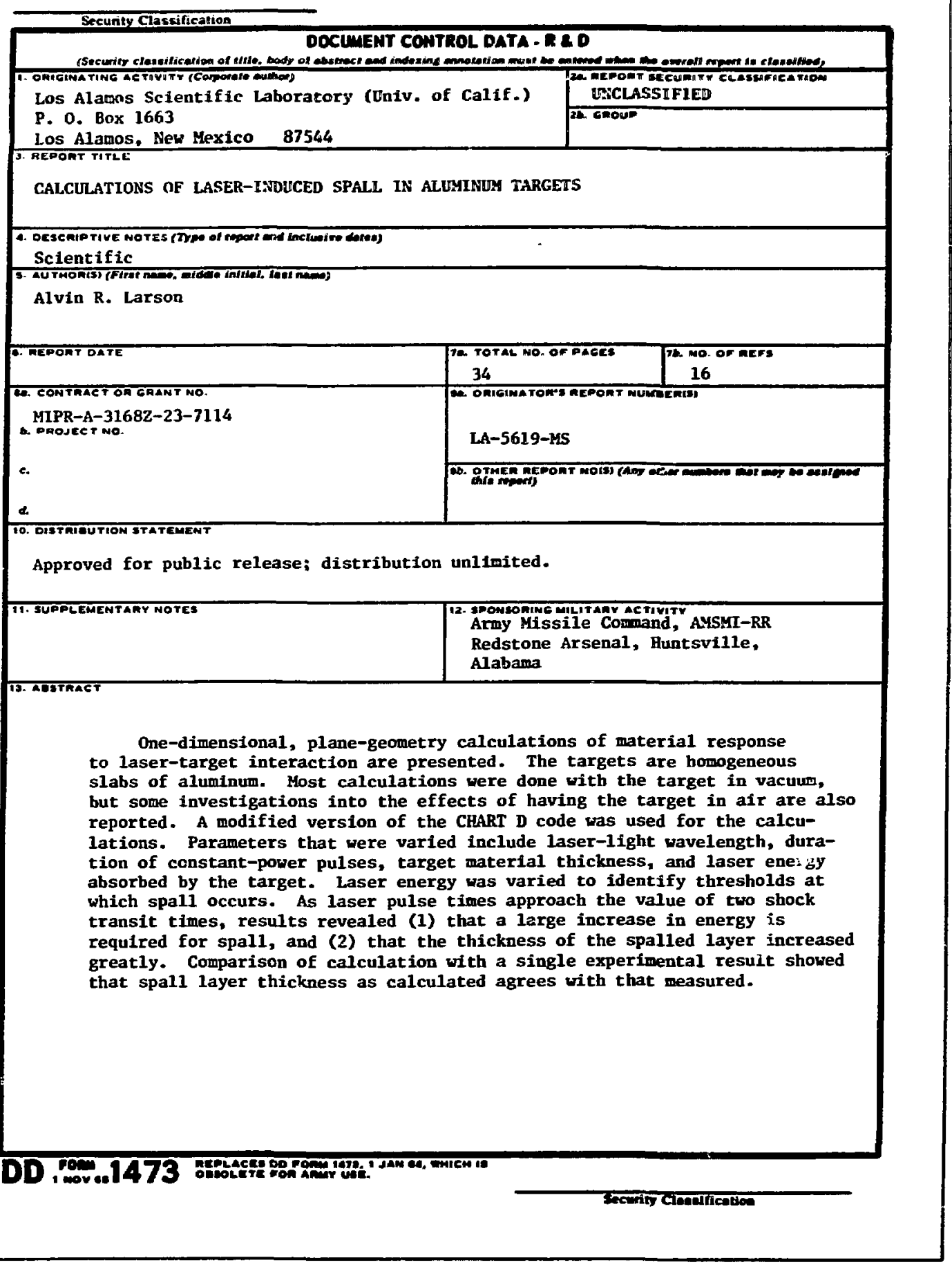




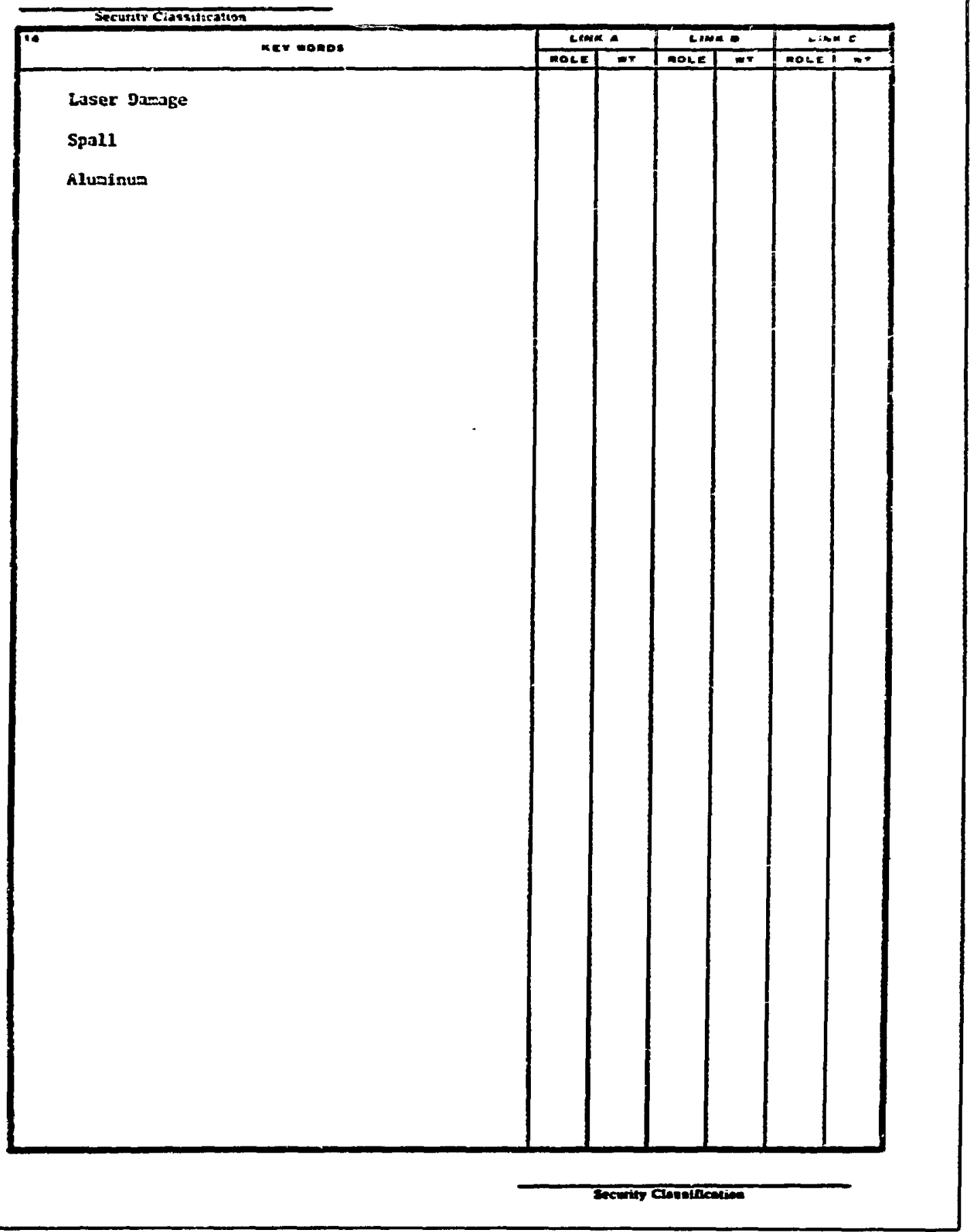

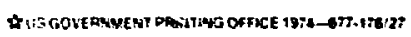

$20: 268(110)$ 